\title{
An Investigation of At-Intersection Collisions in York Region
}

\author{
By \\ Brianna Hutchinson, \\ BA Ryerson University 2015

\begin{abstract}
A MRP
Presented to Ryerson University

in partial fulfillment of the

requirements for the degree of a Masters in Spatial Analysis

in the program of Spatial Analysis
\end{abstract}

Toronto, Ontario, 2017,

(C) Brianna Hutchinson, 2017 


\section{AUTHOR'S DECLARATION}

I hereby declare that I am the sole author of this MRP. This is a true copy of the MRP, including any required final revisions. I authorize Ryerson University to lend this MRP to other institutions or individuals for the purpose of scholarly research. I further authorize Ryerson University to reproduce this MRP by photocopying or by other means, in total or in part, at the request of other institutions or individuals for the purpose of scholarly research. I understand that my MRP may be made electronically available to the public 


\begin{abstract}
This paper will look to identify how the built environment can affect collisions at intersections. The Regional Municipality of York was used as the study area. York Region has areas of high-density traffic as well as rural regional road. Due to York Region's proximity to Toronto there is also commuting traffic during rush hours. A literature review looked into different studies of traffic collisions. A focus of many was human factors, such as impaired driving, distracted driving and inexperience to name a few. For this paper, the focus is on the built features and how different design components of on intersection can affect the number of collisions. Using information from the literature review data was gathered for different built environment features, i.e. intersection type, bus stops and red-light cameras. Data was also gathered for collisions that occurred in York Region, this included the location, time of day, day of the week, and initial impact type. To evaluate how these features effected the number of collisions at an intersection, descriptive statistics, linear regression and qualitative analysis was used. The descriptive statistic shows an overview and percentage of accidents that occurred in separate groups. These groups include property damage, injury, and fatal accidents, traffic control types, and intersection types. Linear regression was used to determine which factors were increasing the number of accidents and which were helping to decrease accidents. Finally, qualitative analysis was used to study the intersections that had the top ten number of accidents that were fatal or injury. After completing the analysis, a case study was conducted on three intersections, one that has seen an increase in accidents one that has seen a decrease in accidents and finally one that has consistently had a high accident count. From all the information and analysis conclusions and recommendations were put forward to help improve road safety in York Region.
\end{abstract}




\section{Acknowledgements}

I would like to thank my parents for helping me to continue my journey of higher education and in supporting me through the years. They have helped to continue to strive to achieve my goals.

Thank you to the Regional Municipality of York, The GIS department, Traffic Services and Duncan Rowe for allowing be to use their data. I have learned many things from completing this project and am glad I was able to work with the Region.

Thank you to Shuguang Wang for being the supervisor and helping to guide me through the paper.

Finally, to Katryna Vergis-Mayo for helping me with my studies and with everything the past couple years. 


\section{Table of Contents}

An Investigation of At-Intersection Collisions in York Region ................................. i

AUTHOR'S DECLARATION.............................................................................................ii

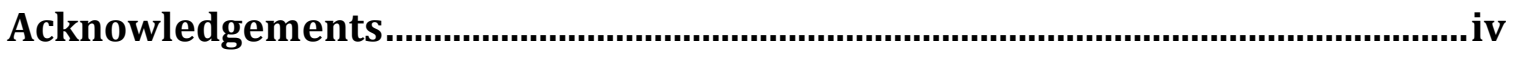

LIST OF TABLES .......................................................................................................

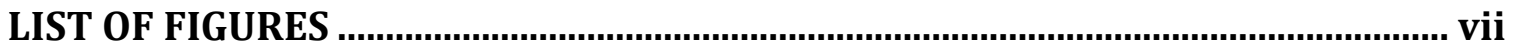

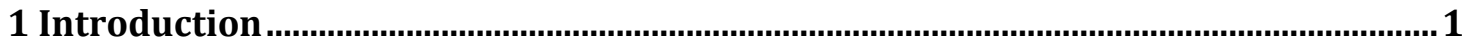

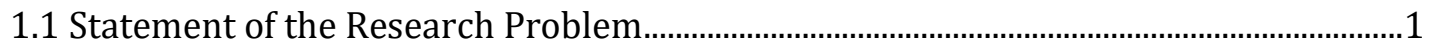

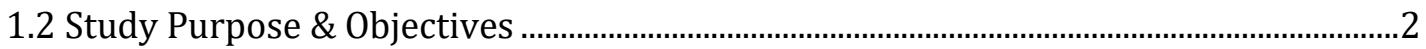

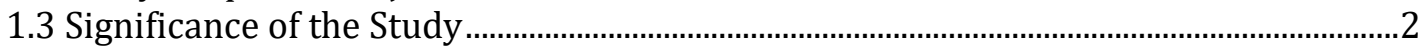

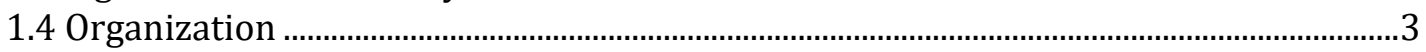

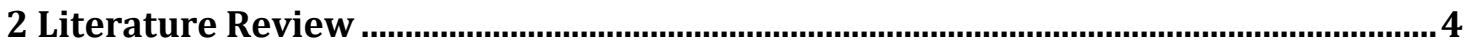

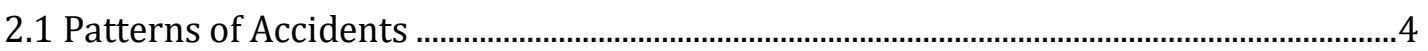

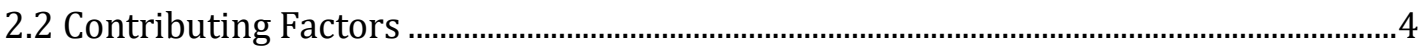

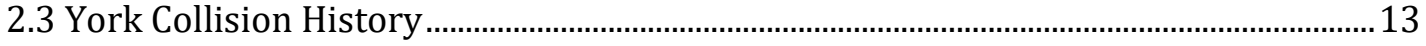

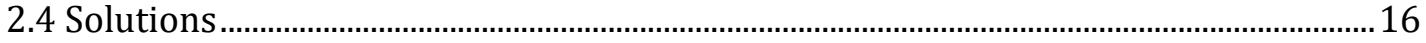

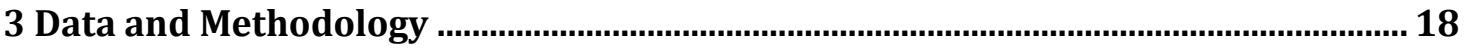

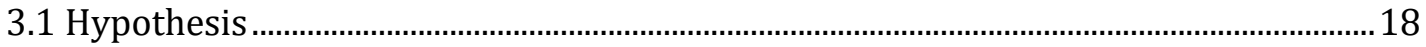

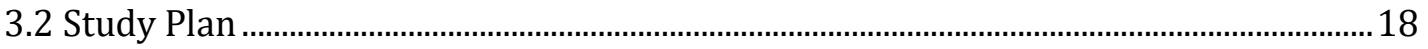

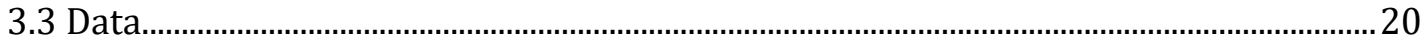

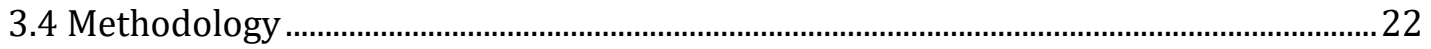

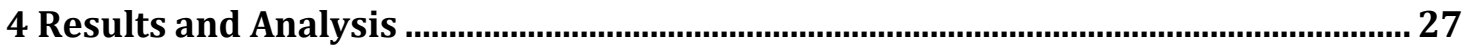

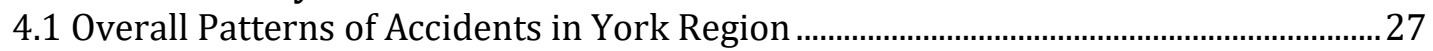

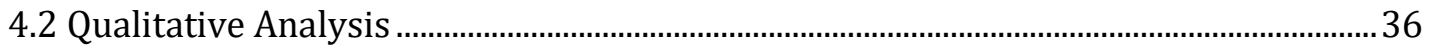

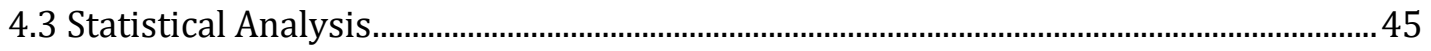

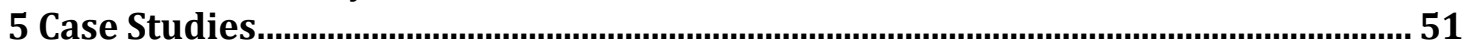

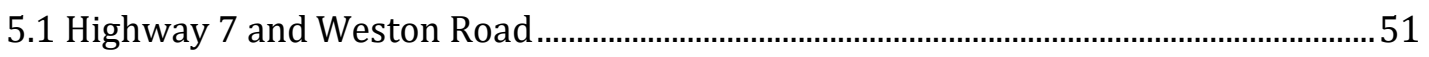

5.2 Major Mackenzie Drive West \& Exit 35 GO Carpool Lot ....................................................... 53

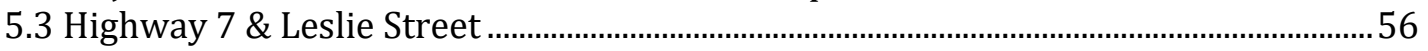

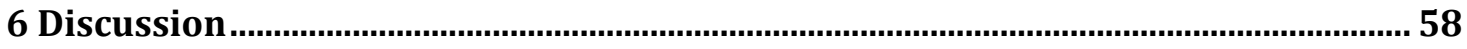

7 Conclusions

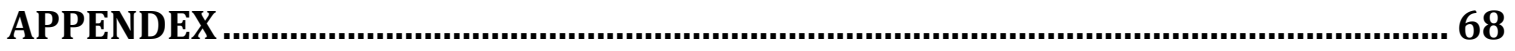

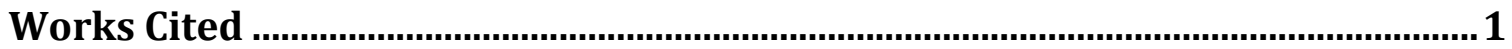




\section{LIST OF TABLES}

Table 1 Variables collected from York Region Transportation Department................ 20

Table 2 Variables collected from York Region GIS Department ....................................... 21

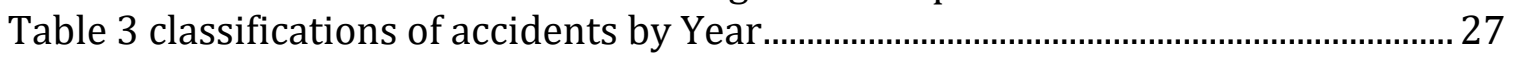

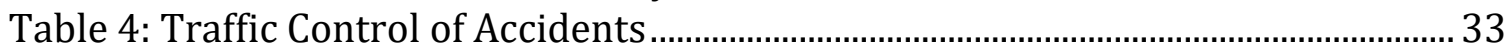

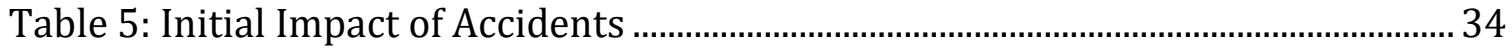

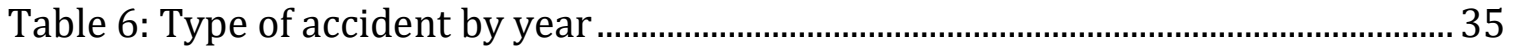

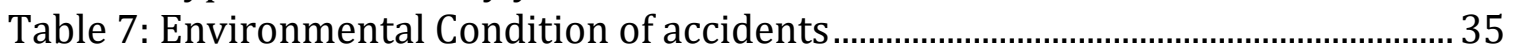

Table 8 Intersections in the top number of Fatal Accidents ............................................. 37

Table 9 Intersections with the top 25\% of Injury accidents ............................................. 38

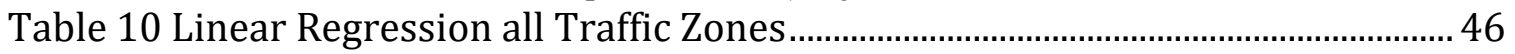

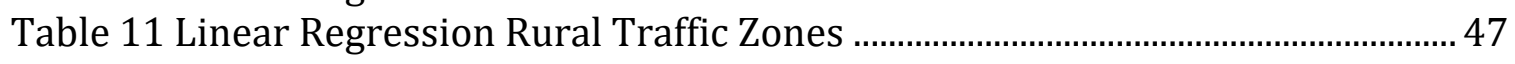

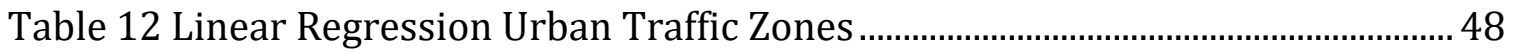

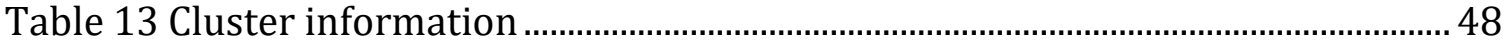

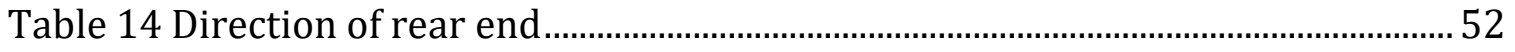

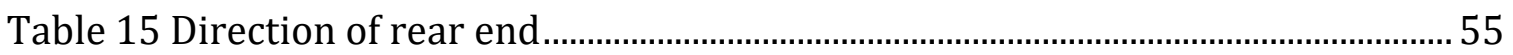

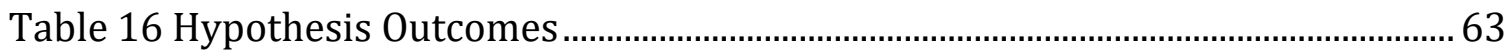




\section{LIST OF FIGURES}

Figure 1 Intersection Types ........................................................................................

Figure 2 Conflict Points at different types of intersections (Wang S., 1993)............... 11

Figure 3: Municipalities in York Region.......................................................................... 19

Figure 4: Graph of the time and day of collision on Weekdays....................................... 28

Figure 5 Graph of the time and day of collisions on Weekends......................................2

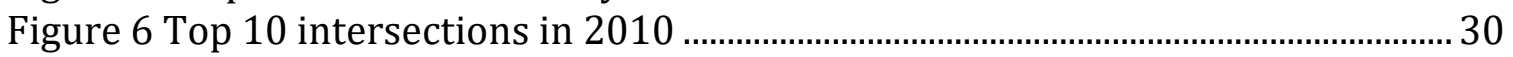

Figure 7 Top Ten Intersections 2015........................................................................... 31

Figure 8 Remotely Sensed Images of Intersections ...................................................... 40

Figure 9 Remotely Sensed Images of Intersections Cont. .............................................. 41

Figure 10 Remotely Sensed Images of Intersections Cont............................................... 42

Figure 11 Remotely Sensed Images of Intersections Cont................................................ 43

Figure 12 Remotely Sensed Images of Intersections Cont................................................ 44

Figure 13Remotely Sensed Images of Intersections Cont................................................ 46

Figure 14 Map of Clusters.............................................................................................. 49

Figure 15 Highway 7 \& Weston Road (taken from Google Maps) .................................. 52

Figure 16 Major Mackenzie Drive West and Exit 35 GO Carpool Lot (taken from

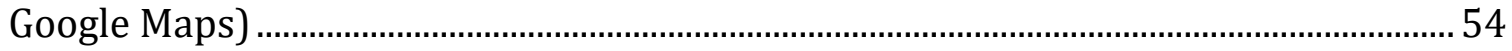

Figure 17 Highway 7 \& Leslie Street (taken from Google Maps) .................................... 57 


\section{Introduction}

\subsection{Statement of the Research Problem}

The Regional Municipality of York has been working to decrease the number of traffic collisions that occur within the region. It regularly releases "Traffic Safety Status Reports" and "Annual Traffic Safety Reports" to monitor patterns of traffic collisions and provide recommendations as to how to improve traffic safety. On all regional roads within York Region, there were 3.26 million daily vehicle trips between 2012 and 2014 (York Region, 2015, p4). Such a high volume of traffic on the roads creates increased chances of collisions. York Region wants to ensure that efforts are made to minimize the risk of traffic collisions. Although the number of traffic collisions has been decreasing over the past ten years and the Region has had the lowest number of collisions in 2015 (York Region, 2015. Page 5), road safety is still a critical concern for the Region's residents and commuters. Therefore, the Regional Municipality of York has examined patterns of traffic collisions and put forward different initiatives to help minimize the number of accidents.

However, a lot of research has had a focus on factors that the Region cannot control, such as weather, and time of the day. While looking at these types of patterns can provide insight into collisions, it will not help in reducing collisions because one cannot control the weather or time. Rather, examining features of the built environment and road networks can help the Region to make the roadways safer for all users. The Region can then decide on how to better lay out roads and what safety features should be installed around an intersection. Some of these features include intersection type, traffic control devices, surrounding land use, points of interest, traffic calming measures, and transit stops. Knowing if any of these control factors can contribute to accidents will allow the Region to plan and build safer roadways.

Since most accidents occur at intersections, this paper focuses on features of the built environment that are present at intersections. It will determine if any 
features can help to reduce collisions. Roadways are a vital part of York Region. They not only serve vehicles, but also pedestrians and cyclists. Safer intersections will help to make the community safer for all the residents of the Region.

The research idea for Traffic Accidents came out of discussions with professionals in the field to inline with my interests, and future goals to work with as a crime analysis. After completing an internship with the Regional Municipality of York, I had the opportunity to complete this research for York Region. The research objectives then grow to create an in depth study of intersection based accidents.

\subsection{Study Purpose \& Objectives}

The purpose of the study is to identify patterns of traffic collisions at intersections in relation to roadways and the surrounding features. Patterns will then be analyzed with different statistical and spatial techniques. By using different analytical techniques, it will identify any features that are associated with high frequency of collisions, or any features that help to decrease the number of collisions. These features can help the Region in planning new roadways or improving existing ones to increase safety.

\subsection{Significance of the Study}

This study expands on the work completed by York Region on identifying patterns and issues with road safety. This paper will expand on factor that were previously used, while also identifying several new factors. It will be used to determine if there are any locations where York Region can improve road safety, and any safety measures that are already in place to reduce the number of collisions. This study will also study the factors that the Region can control and change to improve road safety for motorist, pedestrians and cyclists. Understanding what types of intersections and which traffic controls have the most collisions will help the Region to make a more informed decision when making roads in new 
subdivisions. York Region is growing and will need more infrastructure to support the growing population. It will be easier to make the roads safer when building them than having to modify and change them after they have been built. Making the roads safer for all users will help improve the overall feeling of well-being in York Region.

\subsection{Organization}

The paper is organized into eight sections. The first section is the introduction, which gives an overview of the purpose and study area of the project. The second section is the literature review. It synthesizes what other papers have looked at regarding patterns and causes of accidents. It also considers the work that York Region has already completed on accident patterns. The third section is the Data and Methodology section, which explains what data are used and how and where it was collected. It goes into detail on the methodology that is used to find patterns in intersection-based accidents. The fourth section presents the results and analysis; it is broken into three sub-sections: overall patterns, qualitative, and statistical. The fifth section looks at three different case studies. The case studies were intersections that were seen to be important in understanding patterns of collisions. The sixth section discusses the findings, answers the hypotheses, and explains the limitations. The concluding section summarizes the entire paper and presents recommendations for York Region to improve its road safety. 


\section{Literature Review}

\subsection{Patterns of Accidents}

Traffic collisions can occur at any time. However, there are different patterns that emerge. Several factors can contribute to collisions. These factors can fall into four distinct categories, which include: physical environment, traffic, human, and built environment. These patterns show the overall trend that occurs with regards to accidents. However, there are always outliers. One of the most common physical environmental patterns is weather conditions. When the weather is bad (such as rain or snow), it can make the roads slippery, increasing the chances of sliding, therefore causing accidents. In addition to making roads slippery, rain and snow can reduce visibility, which is another factor. For the two aforementioned reasons, rainy or snowy weather is more likely to cause accidents. Traffic can also affect the number of accidents, because high volume of traffic on the road can increase the chance of accidents as well.

One of the main human factor is related to age: with teenage drivers having the most accidents (Arason, 2014; Prato, 2009). Teenage drivers tend to have less experience on the road and take more chances when they are driving. There is also a pattern in gender, as males tend to be more likely to be in a collison than females (Choueiri, Choueiri, \& Choueiri, 2010; Arason, 2014). This paper will focus on human and built environmental factors only.

\subsection{Contributing Factors}

\subsubsection{Human Behavior}

The human element of driving is a main factor in traffic collisions. There are many different factors of human behavior that can cause an accident. In a study completed by Azadeh, Zarrin and Hamids (2015), the authors found that human factors accounted for $26.7 \%$ of the accidents. When people are driving, they do not always have the required information or experience needed to be a safe driver at all 
times. Neil Arason (2014) categorized all drivers into six groups of human behavior that can cause accidents.

The first group accounts for a large proportion of accidents and this is the "Young and Foolish" group. This group contains people aged 16-24, who do not have the experience to help them make informed decisions at all times, resulting in tendencies to fixate on smaller things and not see the whole situation. They tend to bend to peer pressure and are more likely to participate in risky behavior. This puts them in danger of performing riskier maneuvers above their skill level. Azadeh, Zarrin and Hamids (2015) looked at factors of human decision-making and its effect on accidents, and showed that decision-making is a big component of a driver causing an accident.

The second group is called the "Carless and High Risk". This group tends to be middle-aged men (age 30 to 50) who have a large number of traffic violations over many years (Arason, 2014). They participate in many risky activities that have a higher correlation with collisions and injuries. When no injury occurs in a collision, the top three correlated human factors were violent driving, high speed, and vehicle overload (Azadeh, Zarrin, \& Hamid, 2015). Minor injury was highly correlated with high speed, violent driving, and road surface, while severe injury was caused by violent driving, high speed and driver's distraction (Azadeh, Zarrin, \& Hamid, 2015). These factors are a part of this group but can also affect other groups as well.

The third group is "The Paid Drivers", which includes taxi, bus and commercial vehicle drivers, and who account for $22 \%$ of crashes (Arason, 2014). This group also has problems with speeding and reckless driving, but for reasons that tend to differ from the aforementioned reasons. For example, drivers in this category are on the roads up to 10 times more often than other drivers and practice bad habits to meet deadlines and complete more jobs (Arason, 2014). 
The fourth group is the "motorcyclists". This group has a high likelihood of being involved in an accident. There are two types of accidents that are common for motorcycles. The first is single vehicle accidents. A single vehicle accident is when a motorcycle crashes on its own; it usually occurs when the driver loses control of the vehicle, and often involves alcohol or improper safety equipment (Arason, 2014). This type of accident can correlate with the factors presented by Azadeh, Zarrin and Hamids (2015). The second type is multiple vehicle collision. These accidents are usually caused by another vehicle hitting a motorcycle. Drivers of the other vehicles have a mentality of looking but not seeing; as the bikes have a smaller physical presence and can easily be missed when drivers are looking before completing a maneuver on the road, such as a lane change (Arason, 2014).

The fifth group is the "Medically Unfit to Drive", and occurs where the three senses, mentioned below, may be affected (Arason, 2014). When driving, a driver relies on three main senses: these are sensory, cognitive, and motor skills. Under each of these three senses there are many different features that work together to allow drivers to make decisions. This group of people have medical conditions that can prevent them from driving safely. Conditions could include vision problems which affect the sensory, Alzheimer, which affects the cognitive, and muscle weakness, which affect motor skills (Arason, 2014). If any of these three senses are compromised, then it can increase the likelihood of an accident occurring.

The factors examined below, can affect the sixth group, which is the "Ordinary and Everyday Drivers". In Azadeh, Zarrin and Hamids' study, the authors looked at eleven different human factors that have a correlation with collisions. The factors were violent driving, failing to use seatbelts, high speed, using cell phone while driving, drunk driving, drinking or eating, avoiding safe distance, illegal overtakings, driver's distraction, sleepiness of a driver, and deviation to the left (Azadeh, Zarrin, \& Hamid, 2015). These factors were compared to the different types of injury by severity: no injury, minor injury and severe injury. This group includes people who drive but do not fall within one of the other five groups. Errors 
in judgment can happen to anyone at any time (Arason, 2014). These human factors can help explain how and why collisions occur, however, they are not the only factor, as built environmental factors may also contribute to collisions.

\subsubsection{Features of the Built Environment}

Cities can have different types of road networks and, when built in different time periods, may have different network types, such as the traditional network of gridiron roads and the contemporary limited-access (Ewing \& Dumbaugh, 2009). In the gridiron network, crashes are located mainly around four way intersections, with fewer accidents occurring around three-way intersections ("T-intersection"). In the limited-access road network type, there are fewer four-way intersections and more three-way intersections (Ewing \& Dumbaugh, 2009). Rural and Urban roads have different conditions, and therefore, road designs that work on rural roads to decrease collisions may not work to reduce collisions on urban roads. The accepted solution that Ewing and Dumbaugh developed for rural roads is wider shoulders and more gentle curves for two lane roads to help decrease crashes (Ewing \& Dumbaugh, 2009). The authors also proposed an alternative theory that the width of roads affects the number of collisions. They state that narrow roads (which are about 24 feet wide) are safer (Ewing \& Dumbaugh, 2009). In another study completed by Miranda-Moreno, Morency, and El-Geneidy (2011), the authors examined how road width affects collisions. They examined geometric design, which includes the number of lanes, cross walks and medians. Ewing and Dumbaugh's article stated that roads could be made safer by having shorter uninterrupted road lengths, to reduce the speed of driver, in turn decreasing the severity of crashes (Ewing \& Dumbaugh, 2009). In addition, reducing the number of lanes also helps to decrease the number of collisions as when there are fewer lanes, motorists are forced to match the speed of the driver in front of them, in turn reducing speedingrelated accidents (Ewing \& Dumbaugh, 2009). 
Furthermore, within a road network there can be different type of roads. The study by Miranda-Moreno, Morency and El-Geneidy (2011) examined the four different road types, which are primary highways, secondary highways, arterial road, and local roads. They found that there was a positive correlation between accidents and primary and secondary highways, and arterial roads, and a negative correlation between accidents and local roads. The strongest positive correlation between collisions and roads were in regards to arterial roads (Miranda-Moreno, Morency, \& El-Geneidy, 2011).

Intersection design examines how roads meet when they intersect. There are many different possible combinations for intersection designs (Zhou \& Li, 2015), but five of them are most commonly used: The Cross, the $\mathrm{Y}$, the $\mathrm{T}$, the $\mathrm{L}$ and the Roundabout, shown in Figure 1. The Cross intersection occurs where two roadways meet and there are four different directions vehicles may travel. The Y intersection has three roadways merging at an angle. The $\mathrm{T}$ intersection has two roadways that meet at a 90-degree angle where a vehicle can go one of three ways. The $\mathrm{L}$ intersection has two roadways meeting at a 90-degree angle with the possibility of only going two directions. Finally, the Roundabout allows vehicles to come in from different points on a circle and go around to any of the other exits. Three way (or Tform) intersections are one of the different intersection designs which helps to reduce collisions, in addition to designs including roundabouts which is considered a traffic calming intersection (Ewing \& Dumbaugh, 2009). 

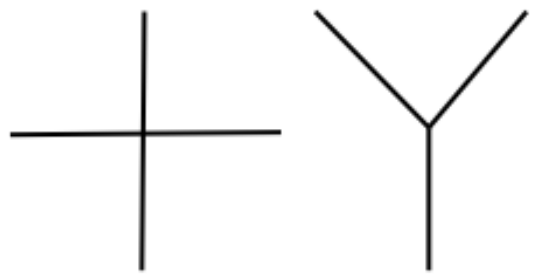

Cross

Intersection
' $\mathrm{Y}$ '

Intersection

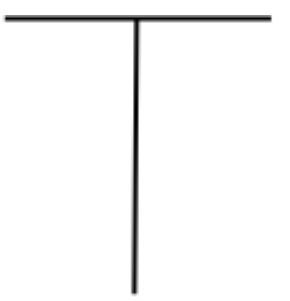

' $\mathrm{T}$ '

Intersection

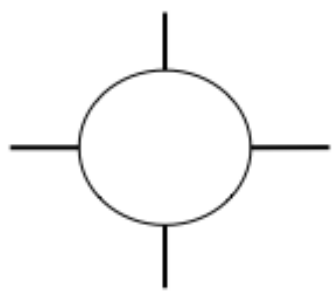

'L' Intersection

Roundabout

Figure 1 Intersection Types

Intersections can have more accidents because of the number of traffic conflict points. Traffic conflict refers to a traffic event where two or more drivers meet at an interaction, while a traffic conflict point is the point where two traffic flows (lanes) merge (Pan, Zhang, Lu, Zhao, \& Wang, 2013). The more traffic conflict points that are present in an intersection, the more likely it can result in a conflict or collision. (Lu, Chen, Ge, \& Pan, 2013). There are three types of traffic conflict points, crossing conflict points, merge conflict points and diverge conflict points. A crossing conflict point is two vehicles coming from different entrance points and going to different exit approaches, such as left turning movements (Pan, Zhang, Lu, Zhao, \& Wang, 2013). Merge conflict points is two vehicles having conflict points in the same exit area or lane. An example of this would be as one vehicle turning left and one turning right into the same lane (Pan, Zhang, Lu, Zhao, \& Wang, 2013). Finally, diverge conflict points occur when two vehicles could have conflict points in the entrance where the lane accommodates two or more movements, such as when one vehicle is turning left and one turning right, both vehicles are in the same lane (Pan, Zhang, Lu, Zhao, \& Wang, 2013).

For example, a four-way intersection has sixteen conflict points; eight are merging and eight are diverging. The number of conflict points changes based on the type of intersection, from the five intersections that will be looked at the Cross intersection contains the most conflict points. As seen in Figure 2, a cross intersection has 16 conflict points for vehicles and eight conflict points for pedestrians. That number has a significant drop at T-intersections and roundabouts. 
A T-intersection has only three conflict points for Vehicles and six conflict points for pedestrian. This can be used to conclude that T-intersections may cause fewer accidents because there are fewer points for collisions to occur. The same can be seen with roundabouts for vehicle on vehicle conflict points, however, pedestrians and vehicles have eight conflict points which is the same number as a cross intersection. 


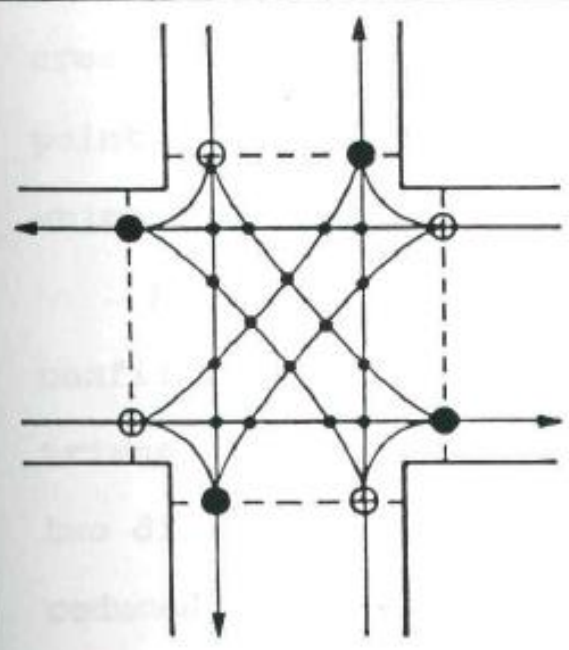

(a) conflict points at cross-intersection

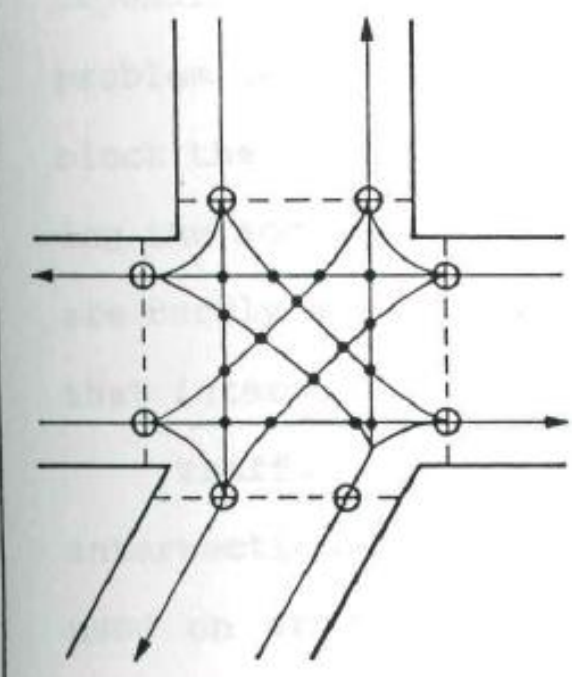

(c) conflict points ot acule-intersection

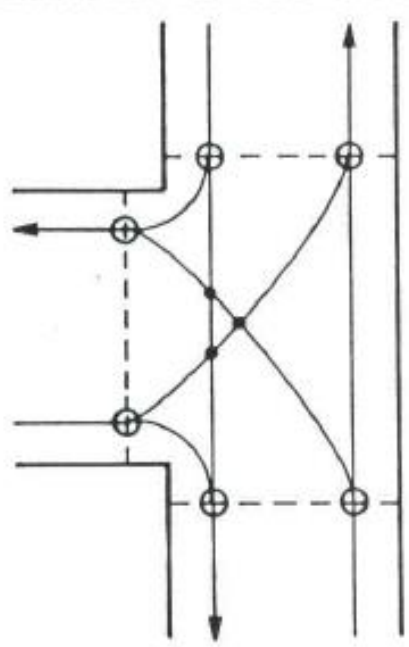

(b) conflict points at T-intersection

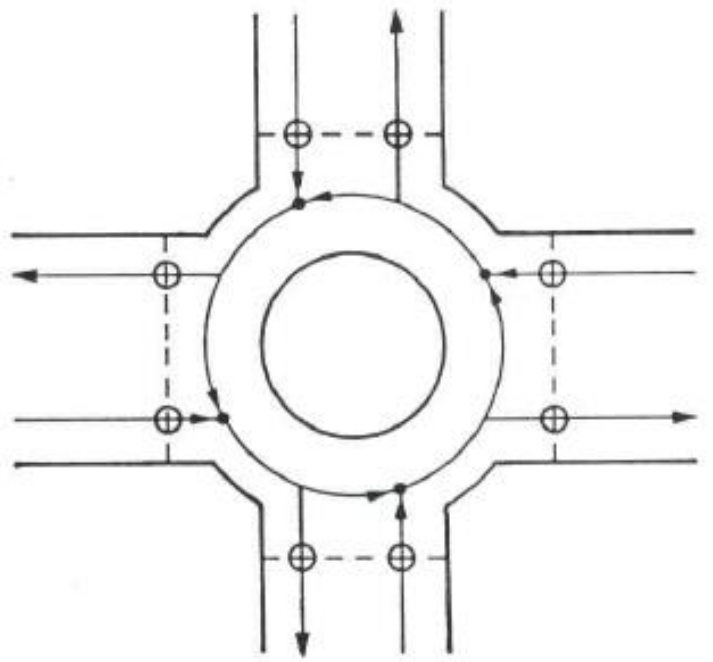

(d) conflict points at a traffic circle

- vehicle-vehicle conflict point

Opedestrian-vehicle conflict point

\section{----pedestrian route}

- pedestrian-vehicle conflict point, where pedestrians may face vehicles from three directions

Figure 2 Conflict Points at different types of intersections (Wang S., 1993)

Built-environmental features consist of features on the road such as bus stops, schools or traffic controls. However, they can also relate to the number of vehicles on the road and the distance travelled. Many articles state that traffic volume is a large factor in determining collisions (Ewing \& Dumbaugh, 2009, 
Fernandes \& Neves, 2013, Miranda-Moreno, Morency, \& El-Geneidy, 2011). The more cars there are on the road, the higher the number of chances for collisions to occur. Along with traffic volume, kilometers travelled also have an effect on the number of collisions (Quddus, 2008). Ewing and Dumbaugh (2009) found that in urban environments, for every $1 \%$ increase in distance travelled, fatalities increase by $1 \%$, and in rural environments for every $1 \%$ increase in distance travelled, fatalities increase by 1.5\% (Ewing \& Dumbaugh, 2009). Since the implementation of red light cameras into the built environment, the intersections with cameras have seen a decrease in the number of collisions, as shown by studies completed in the York Region (York Region, 2015) and in Maine (Garder, 2008)

The frequency and severity of collisions can be impacted by how fast the vehicles are travelling. It was determined that $15 \%$ of vehicles on the roads are driving at unsafe speeds (Arthur \& Waters, 1998). Low speed street designs such as a 'Main Street' can reduce the number of collisions with pedestrians by slowing down vehicles travelling on the road (Ewing \& Dumbaugh, 2009).

Other traffic calming features used to slow down traffic to reduce collisions are speed tables and traffic circles (Ewing \& Dumbaugh, 2009). These calming measures can help reduce traffic conflicts because more collisions happen when vehicles are moving at different speeds, such as when a car pulls out of a parking spot into traffic, or when there are conflicting movements (Ewing \& Dumbaugh, 2009). One of the main conflicting movements is on-street parking, which is considered a buffer between vehicles and pedestrians. However, on-street parking is significant in urban crashes because of children running between cars and when pedestrians are getting in and out of vehicles. It was also determined that angle parking has higher collision rates than parallel parking (Ewing \& Dumbaugh, 2009).

Ewing and Dumbaugh (2009) proposed a theory that there are four factors that influence travel behaviors and affect collisions. These are density, diversity, design and destination. Density includes the number of jobs, and households per 
unit area. Diversity refers to land use mixing. The third factor is design, which refers to how the road is laid out, such as where the sidewalks and trees are placed, and finally destination refers to the accessibility of jobs and housing in the area (Ewing \& Dumbaugh, 2009). Another article examined three factors that can affect collisions, which are the built environment, risk exposure, and geometric design (Miranda-Moreno, Morency, \& El-Geneidy, 2011). The article looked at these factors in different lengths around intersections. The study found that commercial areas, open space, the number of jobs and schools, population and employee numbers are highly correlated within 400 meters around an intersection and that metro and bus stops are highly correlated at 150 meters (Miranda-Moreno, Morency, \& El-Geneidy, 2011).

The above literature review examines the many different factors that may contribute to collisions, including human factors (like age, gender, years driving etc.,) and built environment factors (such as number of lanes, width of roads, intersection type, and land type).

\subsection{York Collision History}

The Regional Municipality of York has been working to decrease the number of traffic collisions that occurs within the region. It releases regularly "Traffic Safety Status Reports" and "Annual Traffic Safety Reports" to monitor patterns of traffic collisions and provide recommendations as to how to improve traffic safety. On Regional roads in York Region, there were over 3.26 million daily vehicle trips between 2012 and 2014 (York Region, 2015, page 4). Such a large number of vehicles on the road can create high chances of collisions. York Region needs to make more efforts to minimize the risk of traffic collisions. The number of traffic collisions has been decreasing over the past ten years. In 2015, the region had the lowest number of collisions to date (York Region, 2015. Page 5). As previously stated, the Regional Municipality of York has examined patterns of traffic collisions 
and put forward different initiatives to help minimize the number of collisions that occur.

York Region's "Traffic Safety and Status Report 2012 - 2014" considers the collision patterns that have emerged over the three-year period. The report examines the statistics of collisions based on several variables, including collisions by day, month, year, traffic control type, red light camera locations and the location of collisions. The report found that while the number of vehicle accidents has been decreasing, the number of collisions involving pedestrians has increased (York Region, 2015. Page 5). York Region is an area with urban centres, where many residents drive into for work or out of for work in other areas in the Greater Toronto Area. This results in a greater number of vehicles being present on the roads during weekdays.

Over the past three years, Friday has been the day when the most collisions occur (York Region, 2015. Page 5). Though York Region has had a decrease in the number of traffic collisions there has been a rise in several aspects that has brought new concerns to the Region. For example, the number of vehicle collisions has decreased, but the number of collisions involving pedestrians has increased slightly over the past three years (York Region, 2015. P. 5). Collisions involving pedestrians accounts for under $2 \%$ of total accidents, however, since 2012 it has risen from $1.65 \%$ of all accidents to $1.95 \%$ in 2014 (York Region, 2015. P. 5). The percentage of speed and aggressive driving related collisions has also increased since 2012 (York Region, 2015. Page 5). Due to the increase of accidents in these categories, York Region is continuing to determine different initiatives that can help to reduce traffic collisions.

Two of the initiatives discussed in the safety report were the community safety zones and red-light cameras. Community Safety Zones are used to reduce the speed limits around schools in York Region. All schools are eligible to apply for a community safety zone if the school is located on a Regional Road (Transportation 
Services, 2015. P.3). Currently there is approximately fifty-seven community safety zones in York Region that covers about 50 kilometers of road space. Of these fiftyseven zones nine had speed surveys completed (Transportation Services, 2015. P. 3 4 ). The speed surveys found that many motorists were disregarding the community safety zones and only made a small decrease in the vehicle operating speed (Transportation Services, 2015. P.4). Thus, as shown, Community Safety Zones may not have the desired effect to slow vehicles and reduce collisions. However, there may be other initiatives that could potentially be more effective.

One initiative that appears to be helping reduce the number of collisions is red light cameras. In York Region, there are currently 20 red light cameras located at several intersections and have been operational since 2013 (Transportation Services, 2015. P. 4). Since the installation of these cameras, it has been found that right angle collisions have been reduced by $48 \%$ at these intersections, and has slightly reduced the number of rear-end collisions (Transportation Services, 2015. P. 4-5). Due to the success of the 20 red light cameras, York Region is looking to add an additional 20 cameras in 2017, which will account for 5\% of all Regional Road (the highest-level road in the region) intersections (Transportation Services, 2015. P.6).

York Region has done work to examine different causes of accidents. There is room to look more closely at features of the streets themselves to help prevent collisions. Features such as the type of intersection, the road type and the land uses surrounding the accident clusters. These factors could help York Region to improve the overall safety of the residents in the Region of York. 


\subsection{Solutions}

Researchers have proposed several different ways to help decrease the number of collisions, which can be achieved from different government initiatives, education, and changes to the built environments. The government can introduce legislation and regulations to help reduce the number of collisions. Some of the regulations that could be put forward are increasing the minimum driving age; increasing safety requirements for motorcyclists, and monitoring large commercial truck drivers' health and fatigue (Arason, 2014). Education can inform the public of problems that are common, such as being more aware of motorcycles and increased training for younger drivers. There can also be changes to the built environment like red-light cameras (Garder, 2008), and road types.

The York Region Annual Traffic Safety Reports have proposed different initiatives that can help decrease the number of collisions, and examined the results

of these initiatives. In this report, they look at government initiatives, education and changes to the built environment to help reduce collisions. In the 2015 "Annual Traffic Safety Report", York Region Transportation Services put forward seven initiatives to help reduce the severity and number of collisions that occur. These initiatives are as follows:

1. Reducing speed limits on Regional roads

2. Introducing Community Safety Zones to reduce speeds in school areas

3. Installing red light cameras at 20 intersections

4. Reviewing signal timing plans and providing additional pedestrian crossing time at signalized intersections

5. Implementing safety campaigns to enhance awareness for issues affecting pedestrian safety and to raise awareness on the impacts of distracted driving 6. Increase awareness of pedestrians at intersections by installing zebra markings

7. Installing reflective backboards on traffic signals to improve visibility at night and during power outages (Transportation Services, 2015. P. 2) 
York Region has been focusing on education and the built environment in helping to reduce collisions. It looks at using both educational programs (such as increase awareness of pedestrians at intersections by installing zebra markings and implementing safety campaigns to enhance awareness for issues affecting pedestrian safety and raising awareness of the impacts of distracted driving) and features of the roads (such as reducing speed limits on Regional roads, introducing Community Safety Zones to reduce speeds in school areas, installing red light cameras at 20 intersections, and installing reflective backboards on traffic signals to improve visibility at night and during power outages to help decrease the number of collisions that occur). 


\section{Data and Methodology}

\subsection{Hypothesis}

This paper will focus on testing four hypothesizes about the factors of the built environment and road networks.

The first hypothesis pertains to the built environment, which is the closer an intersection is to traffic/pedestrian generators (such as Shopping centres, bus stops and schools), the more likely there will be an accident". An accident can involve a pedestrian as there are several people walking or with another vehicle due to high volumes of traffic in a small area where many different maneuvers being performed.

The second hypothesis is that if there are traffic controls in place at an intersection there will be fewer accidents than at intersections that do not have traffic controls.

The third hypothesis for road networks; "more conflict points at an intersection lead to more accidents". This would mean that cross intersections would have the most accidents, whereas T-intersection will have fewer. This hypothesis is based on information found in Chapter 2.

The final hypothesis is that the traffic zones which are a part of clusters with high employment in urban areas will have more accidents than other zones. This hypothesis is based on the information that clusters with more employment and population will have more traffic and congestion which will lead to more accidents (Golob \& Recker, 2003).

\subsection{Study Plan}

\subsubsection{Study Area}

The Regional Municipality of York is located just north of the City of Toronto, between Peel and Durham Regions. The Region of York is made up of nine local 
municipalities (see figure 1); the Town of Aurora, Town of East Gwillimbury, Town of Georgina, the Township of King, the City of Markham, Town of Newmarket, Town of Richmond Hill, the City of Vaughan and the Town of Whitchurch-Stouffville (York Region, 2016). York Region is a growing area with a population of one million people (Statistics Canada, 2016). Over 50\% of the population live in two municipalities, Markham (with 29.23\%) and Vaughan (with 27.94\%) (York Region, 2015. Page 14). York Region covers 1, 762 squared kilometers (Statistics Canada, 2016) with King (333.30 km2) and Georgina (287.72 km2) having the largetest land areas (Statistics Canada, 2016).

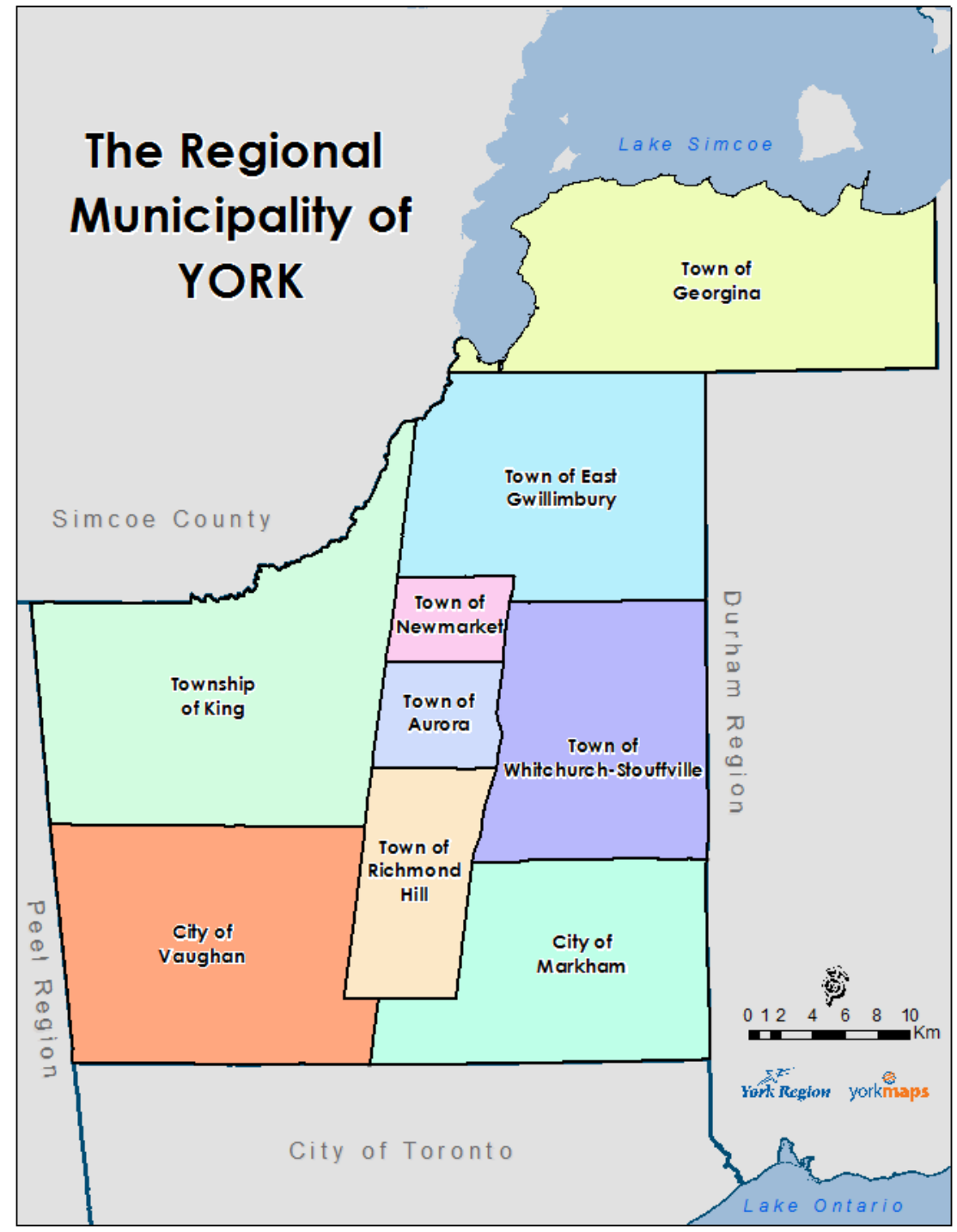

Figure 3: Municipalities in York Region 


\subsubsection{Study Period}

Traffic collision data were gathered from the Regional Municipality of York, over a six-year period, starting on January 1, 2010, and ending December 31, 2015. A six-year period was used because the longer the period, the more confidently the data is able to show reliable patterns of collisions instead of random occurrences.

\subsection{Data}

Data were obtained from two departments: Transportation Services and the GIS Branch. All traffic collision data was collected by the Transportation Services. This includes the coordinates of the accidents, as well as 43 other attributes (such as time, road conditions, and collision type). Table 1 lists the variables that form the main part of the analysis. A full list of variables can be found in the Appendix. This data set shows the attributes of the accidents and can help reveal the factors of a collision, which could be a cause.

Table 1 Variables collected from York Region Transportation Department

\begin{tabular}{|c|c|}
\hline Variable Code & Description \\
\hline Location & Location of the accident \\
\hline Accident_T & Time of the accident \\
\hline Accident_D & Day of the Accident \\
\hline Traffic_C̄o & Traffic control at the location of the accident \\
\hline Collision_ & Damage that occurred during the accident \\
\hline Municipal & Name of the Municipality \\
\hline Vehicle_14 & Movement of the vehicle at the time of the accident \\
\hline Apparent_D & Apparent cause of the accident \\
\hline
\end{tabular}

The data provided by GIS Branch contained different features of intersections and nearby land use patterns (i.e. points of interest) or traffic generators. This data helps to show if there are features around an intersection that contribute to high number of collision. Table 2 shows the variables related to traffic collisions. 
Table 2 Variables collected from York Region GIS Department

\begin{tabular}{ll}
\hline Feature Name & Description \\
\hline Shopping Centre & Shopping centres and plazas \\
Bus Stops & All Bus stops \\
Red Light Camera & Red light cameras at 22 different intersections \\
School & $\begin{array}{l}\text { Catholic, Public and French immersion Elementary } \\
\text { and secondary schools }\end{array}$ \\
Trees & Trees that are municipally owned \\
School Flasher & Flashing lights at 20 different schools \\
Traffic Zone Empol & $\begin{array}{l}\text { Shows the 100 different transit zones and the } \\
\text { number of people working in each zone }\end{array}$ \\
\hline
\end{tabular}

To collect information on the type of intersection (namely Cross, 'T', 'Y', 'L' or Roundabout), Google Maps, York Maps and a digital York Region Street file were used. Each accident location was determined using three different sources. Each intersection was examined and then put into one of the five intersection types. There were four issues that came up when classifying the intersections. The first, when looking at the type of intersections, roads would continue outside of York Region and the intersection were categorized using roads from Durham Region and the City of Toronto for example. This meant the roads located only in York region would cause a T intersection. However, when looking at the intersection and including all roads, it would create a cross. In this case, roads were classified by looking at all roads not only York Region Roads.

Second, when classifying intersections where one side entered into a mall, plaza or Go Station, the roads leading into these areas are not classified as roads. Intersections which contained the entrances or exits, were still classified as a cross intersection as drivers were given the option of going in any of the other directions and the intersection still contained the same number of conflict points as a cross intersection.

Third, roads that make a slight zig zag, like Old Homestead Road and Kennedy Road, and Pollock Drive and Kennedy Road, and are very close to each other, could have been considered either a T intersection or a Cross intersection. In 
this case, they were classified as a Cross intersection if a driver could drive straight through the intersection and continue in the same direction. Whereas, they were classified as $\mathrm{T}$ intersections if two right turns were needed to go in the same direction as in the case of Old Homestead Road.

Finally, the date of the accident needed to be considered as intersections may change over the years, with new roads being built. For example, in the case of King Road and Stan Roots Road, which is now considered a Cross intersection but was considered a $\mathrm{T}$ intersection in 2013 when the accident occurred. To see how the roads have changed over time, the interactive York map imagery slider was used.

\subsection{Methodology}

To understand the patterns emerging from collisions and the built environment, different methods were used to analyze the data. The first is descriptive statistics. This was used to understand the basic patterns of the collisions within York Region. Second, several Crosstabs are made to determine which areas are over- and under-represented with regards to collisions. Third, a linear regression was used to determine which factors contribute to the chances of a collision. Finally, cluster analysis was used to see if there is a type of traffic zone that had more accidents as opposed to other types of zones.

Crosstabs were used to determine types of intersection that are more or less likely to cause accidents. Descriptive statistic helped to show the general patterns of an intersection, such as how many accidents occurred in a year and how many were fatal, caused injury or property damage. It examined two variables at a time and determined the expected frequency to be compared to the observed frequency. Linear Regression is used to find which built features are significant in causing accidents. Cluster analysis classifies the traffic zones into five different clusters based on their similarities and differences. Maps are used to help show any spatial patterns. Using cluster analysis, Traffic Zones in all of York Region were grouped and mapped to determine which type of zones had more or less accidents compared 
to others. With all four types of analysis completed, it provides a deeper understanding of which features are causing accidents in York Region, and will be able to provide York Region with recommendations on how to improve safety at intersections.

\subsubsection{Descriptive Statistics}

The descriptive statistics were gathered using Excel and SPSS to provide an overall pattern of the collisions in York Region. The descriptive statistic was used to find the most common type of accident, day for an accident, road conditions, etc., while also looking to see if there was a change in the number of accidents from 2010 to 2015. The descriptive statistics show accidents in both raw numbers and the percent of total accidents.

\subsubsection{Crosstabs}

Crosstabulation is used when examining the percent of collisions that had occurred. Crosstabs tables were created for the percent of two different variables associated with a collision. These tables have two variables along the $\mathrm{x}$ and $\mathrm{y}$ axis which contain more than one category. For example, intersections were spilt into the five different categories (' + ', ' $\mathrm{L}$ ', ' $\mathrm{T}$ ', ' $\mathrm{Y}$ ', and roundabouts), and accidents spilt into three groups with regards to the different transportation modes (Pedestrian, cyclist and motor vehicle). This helps to demonstrate which types of intersections and features are more likely to contribute to collisions. Considering six different tables and Chi-squared statistics, the three different groups are:

1. Traffic Control and Collision Type

2. Traffic Control and Intersection Type

3. Intersection Type and Collision Type 


\subsubsection{Linear Regression}

Linear regression was used for traffic zones. Within each zone, accident counts were collected for different features that could be contributing to accident numbers. Two factors were measured by traffic zone: employment 2011 and population 2011. Employment 2011 refers to the number of people who worked in a traffic zone in 2011, and population refers the number of people living in a traffic zone in 2011. Population was divided into age groups. For this paper, children and young adults (under 25) and elderly populations (over 65) were also examined. Spatial joins were used to create sums. The factors examined included number of bus stops, Go Stations, red light camera, shopping centres, schools, and bike path lanes. Using SPSS, linear regression ran these variables, to determine if there was a relationship between any of the variable and the number of accidents in a traffic zone.

York Region is a unique regional municipality, as it has areas that are urban, (such as Vaughan, Richmond Hill and Markham), as well as areas that are rural (such as Georgina). This can create issues with regards to the data due to different factors that can affect accident in urban and rural areas, such as schools and red light cameras. Due to this factor, three linear regressions were ran: the first is a linear regression for all traffic zones, the second is a linear regression for only the traffic zones in urban areas. The third was only for rural areas. In this case, the following municipalities are considered as urban:

- the City of Markham

- Town of Newmarket

- Town of Richmond Hill

- the City of Vaughan

- Town of Aurora. 
Rural areas, on the other hand, were smaller townships and municipalities including

- Town of East Gwillimbury

- Town of Georgina

- Township of King

- Town of Whitchurch-Stouffville

\subsubsection{Cluster Analysis}

Cluster analysis was used to group the 353 Traffic zones into clusters. Grouping the zones based on environmental features and population created the Kmeans clusters. Six variables were used to create the clusters. Four of the variables traffic signal, municipal tress, shopping centres and bus stops - were chosen based on the variables that were significantly correlated with accidents based on the logistic regression. The other two variables were population from 2011 and employment from 2011. Population was chosen as a starting point. The more people that live in a traffic zone, this results in more vehicles that will be leaving, entering, and moving around the area, increasing the chances of accidents. Employment was chosen because where people work is a destination. The higher the number, of employment, the more people will be coming into the area.

To create the clusters, a K-means method was used. This type of clustering was used over a hierarchical clustering system, because it could create the number of cluster that was needed. Five clusters were chosen for this analysis because it had a large difference between the clusters while also allowing the zones within the clusters to be similar.

\subsubsection{Spatial Analysis}

Spatial patterns were examined using three different methods. The first was point density. This showed areas where there is a high concentration of accidents. It showed if there were clusters, as well as, which municipality has the highest density 
of accidents. The second used the 100 Traffic Zones in York Region to demonstrate which zones have the highest number of accidents within it, as well as, looking at the number of shopping centres, bus stops, red light cameras, schools, school flashers and municipal trees that are within each Zone. The final method was to take the clusters created by the cluster analysis and map them to determine which clusters had a higher or lower number of collisions. The zones are coloured based on which cluster they belonged to. For every one dot on the dot density map, it is equal to 45 accidents. This map demonstrates the spread of collisions and contains at least one dot for most of the Zones. 


\section{Results and Analysis}

\subsection{Overall Patterns of Accidents in York Region}

From the descriptive statistics, some patterns have emerged. It was found that the number of total collisions has been going down since 2010. In 2010, York Region had 7,258 accidents whereas in 2015 there were 6,336 accidents. There is an outlier with the year 2013, there were more accidents this year than any other year, in total there were 8,059 accidents. In 2013 there were more non-fatal injuries and property damage, however, fatal injuries were cut in half. Many of accidents over the six years is property damage only. When looking at 2013 the number of Nonreportable accidents has cut of drastically and Property damage only has increased. This could have to do in part to the fact that the way accidents were reported changed. Non-Reportable accidents are now being classified under property damage only.

Table 3 classifications of accidents by Year

\begin{tabular}{llllllll}
\hline $\begin{array}{l}\text { Classification of } \\
\text { Accident }\end{array}$ & $\mathbf{2 0 1 0}$ & $\mathbf{2 0 1 1}$ & $\mathbf{2 0 1 2}$ & $\mathbf{2 0 1 3}$ & $\mathbf{2 0 1 4}$ & $\mathbf{2 0 1 5}$ & Total \\
\hline Fatal Injury & 10 & 13 & 12 & 6 & 7 & 2 & 50 \\
$\begin{array}{l}\text { Non-Fatal Injury } \\
\text { Property Damage }\end{array}$ & 1,445 & 1,763 & 1,805 & 2,006 & 1,766 & 1,720 & 10,505 \\
$\begin{array}{l}\text { Only } \\
\text { Non- Reportable }\end{array}$ & 3,444 & 2,837 & 2,609 & 6,020 & 4,671 & 4,566 & 23,060 \\
Other & 2 & 2 & 2,589 & 19 & 3 & 6 & 8,762 \\
\hline
\end{tabular}

The time and the day of the week can affect the number of accidents that occur. There are more vehicles on the road during rush hour and weekends, which means there are more opportunities for an accident to occur. The peak number of accidents is different for weekdays and weekends. When looking at the weekdays there are a higher number of accidents between 7:00 am and 11:00 am as well as 3:00 pm and 7:00 pm. These peaks match with weekday rush hours (figure 4). Weekends have higher accidents between 11:00 am and 7:00 pm (figure 5). There are more vehicles on the roads in the morning hours with people getting to work and in the evening when people go home. More accidents occur between 2:00 pm and 7:00 pm with the most accidents occurring between 5:00 pm and 6:00 pm. 
There are a considerable number of accidents between 8:00 pm and 9:00 pm, it is ranked fifth in number of accidents. Weekdays have the most accidents, with the most accidents happening on Friday. During the week, there are more cars on the roads with people going to and from work, while on the weekends, more people may not be driving as much.

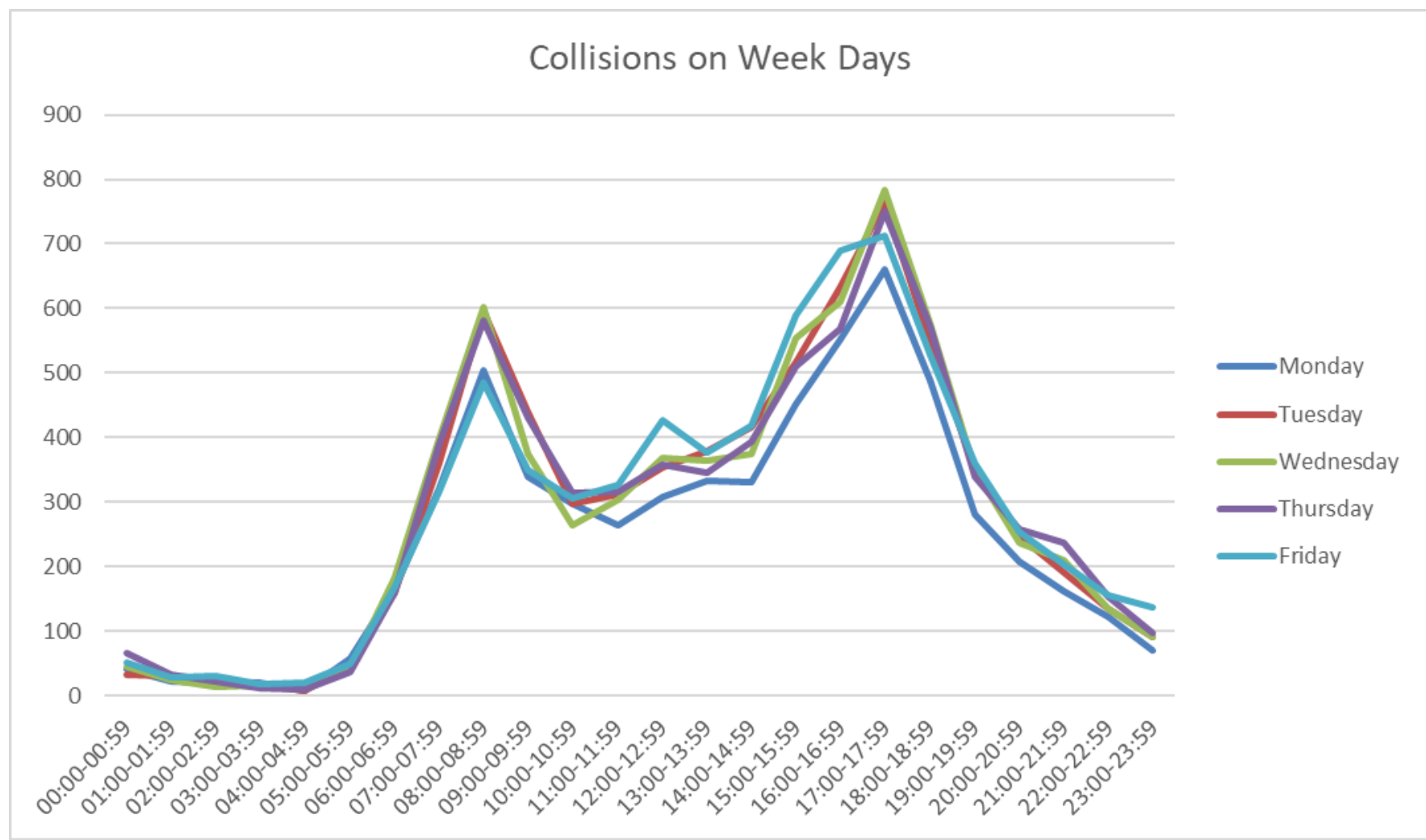

Figure 4: Graph of the time and day of collision on Weekdays 


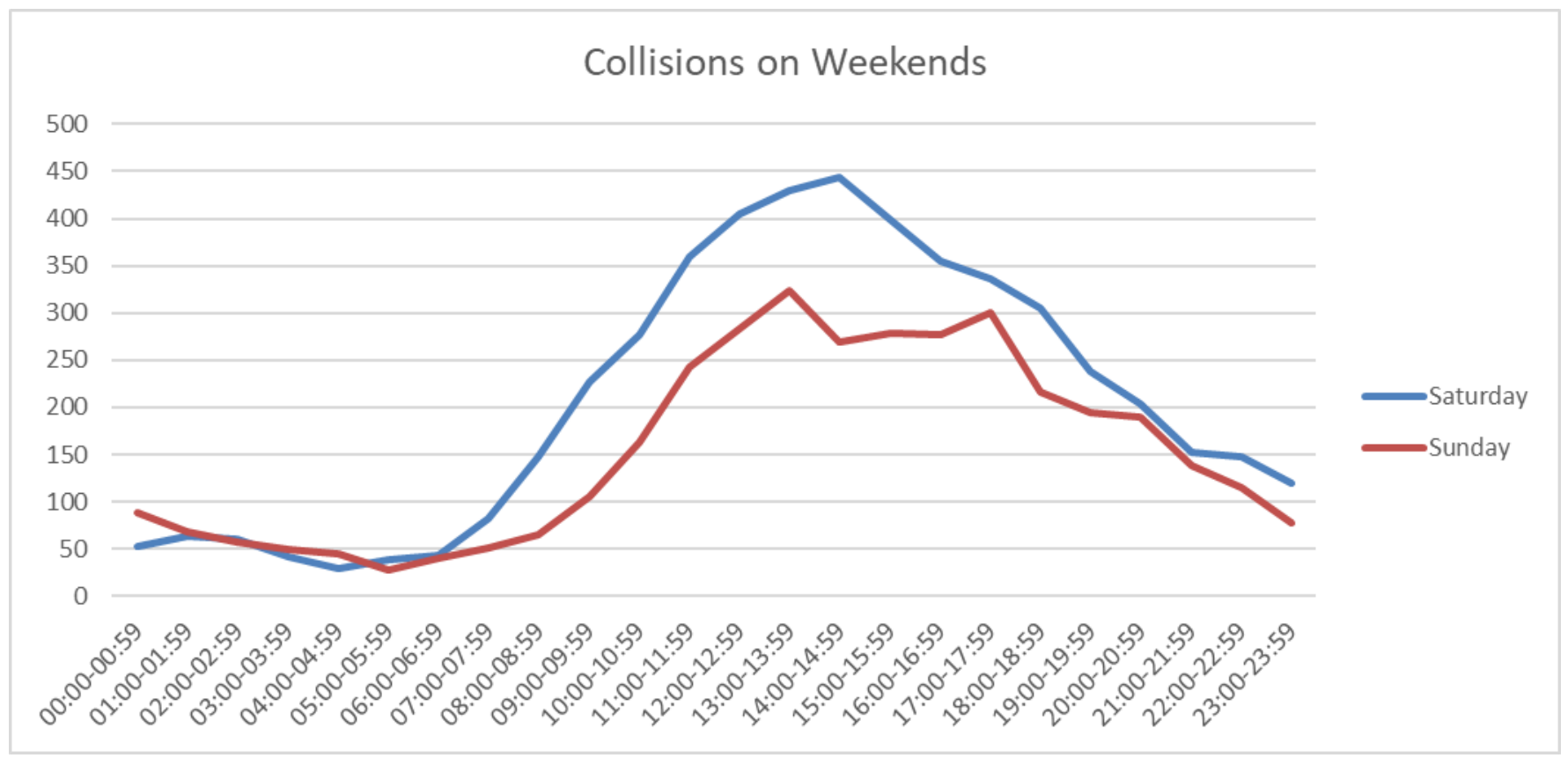

Figure 5 Graph of the time and day of collisions on Weekends

The top thirty intersections were examined to determine how the total number of accidents has changed over the years. There were several intersections that demonstrated substantial change, including Mackenzie Drive West \& Exit 35/GO Carpool Lot; and Jane Street \& Rutherford Road. Major Mackenzie Drive West \& Exit 35/GO Carpool Lot showed a significant increase in the number of traffic collisions, increasing from 5 collisions in 2010 to 59 collisions in 2015. This intersection held the highest number of collisions for 2015. On the other hand, Jane Street \& Rutherford Road is an intersection that demonstrated a substantial decrease in the number of collisions from 2010 to 2015. In 2010, Jane Street \& Rutherford Road was ranked $3^{\text {rd; }}$ however, in 2015 it was ranked 33 $3^{\text {rd }}$, as there was a decreased of 42 collisions. The map shows the location of these intersections in 2010 and 2015. 


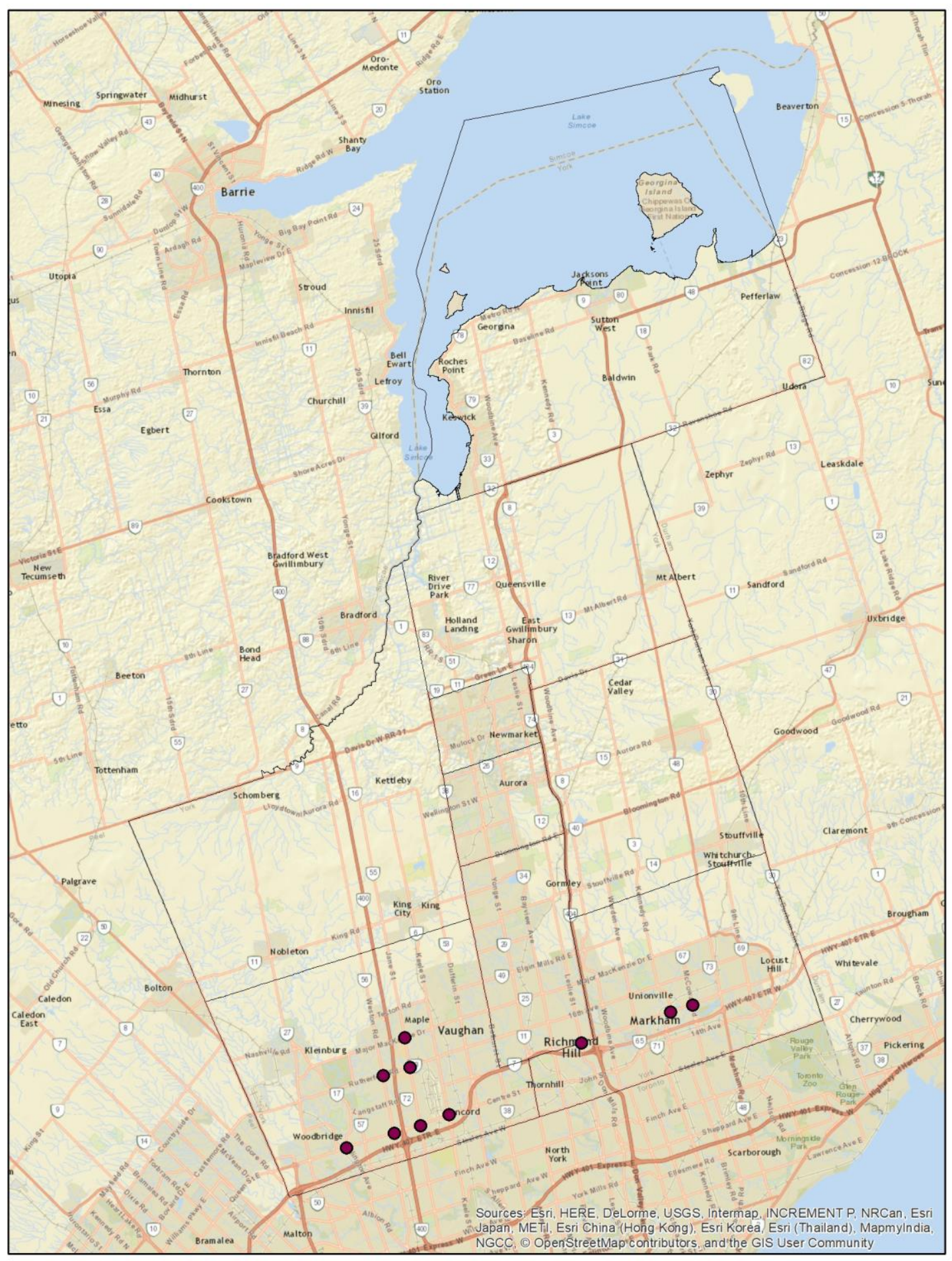

Figure 6 Top 10 intersections in 2010 


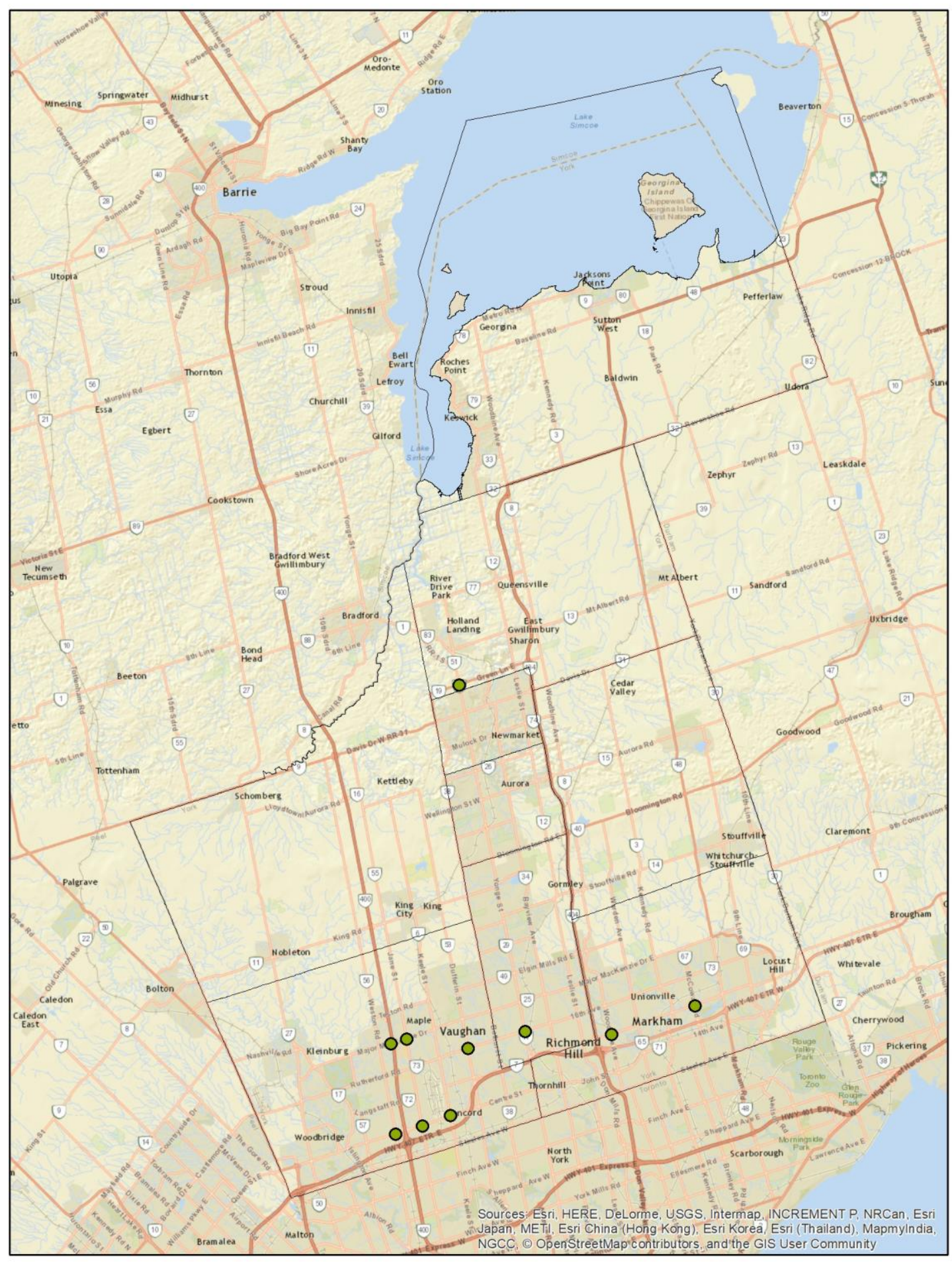

Figure 7 Top Ten Intersections 2015 
Using the many different techniques, a more in-depth evaluation was performed to determine built-environment features that could be causing accidents in York Region. Crosstabs, linear regression, and cluster analysis was used to determine which factors could be used to help improve road safety. The crosstabs looked at two features and gave the number of accidents that fell under both. Using this, we can get a better idea of what the types of accidents looked like. From the features used, there were six combinations that were looked at Traffic Control and Classification of Accident, Traffic Control and Intersection Type, Traffic Control and Classification of Accidents, Intersection Type and Classification of Accidents, Intersection Type and Apparent Driver Action and Intersection Type and Vehicle Maneuvers.

Eleven types of Traffic Controls were examined. These include:

- traffic signal

- stop sign

- yield sign

- pedestrian crossover

- police control

- school guard

- school bus

- traffic gate

- traffic controller

- no control

- others

Over the duration of the six years that constituted this study, it was found that of the 42,449 collisions that occurred, $73 \%$ occurred at a traffic signal, $15 \%$ occurred where there was no control and 6\% occurred at a stop sign. These are the three most common type of traffic controls, which could help to explain why more accidents occurred at these three types of control, as opposed to the other eight controls. 


\begin{tabular}{|c|c|c|}
\hline Traffic Controls & $\begin{array}{lll}\text { Number } & \text { of } & \text { All } \\
\text { Accidents } & & \\
\end{array}$ & Percent \\
\hline 01-Traffic Signal & 28605 & 73.60 \\
\hline 02-Stop Sign & 2480 & 6.38 \\
\hline 03- Yield Sign & 56 & 0.14 \\
\hline 04- Ped. Crossover & 25 & 0.06 \\
\hline 05- Police Control & 49 & 0.13 \\
\hline 06- School Guard & 3 & 0.01 \\
\hline 07-School Bus & 31 & 0.08 \\
\hline 08- Traffic Gate & 19 & 0.05 \\
\hline 09- Traffic Controller & 1419 & 3.65 \\
\hline 10- No Control & 6125 & 15.76 \\
\hline 99- Other & 54 & 0.14 \\
\hline TOTALS & 38866 & 100 \\
\hline
\end{tabular}

Over the past six years, three Initial Impact types, the first location of the collision, have created significant changes in the number of accidents. Angle and rear-ending accident have decreased and turning movement accidents have increased over the past 6 years. In 2010, the top three Initial Impact types were rear-ending (51.4\%), angle (22.3\%) and sideswipe (8.8\%). In 2015 the top three were rear-ending (41.5\%), turning movement $(29.9 \%)$ and SMV (single motor vehicle) other (9.6\%). As mentioned, over the years there has been a change in which impact type is most common in accidents. The two Initial Impacts types, that have seen a decrease, were examined first. Angle collisions have dropped significantly from 2010 to 2016. In 2010, this Initial Impact type accounted for $22.3 \%$ of all accidents; however, in 2015 it was only 7\% of all accidents. Rear ending has also decreased over the past five years from accounting for half of all accidents to under half, yet remains the most common impact type. There has been a steady decline in rear-end accidents since 2010. Turning movements has seen a steady increase in the number of accidents. From 2010 to 2015, the number of "other" accidents has tripled. It now is the second most common Initial Impact, but was originally the fourth most common. 
Table 5: Initial Impact of Accidents

\begin{tabular}{|c|c|c|c|c|c|c|c|c|c|c|c|c|c|}
\hline \multirow{2}{*}{$\begin{array}{l}\text { Initial } \\
\text { impact }\end{array}$} & \multicolumn{2}{|c|}{2010} & \multicolumn{2}{|c|}{2011} & \multicolumn{2}{|c|}{2012} & \multicolumn{2}{|c|}{2013} & \multicolumn{2}{|c|}{2014} & \multicolumn{2}{|c|}{2015} & \multirow{2}{*}{$\begin{array}{l}\text { total } \\
\#\end{array}$} \\
\hline & \# & $\%$ & \# & $\%$ & $\#$ & $\%$ & \# & $\%$ & \# & $\%$ & \# & $\%$ & \\
\hline Approaching & 132 & 1.82 & 171 & 2.34 & 144 & 2.05 & 553 & 6.86 & 243 & 3.76 & 56 & 0.88 & 1299 \\
\hline Angle & 1616 & 22.27 & 1802 & 24.61 & 1638 & 23.35 & 1527 & 18.95 & 744 & 11.52 & 447 & 7.05 & 7774 \\
\hline Rear end & 3730 & 51.39 & 3733 & 50.99 & 3542 & 50.49 & 3549 & 44.04 & 2712 & 41.98 & 2629 & 41.49 & 19895 \\
\hline Sideswipe & 640 & 8.82 & 749 & 10.23 & 810 & 11.55 & 722 & 8.96 & 635 & 9.83 & 566 & 8.93 & 4122 \\
\hline $\begin{array}{l}\text { Turning } \\
\text { movement }\end{array}$ & 536 & 7.38 & 244 & 3.33 & 240 & 3.42 & 861 & 10.68 & 1509 & 23.36 & 1894 & 29.89 & 5284 \\
\hline $\begin{array}{l}\text { SMV } \\
\text { unattended } \\
\text { vehicle }\end{array}$ & 226 & 3.11 & 216 & 2.95 & 248 & 3.54 & 15 & 0.19 & 16 & 0.25 & 29 & 0.46 & 750 \\
\hline SMV other & 298 & 4.11 & 365 & 4.99 & 344 & 4.90 & 431 & 5.35 & 524 & 8.11 & 609 & 9.61 & 2571 \\
\hline Other & 61 & 0.84 & 34 & 0.46 & 22 & 0.31 & 39 & 0.48 & 51 & 0.79 & 71 & 1.12 & 278 \\
\hline $\begin{array}{l}\text { (missing } \\
\text { data }\end{array}$ & 19 & 0.26 & 7 & 0.10 & 27 & 0.38 & 362 & 4.49 & 26 & 0.40 & 35 & 0.55 & 476 \\
\hline Total & 7258 & 100.00 & 7321 & 100.00 & 7015 & 100.00 & 8059 & 100.00 & 6460 & 100.00 & 6336 & 100.00 & 42449 \\
\hline
\end{tabular}

Three main accident types were examined. These accident types included vehicle-vehicle accidents, vehicle-pedestrian accidents, and vehicles-cyclist accidents. The type of collision that occurred varied among the three different types. Over the past six years, vehicle-vehicle accidents had a majority of accident resulting in property damage only. A total of $77 \%$ of all accidents resulted in property damage; and of all the accidents that occurred, $74.9 \%$ were vehicle-vehicle accidents. Vehicles-cyclist accidents were more likely to end in injury, as injury resulted from $82.7 \%$ of such accidents. Injury accounted for the most common outcome in vehicles-cyclist accidents, however, these accidents accounted for less than 15\% of total accidents between 2010 and 2015. Injury was also the most common outcome in vehicle-pedestrian accidents. Of all vehicle-pedestrian accidents, 93.7\% ended in injury, and this type accounted for $1.8 \%$ of all accidents that occurred. In York Region, vehicle-vehicle accidents account for $96.9 \%$ of all accidents that occurred. Of all 42,000 accidents, 468 involved a cyclist and 836 involved pedestrians. 
Table 6: Type of accident by year

\begin{tabular}{llllllll}
\hline & $\mathbf{2 0 1 0}$ & $\mathbf{2 0 1 1}$ & $\mathbf{2 0 1 2}$ & $\mathbf{2 0 1 3}$ & $\mathbf{2 0 1 4}$ & $\mathbf{2 0 1 5}$ & Total \\
\hline Motor Vehicle & 7070 & 7126 & 6805 & 7818 & 6222 & 6104 & 41,145 \\
Pedestrian & 124 & 131 & 137 & 146 & 147 & 151 & 836 \\
Cyclist & 64 & 64 & 73 & 95 & 91 & 81 & 468 \\
\hline
\end{tabular}

Weather/climate conditions can be a factor in the causes of accidents, but when looking at all the accidents, it was found that $80.4 \%$ of all accidents happened during clear conditions. This helps to show that other factors that are more prominent in causing accidents as opposed to harsh weather. Rain (12.5\%) and snow (5.3\%), as shown in the Table 7 , are sometimes a cause of accidents, and therefore are still considered factors in causing accidents.

Table 7: Environmental Condition of accidents

\begin{tabular}{lll}
\hline $\begin{array}{l}\text { Weather/Climate } \\
\text { Conditions }\end{array}$ & Accident Count & Percent \\
\hline 01 - Clear & 33667 & 80.37 \\
02 - Rain & 5226 & 12.48 \\
03 - Snow & 2210 & 5.28 \\
04 - Freezing Rain & 201 & 0.48 \\
05 - Drifting Snow & 187 & 0.45 \\
06 - Strong wind & 77 & 0.18 \\
07 - Fog, mist, smoke, dust & 199 & 0.48 \\
99 - Other & 122 & 0.29 \\
\hline
\end{tabular}

Crosstabs were used to examine two factors and see where the majority of accidents fit within them. Traffic Control and Type of Accident (Appendix B Table 1) found that fatal accidents occurred most often at Traffic Signals (56\% of all fatal accidents) and no control (16\% of all fatal accidents). However, when examining the number of intersections that had accidents, it is shown that fatal accidents make up only $0.09 \%$ of all accidents that occur at a traffic signal, while at no control intersections fatal accidents make up $0.13 \%$ of all accidents. Both numbers are extremely low. However, there is a higher percentage of fatal accidents occurring at no control intersections. Of all injury accidents, $69.3 \%$ were at traffic signals and $14.7 \%$ occurred at no control intersections. The highest percent of injuries occurred 
at Pedestrian crossover, which accounted for $68 \%$ of the accidents (17 out of 25 accidents ended in an injury). Concerning property damage, it was found that the majority of accidents occurred at traffic signals accounting for $66.8 \%$ and $14.3 \%$ of accident occurring at no control intersections.

The second crosstab (Appendix B Table 2) examined Traffic Control and Intersection Type. This table demonstrated that the most accidents occurred at cross intersections with traffic signals. This intersection combination is the most common as shown in the data set. This combination accounts for $83.5 \%$ of all accidents at a traffic signal and $70.8 \%$ of accidents at a cross intersection. The Tintersection has the next highest number of accidents and the most common traffic control for accidents to occur at is the Traffic signal (54.4\%). However, overall the accidents are spread throughout all the controls within the cross intersections, as no Control had $20.9 \%$ and stop signs accounted for $12.9 \%$.

Third was Intersection Type and Collision Type and this crosstab was used to demonstrate the most common intersection type. It was found that the type of collision is property damage only at cross intersections. This combination makes up $79.7 \%$ of all property damage only accidents and $75.4 \%$ of all cross-intersection accidents. A majority of fatal and injury accident also occur at cross intersections. The statistics of $\mathrm{T}$ intersections is that $74.1 \%$ of accidents are property damage only, $25.7 \%$ are injuries and $0.2 \%$ are fatal.

These tables help to answer the hypothesis that the closer an intersection is to a traffic/pedestrian generator (such as Shopping centres, bus stops and schools), the more likely there will be an accident. As well as, if there are traffic controls in place at an intersection there will be fewer accidents than at intersections that do not have traffic controls. Finally, more conflict points at an intersection will lead to more accidents.

\subsection{Qualitative Analysis}

To help understand features at intersections that could cause accidents, the intersections that were in the top $25 \%$ in number of accidents, were looked at using imagery from York Maps and Google Street view. The top 25\% intersection 
accidents were looked at for both fatal and injury. Each intersection was examined and information about the built environment was recorded. The information fell under the following headings: Number of Injuries, Bus Stop, Traffic Control, Intersection Type, Shopping Centre, School, Speed Limit, Number of Lanes, Land Use, Other, and the change 2010 to 2016.

When looking at fatal accidents, most intersections only experienced one fatal accident, and only four intersections experienced two fatal accidents. These four intersections were examined. Table 10 shows the built environmental features that are surrounding each of the intersections. From this table, it can be determined if there are any patterns around the intersections. Using different features, the table helps to reveal if one feature is more common when fatal accidents occur.

Table 8 Intersections in the top number of Fatal Accidents

\begin{tabular}{|c|c|c|c|c|c|c|c|c|c|c|c|}
\hline 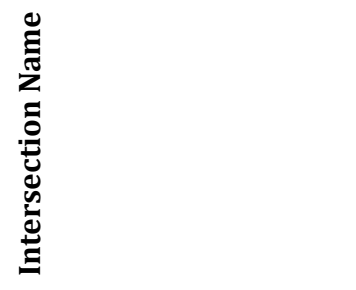 & 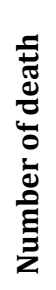 & 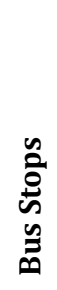 & 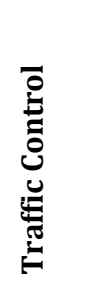 & 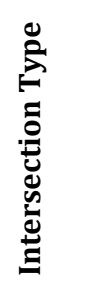 & 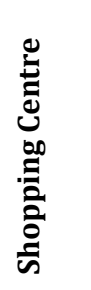 & 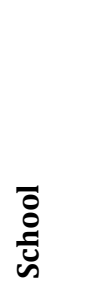 & 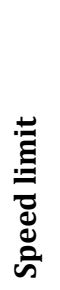 & 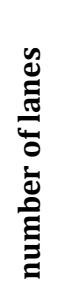 & 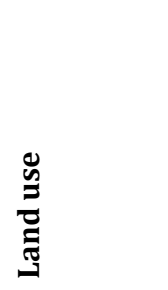 & 离 & 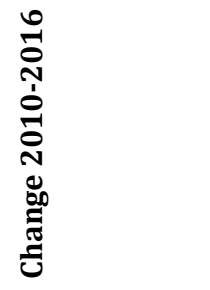 \\
\hline $\begin{array}{l}\text { Dufferin Street \& } \\
\text { Dufferin Hill } \\
\text { Drive/Apple Blossom } \\
\text { Drive }\end{array}$ & 2 & 1 & $\begin{array}{l}\text { Street } \\
\text { Light }\end{array}$ & Cross & No & $\begin{array}{l}\text { Private } \\
\text { school }\end{array}$ & 60 & 2 & Residential & $\begin{array}{l}\text { Park, } \\
\text { middle } \\
\text { divide }\end{array}$ & $\begin{array}{l}\text { Park was built } \\
\text { in } 2013\end{array}$ \\
\hline Highway 7 \& Ninth Line & 2 & 3 & $\begin{array}{l}\text { Street } \\
\text { Light }\end{array}$ & $\mathrm{X}$ & No & No & 60 & 2 & Residential & $\begin{array}{l}\text { Green } \\
\text { Space }\end{array}$ & $\begin{array}{l}2011 \\
\text { residential } \\
\text { built to the } \\
\text { north }\end{array}$ \\
\hline $\begin{array}{l}\text { Major Mackenzie Drive } \\
\text { West \& Exit } 35\end{array}$ & 2 & 1 & $\begin{array}{l}\text { Street } \\
\text { Light }\end{array}$ & Cross & Plaza & No & & 2 & Residential & $\begin{array}{l}\text { GO } \\
\text { Station, } \\
\text { green } \\
\text { space }\end{array}$ & \\
\hline $\begin{array}{l}\text { Major Mackenzie Drive } \\
\text { West \& Exit } 35\end{array}$ & 2 & 2 & $\begin{array}{l}\text { Street } \\
\text { Light }\end{array}$ & Cross & $\begin{array}{l}\text { Small } \\
\text { Plaza }\end{array}$ & No & 60 & 2 & Residential & Park & \\
\hline
\end{tabular}

A total of 22 intersections were in the top 25\%, and each intersection was examined using York Region Maps and information that was provided by York Region. 


\begin{tabular}{|c|c|c|c|c|c|c|c|c|c|c|c|}
\hline 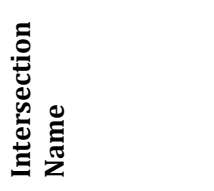 & 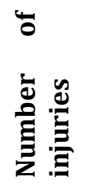 & 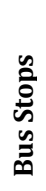 & 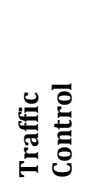 & 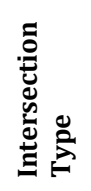 & 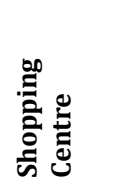 & : & 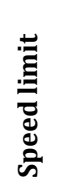 & 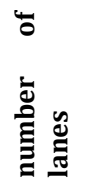 & 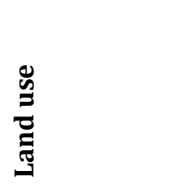 & 远 & 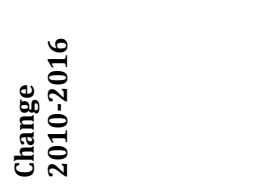 \\
\hline $\begin{array}{l}\text { Highway } 7 \text { \& } \\
\text { Weston Road }\end{array}$ & 77 & 4 & $\begin{array}{l}\text { Street } \\
\text { Light }\end{array}$ & Cross & $\overline{\text { Plaza }}$ & No & 70 & 3 & Industrial & & $\begin{array}{l}\text { Construction of the } \\
\text { new plaza }\end{array}$ \\
\hline $\begin{array}{l}\text { Weston Road } \\
\text { \& Rutherford } \\
\text { Road }\end{array}$ & 77 & 3 & $\begin{array}{l}\text { Street } \\
\text { Light }\end{array}$ & Cross & Plaza & No & 60 & 2 & $\begin{array}{l}\text { Commercial } \\
\text { Surrounded } \\
\text { by } \\
\text { Residential }\end{array}$ & & $\begin{array}{l}\text { No } \\
\text { change }\end{array}$ \\
\hline $\begin{array}{l}\text { Major } \\
\text { Mackenzie } \\
\text { Drive West \& } \\
\text { Jane Street }\end{array}$ & 71 & 3 & $\begin{array}{l}\text { Street } \\
\text { Light }\end{array}$ & Cross & Plaza & No & 60 & 2 & Commercial & Wonderland & $\begin{array}{l}\text { Construction on the } \\
\text { north east corner } \\
\text { from } 2013 \text { to } 2014\end{array}$ \\
\hline $\begin{array}{l}\text { Yonge Street } \\
\text { \& Carrville } \\
\text { Road } / 16^{\text {th }} \\
\text { Avenue }\end{array}$ & 70 & 3 & $\begin{array}{l}\text { Street } \\
\text { Light }\end{array}$ & Cross & $\begin{array}{l}\text { Shoppin } \\
\text { g Centre }\end{array}$ & No & 50 & 2 & $\begin{array}{l}\text { Commercial } \\
\text { and } \\
\text { residential }\end{array}$ & & $\begin{array}{l}\text { construction half a } \\
\text { block south since } \\
2013\end{array}$ \\
\hline $\begin{array}{l}\text { Highway } 7 \& \\
\text { Pine Valley } \\
\text { Drive }\end{array}$ & 68 & 3 & $\begin{array}{l}\text { Street } \\
\text { Light }\end{array}$ & Cross & Plaza & No & 60 & 3 & $\begin{array}{l}\text { Commercial } \\
\text { Surrounded } \\
\text { by } \\
\text { Residential }\end{array}$ & & $\begin{array}{l}\text { No } \\
\text { change }\end{array}$ \\
\hline $\begin{array}{l}\text { Yonge Street } \\
\text { \& Green Lane } \\
\text { East/ Green } \\
\text { Lane West }\end{array}$ & 63 & 3 & $\begin{array}{l}\text { Street } \\
\text { Light }\end{array}$ & $\mathrm{X}$ & Plaza & No & 70 & 2 & Commercial & $\begin{array}{l}\text { Green land } \\
\text { farm land to } \\
\text { the north }\end{array}$ & $\begin{array}{l}\text { Significant } \\
\text { development of } \\
\text { plazas on the north } \\
\text { east side }\end{array}$ \\
\hline $\begin{array}{l}\text { Highway } 7 \text { \& } \\
\text { McCowan } \\
\text { Road }\end{array}$ & 60 & 4 & $\begin{array}{l}\text { Street } \\
\text { Light }\end{array}$ & Cross & $\begin{array}{l}\text { Shoppin } \\
\text { g Centre } \\
\text { and } \\
\text { plaza }\end{array}$ & No & $\begin{array}{l}50 \\
\text { E-W } \\
60 \\
\text { N-S }\end{array}$ & 2 & $\begin{array}{l}\text { Commercial } \\
\text { surrounded } \\
\text { by } \\
\text { residential }\end{array}$ & & $\begin{array}{l}\text { construction on the } \\
\text { south east corner } \\
2012 \text { to } 2013\end{array}$ \\
\hline $\begin{array}{l}\text { Keele Street \& } \\
\text { Highway } 7\end{array}$ & 59 & 2 & $\begin{array}{l}\text { Street } \\
\text { Light }\end{array}$ & Cross & Plaza & No & $\begin{array}{l}70 \\
\text { E-W } \\
60 \\
\text { N-S }\end{array}$ & $\begin{array}{l}3 \mathrm{E}-\mathrm{W} \\
2 \mathrm{~N}-\mathrm{S}\end{array}$ & $\begin{array}{l}\text { Commercial } \\
\text { and } \\
\text { residential }\end{array}$ & $\begin{array}{l}\text { Go Station } \\
\text { Stop }\end{array}$ & $\begin{array}{ll}\text { No } & \text { Significant } \\
\text { change } & \end{array}$ \\
\hline $\begin{array}{l}\text { Major } \\
\text { Mackenzie } \\
\text { Drive West \& } \\
\text { Exit 35/GO } \\
\text { Carpool Lot - } \\
\text { Hwy 400 \& } \\
\text { Major } \\
\text { Mackenzie } \\
\text { Drive West }\end{array}$ & 56 & 1 & $\begin{array}{l}\text { Street } \\
\text { Light }\end{array}$ & Cross & No & No & 60 & 2 & $\begin{array}{l}\text { Commercial } \\
\text { and green } \\
\text { space }\end{array}$ & $\begin{array}{l}\text { Highway off } \\
\text { Ramp }\end{array}$ & $\begin{array}{l}\text { Construction of new } \\
\text { shopping centres on } \\
\text { the north west side }\end{array}$ \\
\hline $\begin{array}{l}\text { Bathurst } \\
\text { Street \& Clark } \\
\text { Avenue West }\end{array}$ & 54 & 3 & $\begin{array}{l}\text { Street } \\
\text { Light }\end{array}$ & Cross & $\begin{array}{l}\text { Shoppin } \\
\text { g Centre }\end{array}$ & No & 50 & 2 & Residential & $\begin{array}{l}\text { CF } \\
\text { Promenade } \\
\text { mall, school } \\
\text { and library a } \\
\text { block away }\end{array}$ & $\begin{array}{ll}\text { No } & \text { Significant } \\
\text { change } & \end{array}$ \\
\hline $\begin{array}{l}\text { Highway } 7 \text { \& } \\
\text { Jane Street }\end{array}$ & 54 & 3 & $\begin{array}{l}\text { Street } \\
\text { Light }\end{array}$ & Cross & $\begin{array}{l}\text { Shoppin } \\
\text { g centre } \\
\text { and } \\
\text { Plaza }\end{array}$ & No & 70 & 3 & Commercial & $\begin{array}{l}\text { Off the } \\
\text { highway }\end{array}$ & $\begin{array}{l}\text { Construction of new } \\
\text { shopping centre } \\
\text { north west }\end{array}$ \\
\hline $\begin{array}{l}\text { Islington } \\
\text { Avenue \& } \\
\text { Rutherford } \\
\text { Road }\end{array}$ & 54 & 2 & $\begin{array}{l}\text { Street } \\
\text { Light }\end{array}$ & $\mathrm{X}$ & Plaza & $\begin{array}{l}\text { Yes } \\
(\text { Em } \\
\text { ily } \\
\text { Carr } \\
\text { ) } \\
\end{array}$ & 60 & 2 & Residential & Green space & $\begin{array}{l}\text { No } \quad \text { significant } \\
\text { change }\end{array}$ \\
\hline
\end{tabular}




\begin{tabular}{|c|c|c|c|c|c|c|c|c|c|c|c|}
\hline $\begin{array}{l}\text { Highway } 7 \text { - } \\
\text { Yonge Street } \\
\text { Ramp \& } \\
\text { Highway } 7\end{array}$ & 53 & 1 & $\begin{array}{l}\text { Street } \\
\text { Light }\end{array}$ & $\mathrm{T}$ & No & No & 50 & 3 & $\begin{array}{l}\text { Highway off } \\
\text { ramp }\end{array}$ & $\begin{array}{l}\text { Surrounded } \\
\text { by green } \\
\text { space }\end{array}$ & $\begin{array}{ll}\begin{array}{l}\text { No } \\
\text { change }\end{array} & \text { significant } \\
\end{array}$ \\
\hline $\begin{array}{l}\text { Highway } 7 \text { - } \\
\text { Bayview } \\
\text { Avenue Ramp } \\
\text { \& Highway } 7\end{array}$ & 52 & 1 & $\begin{array}{l}\text { Street } \\
\text { Light }\end{array}$ & Cross & Plaza & $\begin{array}{l}\text { Yes } \\
\text { (TM } \\
\text { I } \\
\text { Toro } \\
\text { nto } \\
\text { and } \\
\text { Bay } \\
\text { view } \\
\text { ) }\end{array}$ & 60 & 3 & Commercial & $\begin{array}{l}\text { Off ramp of } \\
\text { a highway }\end{array}$ & $\begin{array}{l}\text { No significant } \\
\text { change }\end{array}$ \\
\hline $\begin{array}{l}\text { Major } \\
\text { Mackenzie } \\
\text { Drive East \& } \\
\text { Bayview } \\
\text { Avenue }\end{array}$ & 52 & 3 & $\begin{array}{l}\text { Street } \\
\text { Light }\end{array}$ & Cross & Plaza & $\begin{array}{l}\text { Yes } \\
\text { (Bay } \\
\text { view } \\
\text { ) }\end{array}$ & 60 & 3 & Residential & & $\begin{array}{l}\text { No significant } \\
\text { change }\end{array}$ \\
\hline $\begin{array}{l}\text { Jane Street \& } \\
\text { Rutherford } \\
\text { Road }\end{array}$ & 51 & 4 & $\begin{array}{l}\text { Street } \\
\text { Light }\end{array}$ & Cross & $\begin{array}{l}\text { Shoppin } \\
\text { g centre } \\
\text { and } \\
\text { Plaza }\end{array}$ & No & 60 & $\begin{array}{l}3 \mathrm{E}-\mathrm{W} \\
2 \mathrm{~N}-\mathrm{S}\end{array}$ & Commercial & $\begin{array}{l}\text { Vaughn } \\
\text { Mills }\end{array}$ & $\begin{array}{l}\text { No } \\
\text { change }\end{array}$ \\
\hline $\begin{array}{l}\text { Major } \\
\text { Mackenzie } \\
\text { Drive West \& } \\
\text { Bathurst } \\
\text { Street }\end{array}$ & 51 & 1 & $\begin{array}{l}\text { Street } \\
\text { Light }\end{array}$ & Cross & No & No & 60 & 2 & Residential & $\begin{array}{l}\text { Developmen } \\
\text { ts }\end{array}$ & $\begin{array}{l}\text { Lots of residential } \\
\text { developments }\end{array}$ \\
\hline $\begin{array}{l}\text { Highway } 7 \text { \& } \\
\text { Leslie Street }\end{array}$ & 50 & 6 & $\begin{array}{l}\text { Street } \\
\text { Light }\end{array}$ & Cross & Plaza & No & 60 & $\begin{array}{l}3 \mathrm{E}-\mathrm{W} \\
2 \mathrm{~N}-\mathrm{S}\end{array}$ & Commercial & $\begin{array}{l}\text { Middle } \\
\text { dived for } \\
\text { bus and bike } \\
\text { lanes }\end{array}$ & $\begin{array}{l}\text { Construction on } \\
\text { divides 2012-2014 }\end{array}$ \\
\hline $\begin{array}{l}\text { Highway } 7 \& \\
\text { Woodbine } \\
\text { Avenue }\end{array}$ & 50 & 5 & $\begin{array}{l}\text { Street } \\
\text { Light }\end{array}$ & Cross & $\begin{array}{l}\text { Shoppin } \\
\text { g Centre } \\
\text { and } \\
\text { Plaza }\end{array}$ & $\begin{array}{l}\text { Sene } \\
\text { ca } \\
(\text { A } \\
\text { bloc } \\
\mathrm{k} \\
\text { over } \\
\text { ) }\end{array}$ & 60 & 3 & $\begin{array}{l}\text { Commercial } \\
\text { surrounded } \\
\text { by } \\
\text { residential }\end{array}$ & $\begin{array}{l}\text { Middle } \\
\text { dived for } \\
\text { bus and bike } \\
\text { lanes }\end{array}$ & $\begin{array}{l}\text { Construction on } \\
\text { divides 2013-2014 }\end{array}$ \\
\hline $\begin{array}{l}\text { Yonge Street } \\
\text { \& Elgin Mills } \\
\text { Road } \\
\text { West/Elgin } \\
\text { Mills Road } \\
\text { East }\end{array}$ & 49 & 3 & $\begin{array}{l}\text { Street } \\
\text { Light }\end{array}$ & Cross & Plaza & No & 60 & 2 & $\begin{array}{l}\text { Commercial } \\
\text { and } \\
\text { residential }\end{array}$ & & $\begin{array}{l}\text { No significant } \\
\text { change }\end{array}$ \\
\hline $\begin{array}{l}\text { 14th Avenue } \\
\text { @ Markham } \\
\text { Road }\end{array}$ & 48 & 3 & $\begin{array}{l}\text { Street } \\
\text { Light }\end{array}$ & $\mathrm{X}$ & $\begin{array}{l}\text { Box } \\
\text { Store }\end{array}$ & No & 50 & 2 & $\begin{array}{l}\text { Green space, } \\
\text { commercial } \\
\text { and } \\
\text { residential }\end{array}$ & & $\begin{array}{l}\text { Bus stops put in } \\
\text { around } 2010\end{array}$ \\
\hline $\begin{array}{l}\text { Highway } 27 \text { \& } \\
\text { Rutherford } \\
\text { Road }\end{array}$ & 48 & 1 & $\begin{array}{l}\text { Street } \\
\text { Light }\end{array}$ & $\mathrm{X}$ & No & No & $\begin{array}{l}60 \\
\text { E-W } \\
70 \\
\text { N-S } \\
\end{array}$ & 2 & Green Space & & $\begin{array}{l}\text { No significant } \\
\text { change }\end{array}$ \\
\hline
\end{tabular}

All of the top intersections for accidents had streetlights as the traffic control. The remotely sensed images (Figure 5 -10) show the land uses around each of the intersection. Around most of the intersections, residential and commercial areas are present. There are also areas of green space surrounding some of the intersections, 
such as Highway 7 and Leslie street, Highway 7 and Rutherford road, Major Mackenzie Drive and Jane street, and Yonge street and Green Lane East/ West. These areas could be considered for future development and construction, and this was seen to be a common factor in accidents.
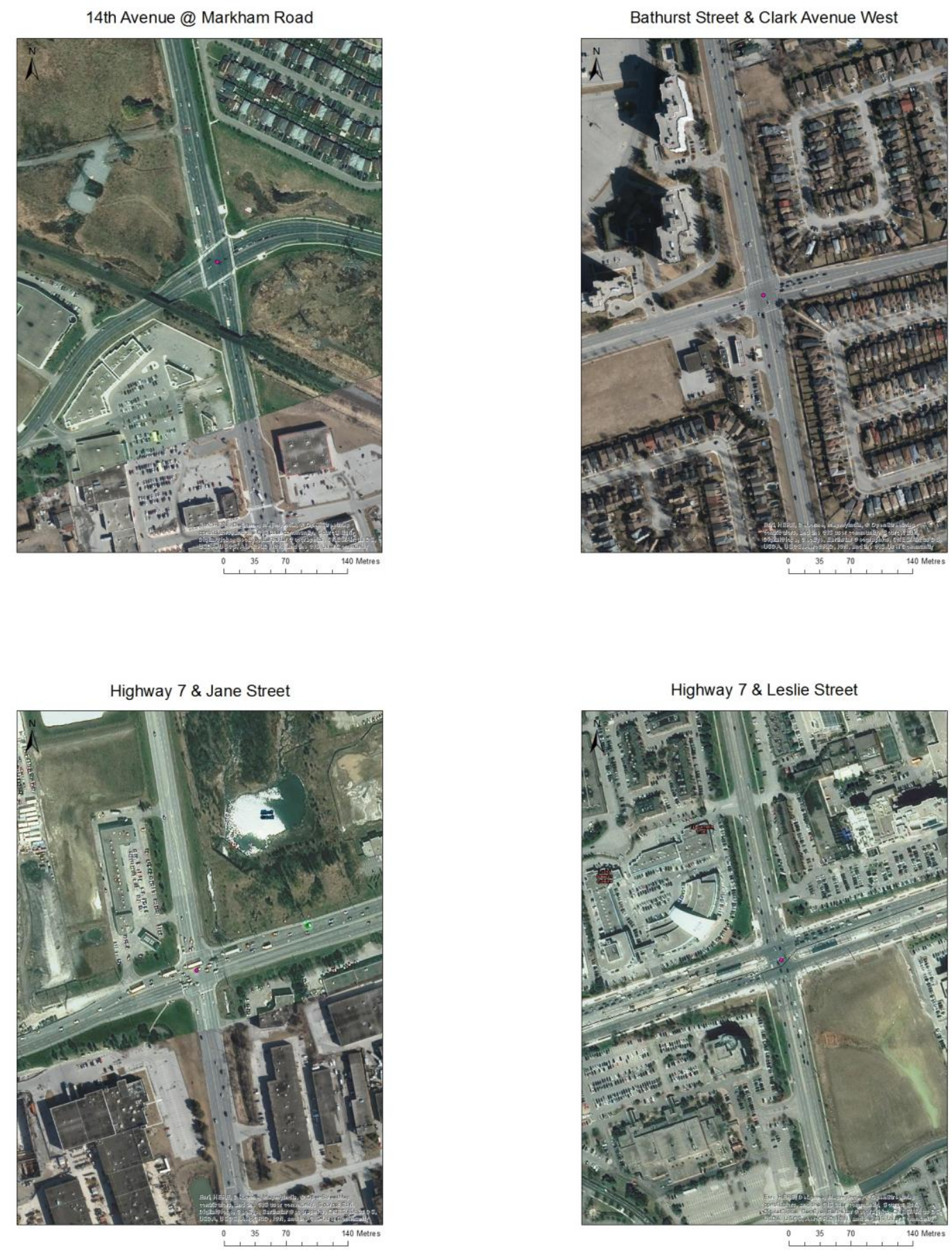

Figure 8 Remotely Sensed Images of Intersections 

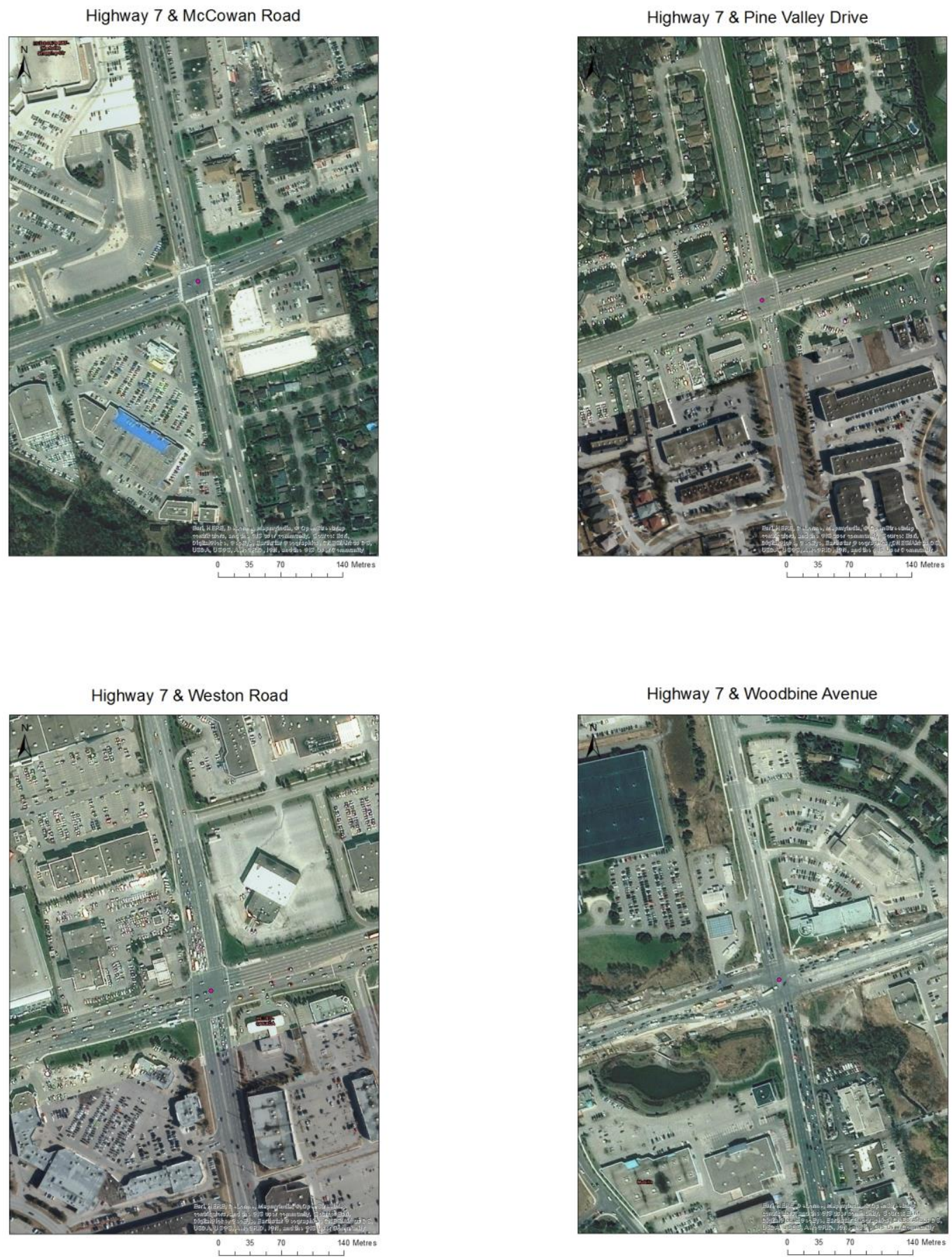

Figure 9 Remotely Sensed Images of Intersection Cont. 
Highway 7 - Yonge Street Ramp \& Highway 7

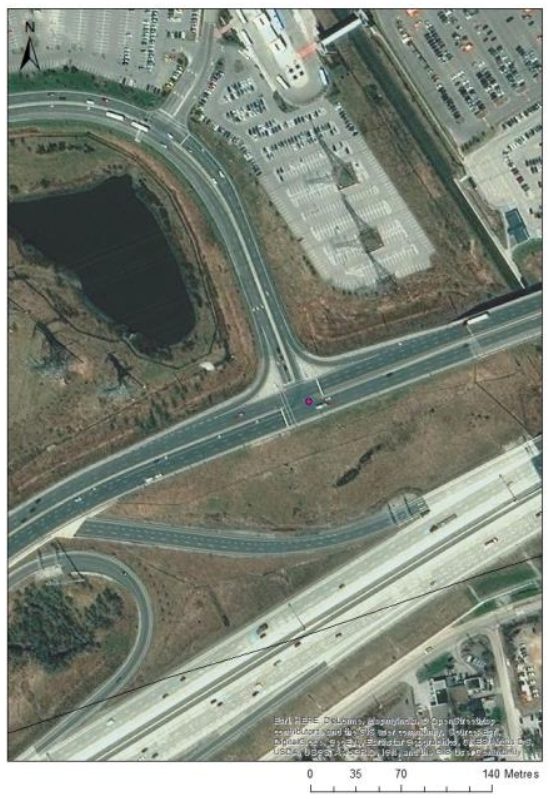

Islington Avenue \& Rutherford Road

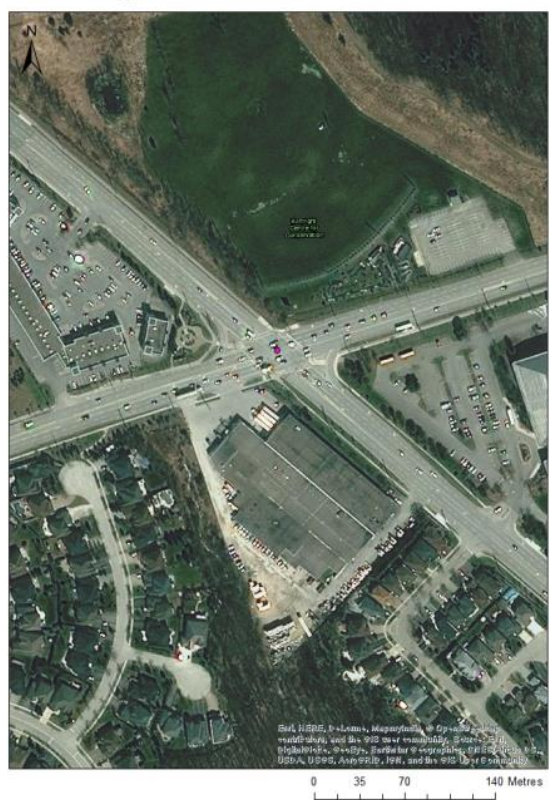

Highway 27 \& Rutherford Road
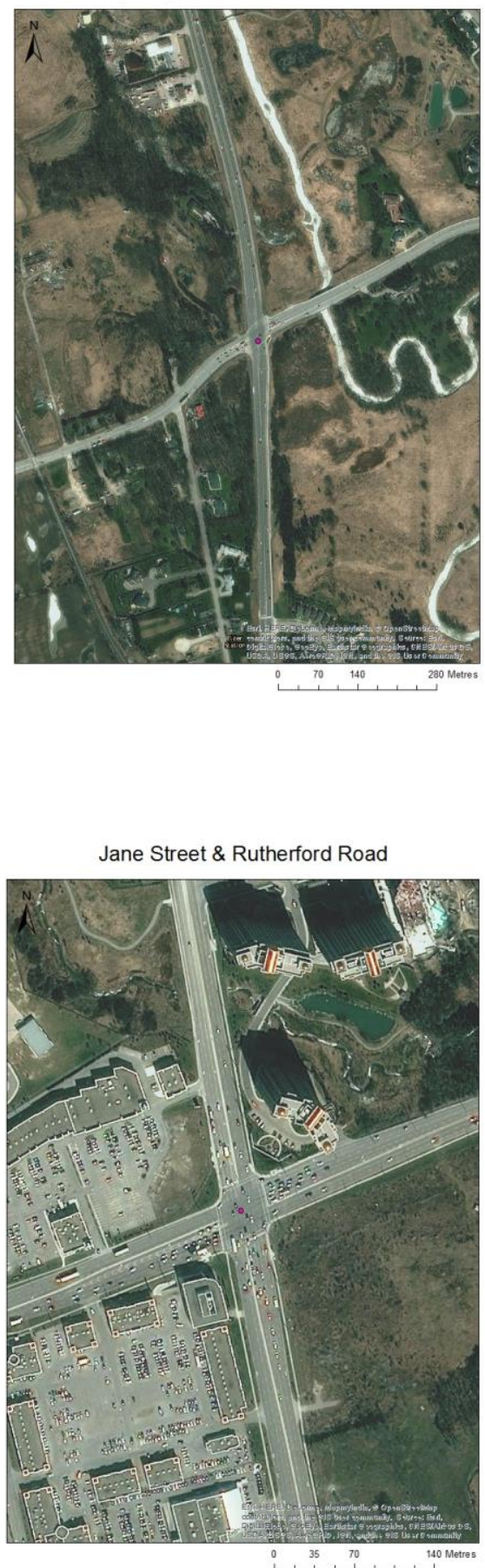

Figure 10 Remotely Sensed Images of Intersections Cont. 

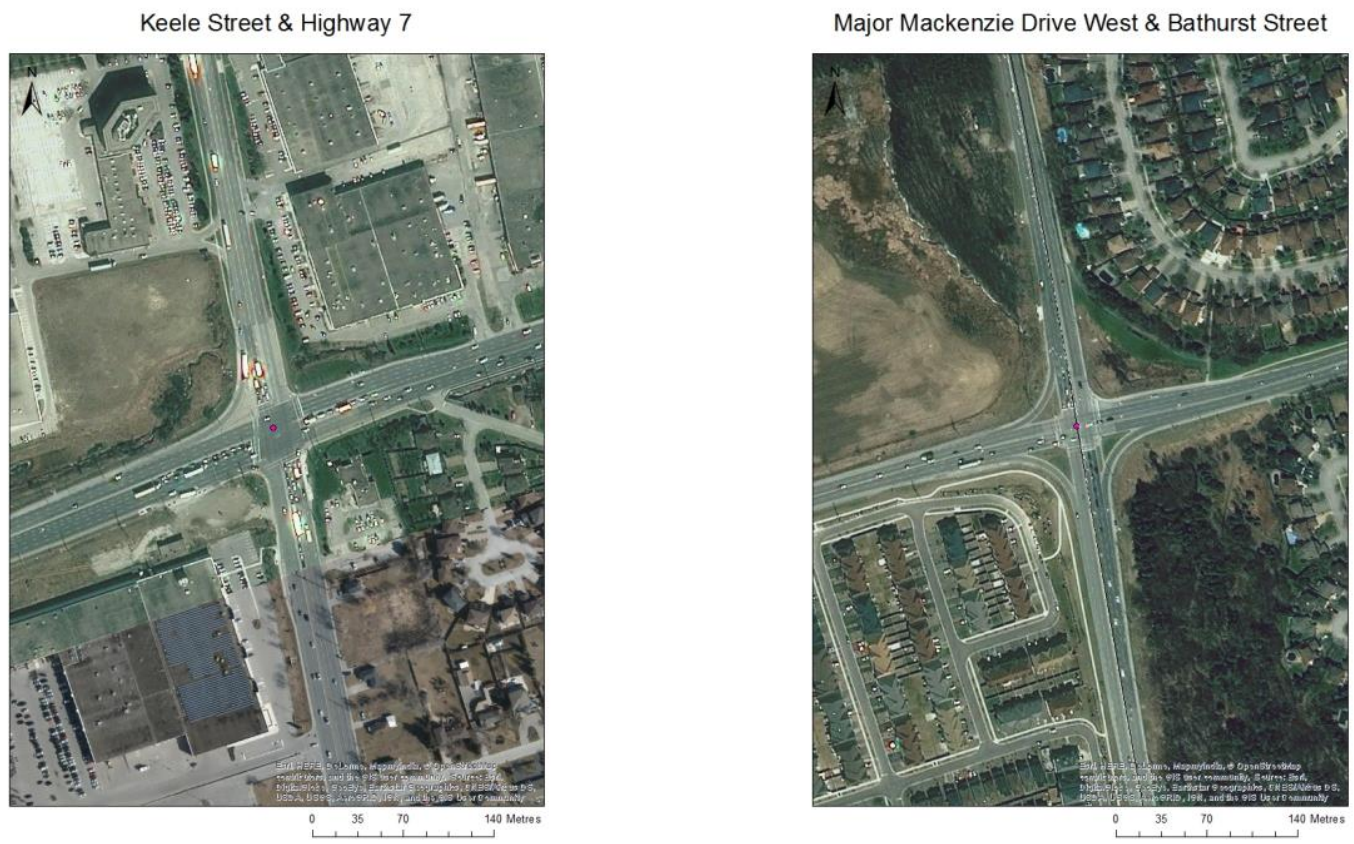

Major Mackenzie Drive East \& Bayview Avenue

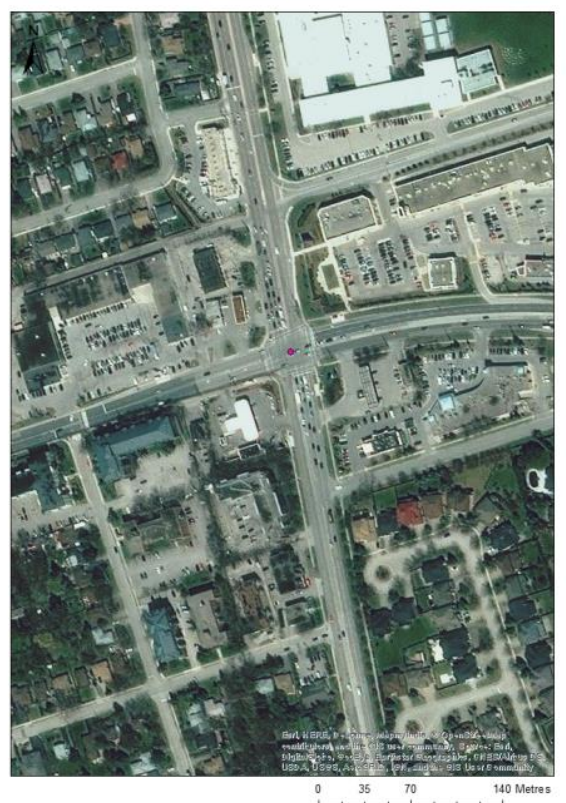

Major Mackenzie Drive West \& Exit 35/GO Carpool Lot Hwy 400 \& Major Mackenzie Drive West

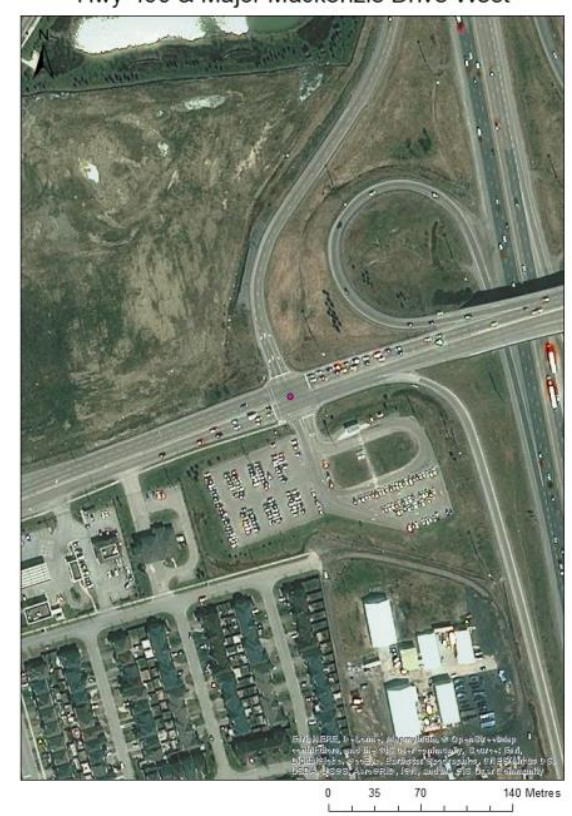

Figure 11 Remotely Sensed Images of Intersections Cont. 
Major Mackenzie Drive West \& Jane Street

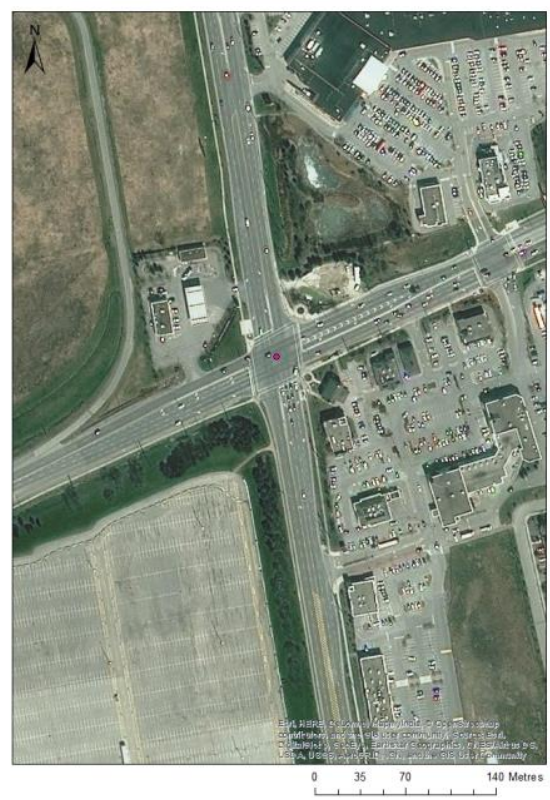

Yonge Street \& Carrville Road/16th Avenue

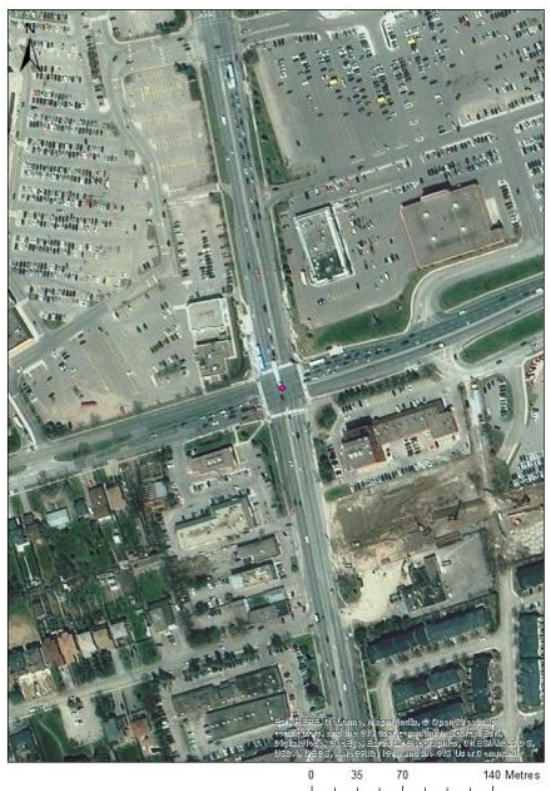

Weston Road \& Rutherford Road

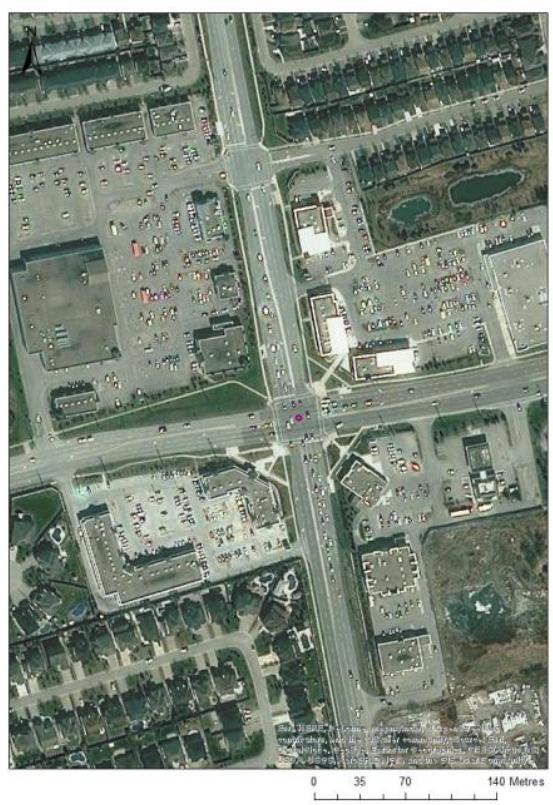

Yonge Street \& Elgin Mills Road West/Elgin Mills Road East

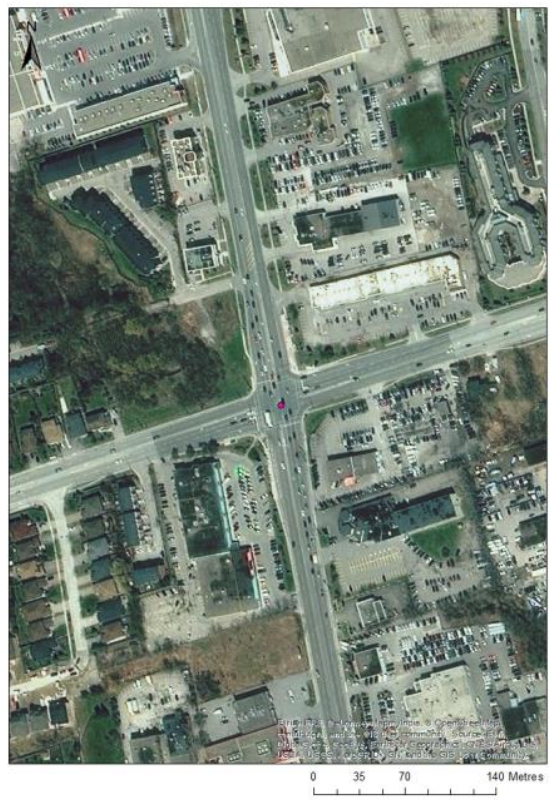

Figure 12 Remotely Sensed Images of Intersection Cont. 

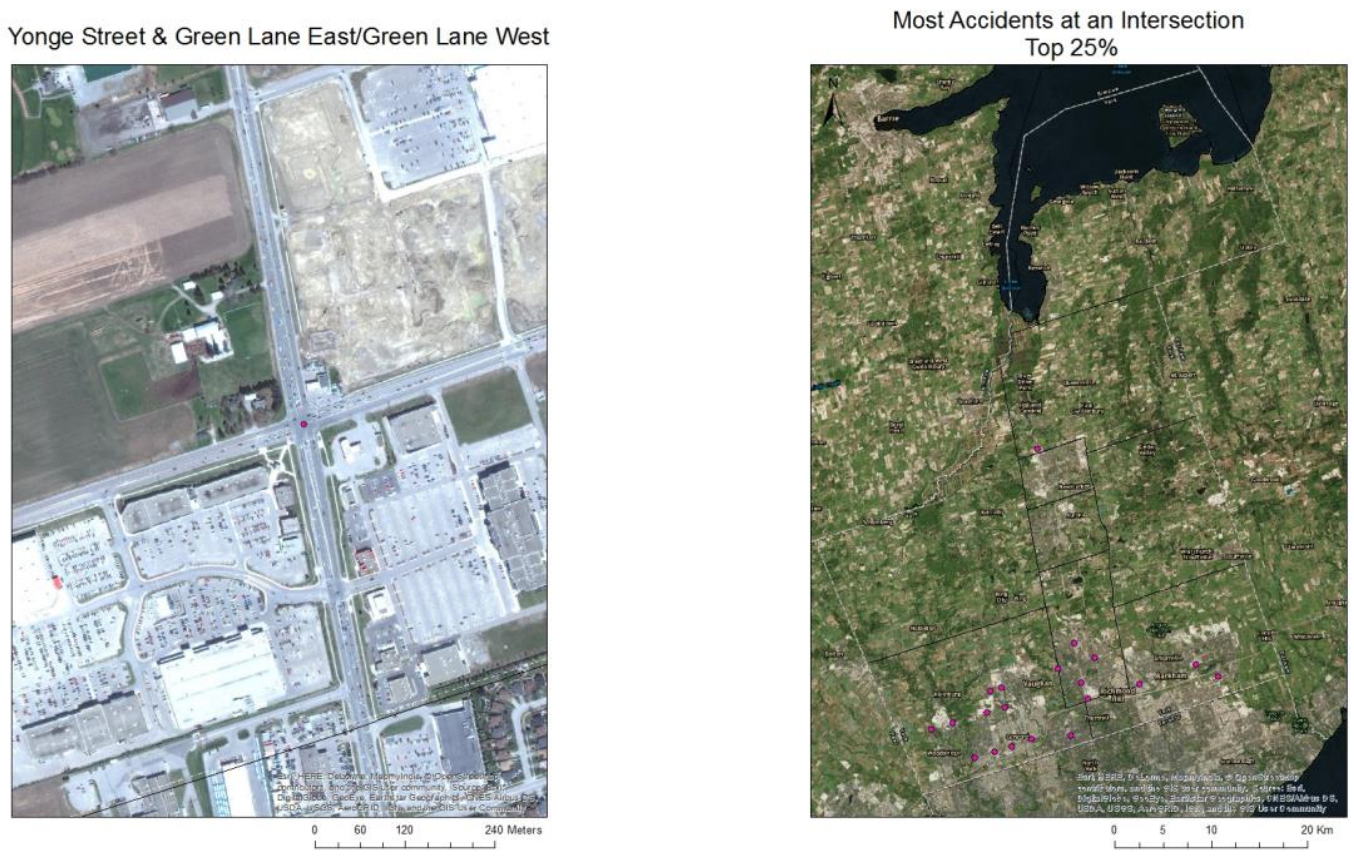

Figure 13 Remotely Sensed Images of Intersections Cont.

These remotely sensed images help to answers hypothesis about land use around intersections effecting accidents. From the images, it shows many of the intersections are near commercial land use, like shopping centres and plazas. Also, many of these intersections have seen periods of construction, whether it is the building of new shopping centres or adding bus lanes to the road.

\subsection{Statistical Analysis}

The linear regression used 353 Traffic zones within York Region on the counts collected on the different built environment factors. Three linear regressions were run: the first was for all traffic zones, the second was for rural traffic zones, and the third for urban traffic zones. This was done because there are different causes of accidents in rural and urban areas. When all traffic zones are included, there is an R squared value of 1.00 , which is a strong $\mathrm{R}$ squared. When looking at the correlations between all the features and the number of accidents, it was found that there is a significant positive moderate correlation between the number of 
accidents, and the number of traffic signals, and the number of bus stops. The $\mathrm{R}$ Squared values from this analysis were all very high; this could be due to the nature of the data. Using data from Statistics Canada for population and employment could drop the R Squared values.

Statistical analysis will be used to test the hypothesis that having built features near the intersection will affect the number of accidents, as well as which type of intersection correlates with accidents. When looking at all the traffic zones it can be seen that five features have a negative values Employment in 2011, Count of red light cameras, Count of shopping centres, Count of schools and count of signals. This means that for every increase in feature there is a decrease in accidents. Six of the features had a positive value, Population in 2011, Count of Bus Stops, Length of bike paths, Number of $\mathrm{T}$ intersections, and Number of Cross Intersections. The positive values shows that for every increase in count for the feature accidents will increase as well.

Table 10 Linear Regression all Traffic Zones

\begin{tabular}{lcc}
\hline \multicolumn{1}{c}{ Feature } & B value & Sig. (1-tailed) \\
\hline Sum of Accidents & - & - \\
\hline Employment in 2011 & -2.65 & .000 \\
\hline Population in 2011 & 4.94 & .000 \\
\hline Count of Bus Stops & .007 & .000 \\
\hline Count of Red Light Cameras & -.062 & .024 \\
\hline Count of Shopping Centres & & .000 \\
\hline Count of Schools & -.006 & .000 \\
\hline Count of Signals & & .000 \\
\hline Length of bike paths & -.047 & .000 \\
\hline Number of T intersections & -0.85 & .000 \\
\hline Number of Cross Intersections & 4.59 & .000 \\
\hline
\end{tabular}

When looking at rural traffic zones, there is a moderate correlation between the number of accidents and the number of traffic signals, as well as number of accidents and the number of red light cameras. In rural traffic zones features were seen to increase the number of accidents, Employment in 2011, Population in 2011, Count of Schools, Count of Red Light Camera, Length of bike paths, Number of $\mathrm{T}$ intersections and Number of Cross Intersections. These are the features that are 
seen to increase accidents. Three features were seen to decrease accidents, Count of Bus Stops, Count of Shopping centres, and count of singals.

Table 11 Linear Regression Rural Traffic Zones

\begin{tabular}{lll}
\hline Feature & B value & Sig. (1-tailed) \\
\hline Sum of Accidents & & - \\
Employment in $\mathbf{2 0 1 1}$ & .000 & .005 \\
\hline Population in 2011 & 3.73 & .221 \\
\hline Count of Bus Stops & -0.51 & .108 \\
Count of Red Light Cameras & .129 & .000 \\
\hline Count of Shopping Centres & -.386 & .023 \\
& & \\
Count of Schools & .358 & .178 \\
\hline Count of Signals & -.368 & .000 \\
\hline Length of bike paths & 3.315 & .000 \\
\hline Number of T intersections & 1.022 & .000 \\
Number of Cross Intersections & 1.006 & .000 \\
\hline
\end{tabular}

When looking at urban traffic zones, there is a moderate correlation between number of accidents and the number of traffic signals, as well as number of accidents and the number of red light cameras. In urban traffic zones the features that increased accidents were; Population in 2011, Count of Bus Stops, Count of Shopping centres, Length of bike paths, Number of T intersections and Number of Cross Intersections. The features that were seen to decrease accidents, Employment in 2011, Count of Schools, Count of Red Light Camera , and count of signals. 
Table 12 Linear Regression Urban Traffic Zones

\begin{tabular}{lll}
\hline Feature & B value & Sig. (1-tailed) \\
\hline Sum of Accidents & .453 & - \\
Employment in 2011 & -2.70 & .000 \\
\hline Population in 2011 & 6.88 & .000 \\
Count of Bus Stops & .008 & .000 \\
Count of Red Light Cameras & -.272 & .023 \\
Count of Shopping Centres & .019 & .000 \\
Count of Schools & & \\
Count of Signals & -.084 & .000 \\
Length of bike paths & -.080 & .000 \\
\hline Number of T intersections & 1.87 & .001 \\
\hline Number of Cross Intersections & 1.002 & .000 \\
\hline
\end{tabular}

From this analysis, employment, population, bus stops, red light cameras, shopping centres, schools, signals and bike path can affect the number of accidents in rural and urban traffic zones. This means that there needs to be two different plans to reduce the number of accidents.

Using the 353 Traffic Zones, 5 clusters were created using six variables. The five clusters had distinct characteristics that may help to find features that are contributing to traffic accidents. For employment and population, a scale from low to very high is used to describe the raw numbers.

Table 13 Cluster information

\begin{tabular}{|c|c|c|c|c|c|c|c|}
\hline Cluster Number & $\begin{array}{l}\text { Number } \\
\text { of Zones }\end{array}$ & Employment & Population & $\begin{array}{c}\text { Urban or } \\
\text { Rural }\end{array}$ & $\begin{array}{c}\text { Average } \\
\text { Number } \\
\text { Bus Stops } \\
\end{array}$ & $\begin{array}{l}\text { Number Red } \\
\text { light camera }\end{array}$ & $\begin{array}{c}\text { Average } \\
\text { accident Per } \\
\text { Zone } \\
\end{array}$ \\
\hline Urban employment & 32 & High & Low & Urban & 15 & 3 & 35.38 \\
\hline $\begin{array}{l}\text { Urban high density } \\
\text { employment }\end{array}$ & 8 & Very High & Low & Urban & 32 & 0 & 33.13 \\
\hline Urban living & 100 & Moderate & High & Urban & 23 & 0 & 122.7 \\
\hline
\end{tabular}

From this analysis, it will help determine which clusters have the most accidents within each type, and which traffic zone will need more attention to help reduce the number of collisions. 


\section{Traffic Zone Clusters}

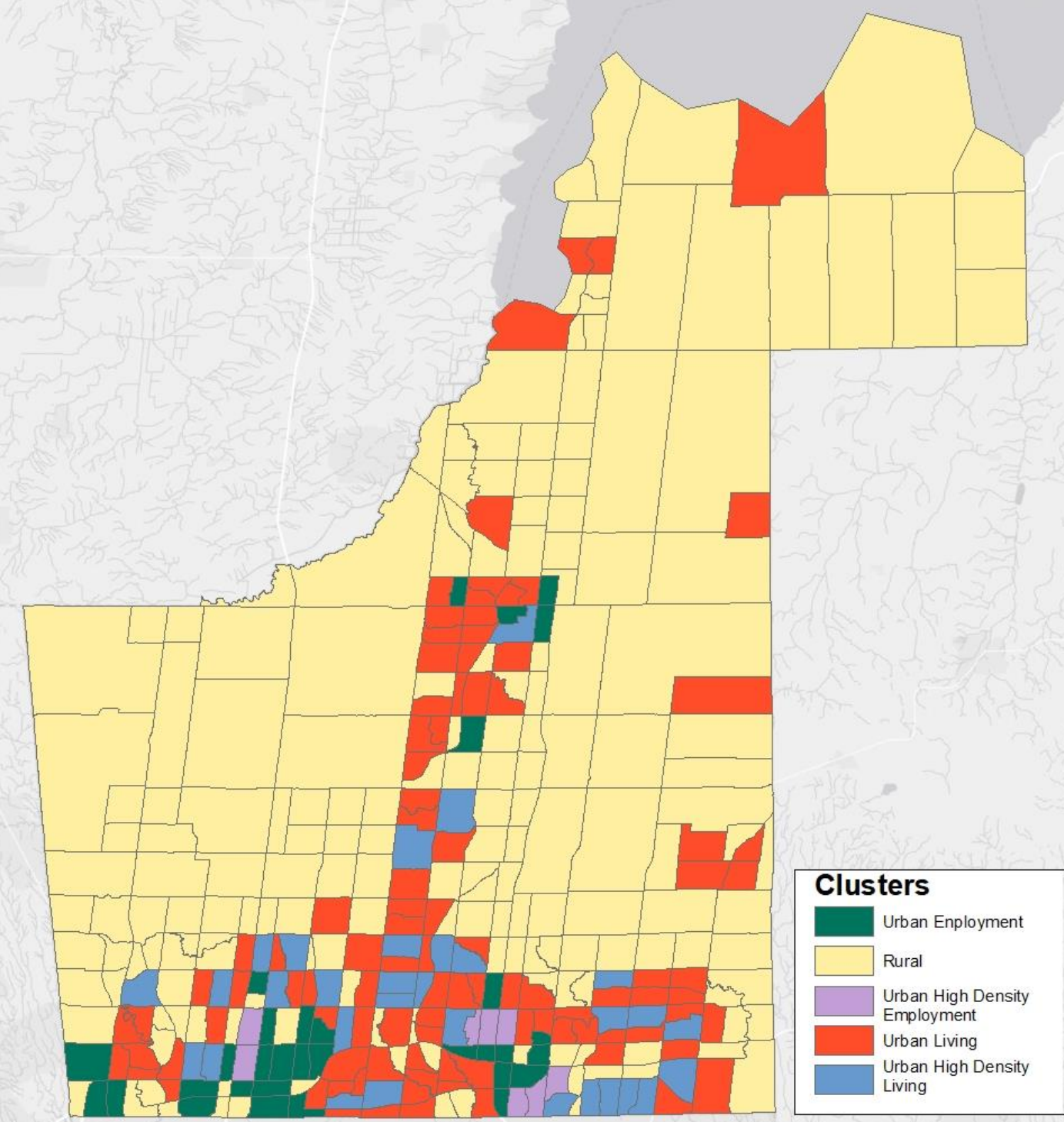

Figure 14 Map of Clusters 
Logistic regression was performed on the intersections based on if the accident involved only motor vehicles, pedestrians or cyclist. Six variables were used. Logistic regression was included in the analysis because it was a binary input. It is useful for this analysis because at each individual intersection the existence of a feature could be yes or no ( 1 or 0 ). For example, if the intersection was near a school it was given the value of one; if there was no school, the value is a zero. However, after the logistic regression was run, no noteworthy results were found. This could be because the number of accidents is too small. It could also be that they were not significant factors within logistic regression. Table 1 in the appendix $C$ shows the output for the logistic regression. 


\section{Case Studies}

From the analysis completed three intersections were identified for case studies to help further understand how the built environment can affect the number of accidents. The first intersection that was identified as a case study was Highway 7 and Weston Road. It was chosen because it has had continuously high accident counts during the study period. The second intersection is Major Mackenzie Drive and Exit 35/ Go Carpool Lot, this intersection was selected after it saw a high increase in accidents. The final intersection, Highway 7 And Leslie Street, was selected as it has seen a decrease in the number of accidents.

\subsection{Highway 7 and Weston Road}

Highway 7 and Weston Road is located within the City of Vaughan specifically in Woodbridge, in close proximity to 400 Highway. Over the six-year study period this intersection has been the highest ranked intersection for accident count 3 times, in 2010, 2012, and 2013. Over the six-year duration it has seen and average of 68 accidents a year, with a total number of accidents of 412 accidents. Highway 7 and Weston Road is the number 1 ranked intersection for total accidents; it has seen 71 more accidents over the six-year period than the intersection rank in second.

The intersection is a cross intersection with a slight angle, there are three lanes going east- west and north south. There are also two additional turning lanes one for left hand turns and one for right hand turns. The intersection is controlled by a stop light and there are left turn signals for all directions of travel. At the intersection, there are bus stops at all four corners and all the stops are between 20 and 40 meters away from the intersection.

When looking into the land use around the intersection is mainly commercial on the north-west corner of the intersection there is a SmartCentres, the other three corners have plazas located on them. This intersection is only a block away from the 
400 Highway. The land use surrounding this intersection is mainly commercial, that including a SmartCentre Colossus Power Centre, and two gas stations. Furthermore, there is currently construction of a condominium on the northeast corner of the intersection.

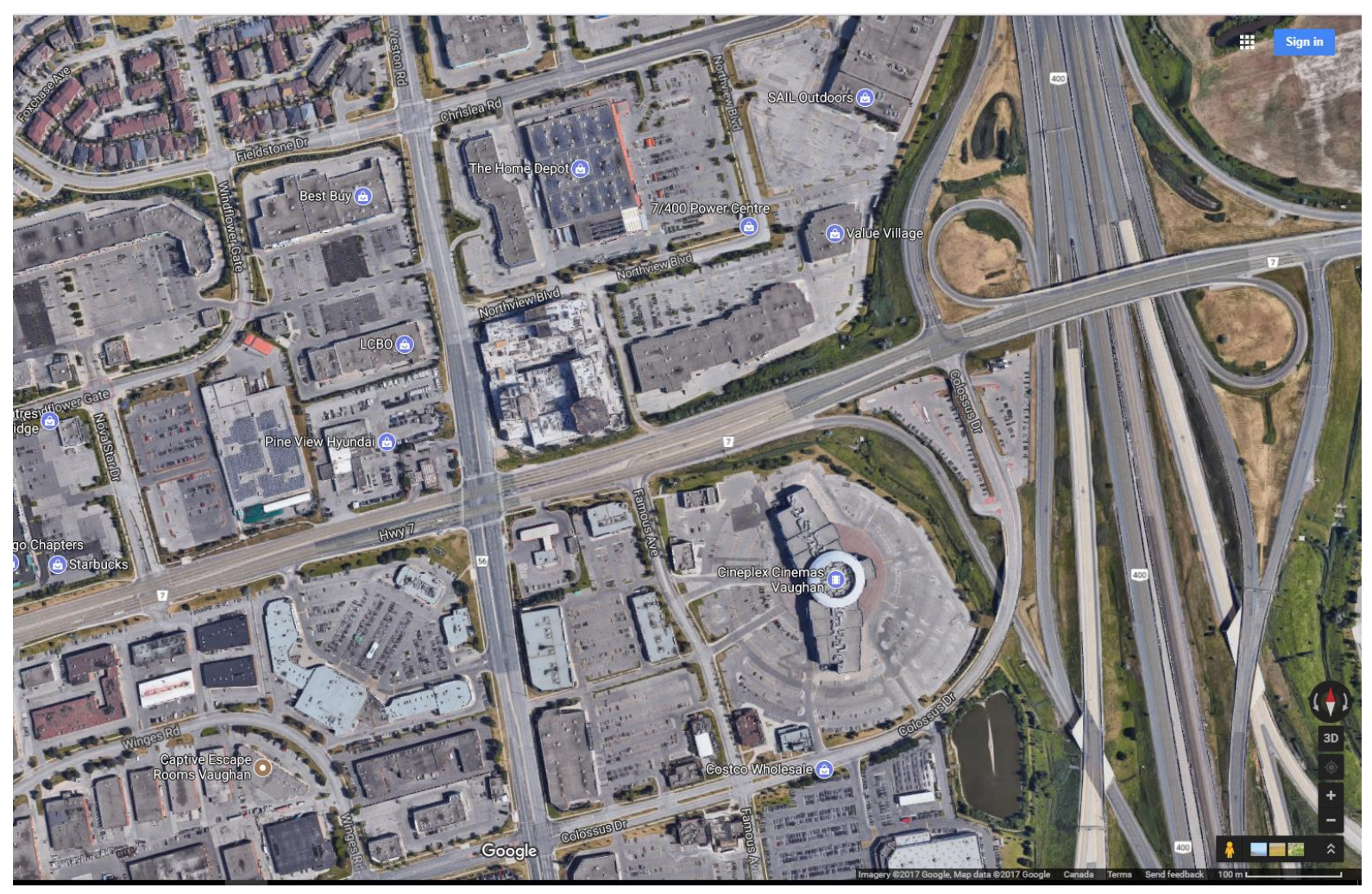

Figure 15 Highway 7 \& Weston Road (taken from Google Maps)

Over the 6-year period this intersection saw one fatal accident in 2011, and 77 non-fatal injuries. Most of the accidents were property damage only (Appendix D Table 1). The most common initial impact type at the intersection is rear end. When considering all the accidents that were rear ending it was found that the highest percentage of rear ends occurred when the driver is driving east (Table 14).

Table 14 Direction of rear end

\begin{tabular}{|l|r|r|r|r|r|r|r|r|r|} 
& 2010 & 2011 & 2012 & 2013 & 2014 & 2015 & Total & Percent of all rear ends \\
\hline North & 6 & 2 & 13 & 6 & 4 & 7 & 38 & 18.4 \\
\hline South & 7 & 11 & 5 & 4 & 3 & 6 & 36 & 17.4 \\
\hline East & 25 & 8 & 16 & 8 & 12 & 7 & 76 & 36.7 \\
\hline West & 14 & 12 & 11 & 11 & 8 & 1 & 57 & 27.5 \\
\hline TOTAL & 52 & 33 & 45 & 29 & 27 & $\mathbf{2 1}$ & 207 & -- \\
\hline
\end{tabular}


When looking at the intersection there does not appear to be any features like trees, billboards or buildings that are blocking the stop light that would cause a rear end collision. However, these east bound lanes are heading towards the 400 Highway. During rush hour this will increase the volume of traffic at this intersection. This means that there could be a long lane of stopped traffic as well as tractor trailer trucks heading toward the highway that could block the light signal. Of the 76 east bound rear end accidents, 42 occurred during the evening rush hours from 3:01pm to $7 \mathrm{pm}$. During this time of the day the traffic is expected to be at it's heaviest.

Highway 7 and Weston Road is a high traffic area with many commuters looking to merge onto the 400 Highway at the next on ramp. During the evening rush hour, many of the commuters are traveling east bound to the 400 Highway, due to this fact there are a high number of rear end that occur. The large volume of traffic and only one ramp onto the 400 north and south can cause congestion and start and stop traffic. From Golob and Recker's article it was shown that rear end collisions are normally associated with stop and go traffic (Golob \& Recker, 2003).

\subsection{Major Mackenzie Drive West \& Exit 35 GO Carpool Lot}

Major Mackenzie Drive West and Exit 35 GO Carpool Lot at Highway 400 is in Woodbridge, in the City of Vaughan. When looking over the study period this intersection has seen the largest increase in number of accidents (Appendix A Table 3). In 2010 there were 5 accidents while in 2015 there were 59, in this year the intersection was ranked number one. In 2013, it was seen that the number of accidents started to grow, as seen in Appendix D table 3.

The intersection is a cross intersection, where the south side lanes are not through streets they are the entrance and exit of the GO Carpool Lot and where the 66 GO Bus has a stop. The North side lanes are also not through streets as they are three lanes that have exited from the 400 Highway. There are two lanes going EastWest and a right turn lane into the GO Carpool Lot. The intersection is controlled by 
a stop light and there are left turn signals for South bound traffic from the 400 and north bound out of the Carpool Lot.

The land use around the intersection is commercial land use with residential suburbs outside the commercial area. There is a SmartCentre at the next intersection to the West. At the North-West side, there is construction on a new retail centre. The GO Carpool Lot take up the south east and west sides of the intersection. There is a fire station just west of the carpool lot. The 400 highway is just east of the intersection, and the exit for the highway comes out southbound into the intersection.

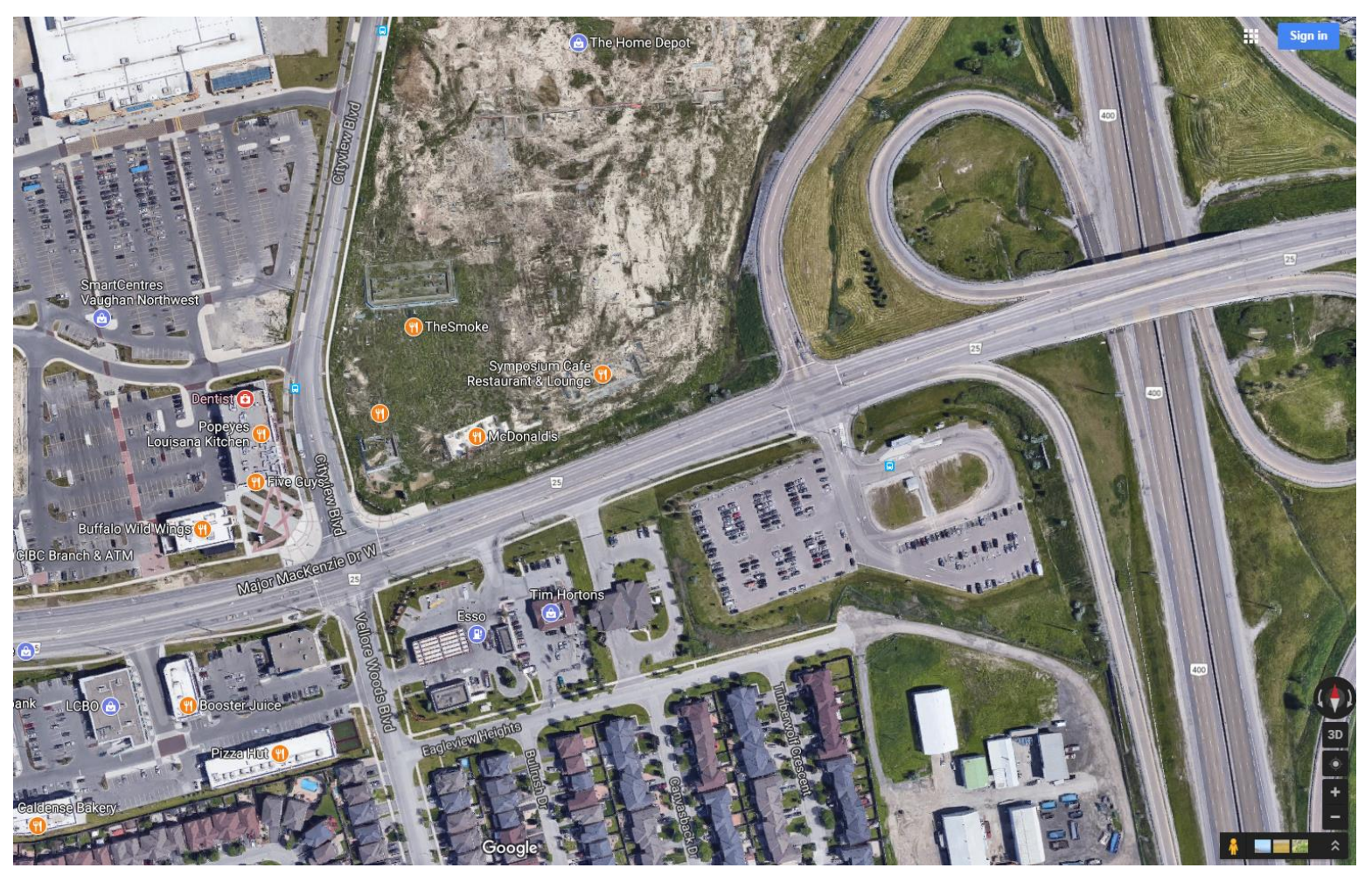

Figure 16 Major Mackenzie Drive West and Exit 35 GO Carpool Lot (taken from Google Maps)

During the study period, there were no fatal accidents at the intersection, there were 56 injuries and 140 Property damage only accidents (Appendix D Table 3). The most common type of impact is rear ending which accounts for $67 \%$ of all accidents at the intersection. Within the initial impact type of rear ending half of the accidents occurred in the West direction (Table 15). This direction is heading towards the 400 Highway, and has similar issues that Highway 7 and Weston face. The high volume of traffic and generally low speed are the idle conditions to cause rear end 
collisions (Golob \& Recker, 2003). Another area to note is the increase in rear end collisions in 2013, this is the direction heading out of the GO carpool lot.

Table 15 Direction of rear end

\begin{tabular}{|l|r|r|r|r|r|r|r|r|r|} 
& 2010 & 2011 & 2012 & 2013 & 2014 & 2015 & Total & Percent of all rear ends \\
\hline North & 0 & 0 & 0 & 14 & 4 & 5 & 23 & 17.4 \\
\hline South & 0 & 1 & 0 & 1 & 5 & 6 & 13 & 9.8 \\
\hline East & 1 & 1 & 2 & 9 & 9 & 6 & 28 & 21.2 \\
\hline West & 2 & 3 & 4 & 25 & 19 & 15 & 68 & 51.5 \\
\hline TOTAL & 3 & 5 & 6 & 49 & 37 & 32 & 132 & -- \\
\hline
\end{tabular}

When looking at the West bound lanes of traffic, there are no apparent obstructions to the signal that could increase the number of rear end collisions. East of the intersection is the off ramp for the North bound 400 Highway. Due to this fact as well as the shopping centre to the West there will be an increase in vehicles at the intersection which could lead to stop and go traffic. This type of traffic has the potential to increase the number of rear end collisions. Another factor to consider is the position of the sun, it sets in the West and this can impair a driver's sight and cause a collision, 11 of the 28 collisions occurred during hours in which the sun would start to set. Creating a stop lights and signage that are more visible in the sun's glare could help to reduce accidents.

In 2013, the number of accidents at this intersection saw a significant increase (Table 16). The GO Carpool Lot is a stop on the 66 Newmarket/ North York Express Bus route. During the week, there are 21 buses going north bound and 20 buses going south bound in a day, the buses do not run on the weekend (GO Transit, 2017). The increase in accident could be caused by the increase in GO transit buses, and the number of vehicles parking in the lot. Turning movements has seen a steady increase since 2013. With the volume of vehicles going in and out of the GO Carpool Lot they all are required to turn. Creating new lighting timing or restricting right hand turns to green light only could help to decrease the number of accidents. TO help reduce the number of turning movement collisions adding bus lanes, or wider lanes could help accommodate the wide turning motion of the buses. 
Table 16 North bound traffic and Initial impact type

\begin{tabular}{l|r|r|r|r|r|r|r|} 
& 2010 & 2011 & 2012 & 2013 & 2014 & 2015 & Total \\
\hline Rear End & 0 & 0 & 0 & 14 & 4 & 5 & 23 \\
\hline Turning Movement & 0 & 0 & 0 & 1 & 2 & 7 & 10 \\
\hline
\end{tabular}

\subsection{Highway 7 \& Leslie Street}

Highway 7 and Leslie Street is in the Town of Richmond Hill. The intersection is a cross intersection that is controlled by a traffic signal. There are three lanes of traffic going East and West on Highway 7 and two lanes going North-South on Leslie Street. On Highway 7 there are two bus only lanes that are in the middle of the road way one lane heads East and the other West. The bus only lanes were constructed in 2012 and were finished in 2013. The bus stops along Highway 7 have been moved into the middle of the road ways on either side of the bus only lanes. On Leslie Street, there is a bus stop on the North and South corners both are within $5 \mathrm{~m}$ of the intersection.

The land use surrounding the intersection is commercial there are many shopping plazas, restaurants and a movie theater. The 404 and the 407 are both a short distance away from the intersection. The 407 is a tolled highway that runs a very similar route to that of Highway 7.

This intersection has had one fatal accident in 2012, 50 injury accidents and 223 property damage only accidents from 2010 to 2015 . Over half ( 140 accidents) of all accidents that occurred were rear end (Appendix D table 6), and 65 of those accidents occur while the driver was heading East bound. 


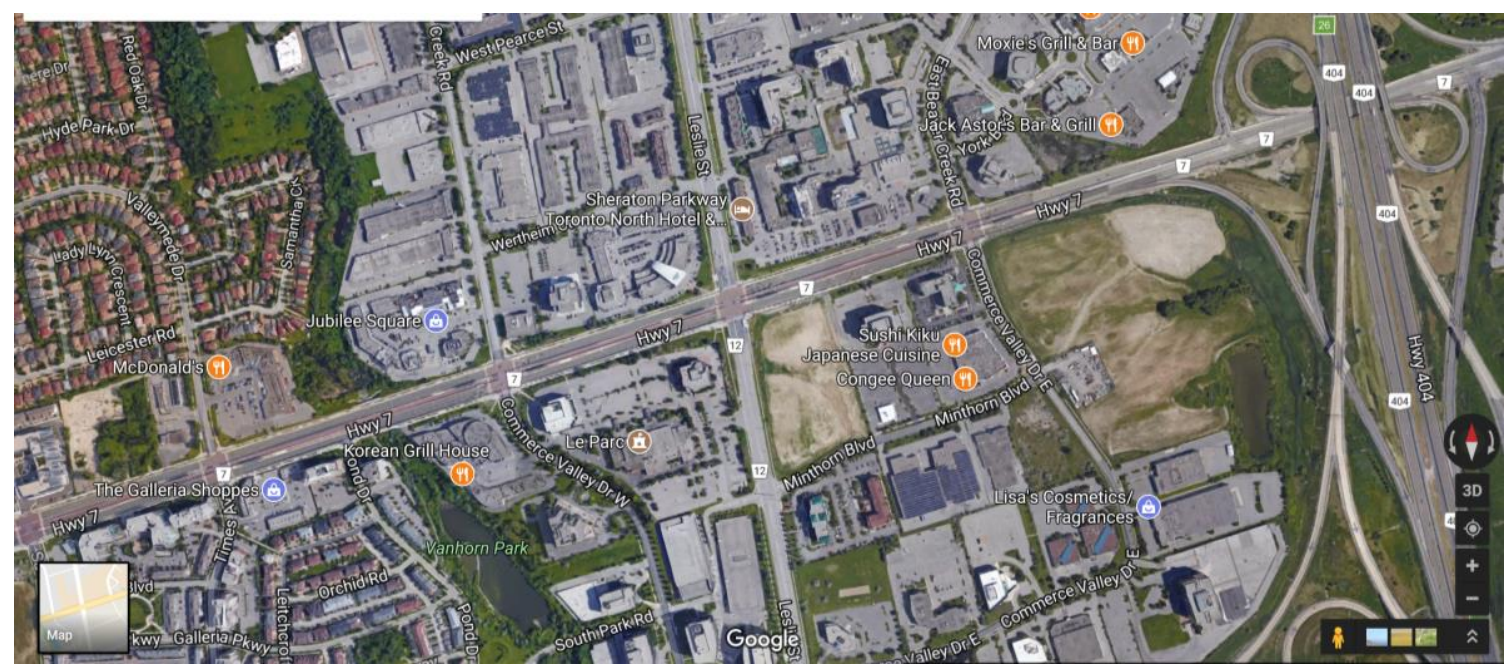

Figure 17 Highway 7 and Leslie Street (taken from Google Maps)

The number of accidents has been decreasing since 2013, they have decreased in three impact types; angle, rear end, and sideswipe. Approaching, and turning movement have stayed consistent at 1 accident for approaching and between 2 and 5 for turning movement (Appendix D Table 7). The decrease in accidents coincides with the creation of the bus only lanes. Since the lanes have been introduced there has been a $18 \%$ decrease in injury accidents and a $51 \%$ decrease in property damage from 2013 to 2014. Another factor that could be the 407-toll highway, the highway runs a very similar route; this could help to share the volume of traffic. Sharing the congestion between two highways can help to prevent stop and go traffic, which will reduce rear end collisions. 


\section{Discussion}

There are many factors that can contribute to causing an accident. Weather conditions can be influential in accidents and make even the safest road dangerous when there are harsh weather conditions occurring. From this it can skew data to show no correlation between built features and accidents or incorrect correlations. However, in this study, 80.4\% of accidents happened in clear weather conditions. This means that the correlations with the built environment are not being highly skewed because of weather conditions.

Days and time are another factor that can affect the number of accidents because there are certain times when there are more cars on the road. During weekdays, most accidents occur around the times when people are going to, and leaving from work. On weekends, more accidents can be seen around midafternoon.

Traffic signal is the most commonly used traffic control. Because of this, more accidents may occur at traffic signals because there are more intersections with them. To help understand if the high counts are also proportionally high, percentages were used. There is also the factor of urban and rural areas, when looking at the data, it was found that several factors caused accidents in these two land types. To understand how the features factor in rural and urban traffic zones, linear regression was used to separate the two types of zones.

To test the first hypothesis that states: the closer schools and shopping centres are to an intersection, the more likely there will be an accident, crosstabs and linear regression were used. From the Linear regression, it shows that all the factors in the study except Populations in 2011 positively associated with high number of accidents. This means that as the number of these features goes up, so do accident counts. This shows that the built environment is influencing the increase in 
number of accidents. Using the crosstabs, it shows that certain features are more associated with more accidents than other features.

It was also found that several factors affected rural and urban traffic zones similarly. Traffic zones in rural areas are moderately correlated with the number of traffic signals. The number of traffic signals is correlated with traffic accidents, with a B-value of -0.368 and a significance value of .000 . This shows that having a signal will slightly decrease the chance of an accident occurring. Traffic signals in the urban zones, had a B-Value of -0.8 and a significance value of .000 . This is similar to rural traffic zones, however, in urban areas there is not as high decreasing unit as that in rural areas.

Another area where rural and urban area collisions acted similarly is with high population numbers. As population increases so do the number of accidents. It was significant at the $95 \%$ rate in rural zones and had a .000 significance in urban (Table 11 and 12). Rural zones had an increase of 3.73 accidents for every unit of population increase, while urban areas saw a 6.88 increase (Table 11 and 12).

When looking at the second hypothesis, features were spilt between urban and rural traffic zones. A few features affect accidents differently in each type of zone. In the urban zones, red light cameras had a B-value of -0.272 at a 0.02 significance level. From this it is seen that there is not a significant correlation between the two. In rural traffic zones, red light cameras have a B-value of 0.129, which shows that for every red-light camera, there is a .129 increase in traffic accidents. When it comes to red light camera it appears that they are more effective in urban areas. Employment numbers in 2011 effect rural and urban zones differently as well. In rural zones employment counts did not increase or decrease the number of collisions (Table 11). However, in urban traffic zones higher employment was seen to reduce accidents (Table 12). 
Some features like shopping centre in rural traffic zones and schools in urban traffic zones were seen to reduce the number of accidents. However, they were not at a significant level (Table 11 and 12).

When looking at traffic controls' effect on accidents, crosstabs and linear regression were used to evaluate each traffic control type. When using the crosstabs, it showed that traffic signals had the most accidents with 28,605 accidents, second was no control with 6,125 accidents, third was stop sign with 2,480 and traffic controller (people who are trained to direct traffic) with 1,419. There were seven other traffic controls, however, the accident counts were under 60 accidents. When looking at Traffic signals, of the 28,605 accidents, $74.4 \%$ were property damage only. The same can be seen at intersections with no control or with stop signs: property damage accounts for $74.7 \%$ of no control accidents and $72.9 \%$ of stop sign accidents. Similar patterns can be seen in injury and fatal accidents. Property damage is the most common type of accident that occurs, and they occur at about the same percentage through out all the traffic controls.

When looking over the six-year period, some traffic controls have seen a decrease in accidents. All the traffic controls have seen a decrease or is the same except no control. No control has seen an increase in accidents over the past six years. In 2010, No control had 485, at the end of 2015 it had seen a $2.5 \%$ increase in the number of accidents. Traffic signal has stronger correlation and decreases accidents more in rural traffic zones than in urban traffic zones. Traffic signals are the most common type of signal, this could increase the correlation between them and accidents.

The third hypothesis for road networks is that the more conflict points an intersection has will lead to more accidents. Cross intersection can be seen to increase the number of accidents. When looking at the cross tabs (appendix B table $1,2,3$ ) it was seen that cross intersection holds the highest number of fatal, injury and property damage accidents. Cross intersection also has the most accidents at all 
the different types of traffic controls. There is one traffic control type where the numbers are close between the intersection types, which is stop sign: cross intersections account for $53.5 \%$ of accidents and $\mathrm{T}$ intersections account for $45.1 \%$ of accidents.

Over the past six years, injury accidents have been increasing in both cross and $\mathrm{T}$ intersections. When adding traffic controls to the previous two variables, injury accidents increased at both traffic signals and No control. Stop signs have held a consistent number of accidents over the six years. In both rural and urban traffic zones, cross intersection was highly correlated with the number of accidents when the linear regression was run. It has a Pearson correlation value of .974, which is very strong. When looking at this and the Significance value and B values, it shows that this correlation is at a significant level and that for every unit of increase in Cross Intersection, accidents will increase one accidents as well. From the literature review we can say that this is caused by the number of conflict points that appear in a cross intersection. A cross intersection has the most conflict points, giving more opportunity for accidents. This same pattern can be seen in both Urban and Rural traffic zones. In Urban traffic zones, there is a correlation of .970 and a B values of 1 , while rural zones have a correlation of .967 and a B value of 1.006 .

Using cluster analysis, the final hypothesis that the traffic zones in the clusters with high employment and in urban areas will have more accidents than other clusters. From the five clusters, the accidents tend to be around the high employment clusters. The clusters show that areas where there are more people living and working are the places were more accidents occur. It also follows where bus stops are; these are the areas where roads with more lane and more traffic. When looking at the clusters, some clusters have more accidents in fewer clusters in comparison to clusters with more zones. There are two clusters where this is seen, Cluster 4 and Cluster 5 . Cluster 5 has the second lowest number of traffic zones; however, this cluster on average has the most accidents per zone. Cluster 4 is similar, as it has 100 zones and an average of 122.7 accidents. This is more than double of the average number of accidents of Cluster 2, which has the most zones 
(182), while having an average of 48.73 accidents per zone. Clusters 4 and 5 are urban clusters with the two highest population numbers; they do not have the highest employment numbers. This coincides with the findings in the linear regression. Population was seen to increase the number of accidents while employment was seen to decrease them. These traffic zones are also smaller in area, which shows that more accidents are occurring in the smaller zones.

Table 16 shows the four hypotheses, and the outcome of whether they were supported or rejected. The First hypothesis was supported it was found that built environment features can affect the number of accidents at an intersection. The second hypothesis was partially supported. It showed that traffic controls can affect accidents differently, however, it was not determined if that was because of the signal or that some traffic control types are more common than others. The third hypothesis was also partially supported for the same reason as the second. It showed that intersections with more collisions points can increase accidents however, it was not determined if that was because of the point or that cross intersections were more common. Creating rates for the second and third hypothesis would be beneficial in future research. Finally the fourth hypothesis was supported as the cluster analysis showed that urban traffic zones did have more accidents than rural zones. 
Hypothesis

Outcome

\begin{tabular}{|c|c|}
\hline $\begin{array}{l}\text { Built environment that is the } \\
\text { closer an intersection or to a } \\
\text { point of interest (such as } \\
\text { Shopping centres, bus stops and } \\
\text { schools) the more likely there } \\
\text { will be an accident }\end{array}$ & Supported \\
\hline $\begin{array}{l}\text { The effect of different types } \\
\text { of traffic controls on the } \\
\text { number of accidents }\end{array}$ & Partially \\
\hline $\begin{array}{l}\text { That intersections with more } \\
\text { collision points will have more } \\
\text { accidents }\end{array}$ & Partially \\
\hline $\begin{array}{l}\text { Traffic zones that are } \\
\text { considered urban would have } \\
\text { more accidents }\end{array}$ & Supported \\
\hline
\end{tabular}

From the quantitative analysis, it showed accidents that end in injuries, had a common factor in their close proximity to shopping centres or retail land use. Eleven of the 22 highest number accident intersections were near shopping plazas, two were near shopping centres, four had both shopping centre and plazas, and one near a box store. Out of all the top intersections, only three were not near any type of commercial stores. From this, it can be inferred that shopping centres bring large numbers of people and vehicles, which lead to more opportunities for accidents and injuries. When looking at the land uses surrounding the intersections with considerable amounts of accidents, commercial land use was the most common type. Commercial areas have more car and pedestrian traffic, which can increase the chances of an accident.

Another common theme was that many of them are in development of the areas. From the qualitative analysis, it was seen that almost half of the intersections had construction and or developments added near the intersection between 2010 and 2015. This construction can be small like the addition of a middle divide or a large project to build a new shopping centre. Of the 22 intersections with the most 
injury accidents, all but four were in the top 30 intersections (Appendix A Table 3) based on count. From the maps of the intersections, we can see that most of the intersections are surround by built up land very close to retail stores.

When using the remotely sensed images from Figure 8 it showed that there is also a residential component that surrounds the retail land use. Many of the intersections that are currently in the top 25 percent of number of accidents have seen a decrease in the number of accidents. Some of the highest ranked intersections have seen a substantial decrease in the number of accidents, the five intersections that has seen decrease are; Highway 7 \& Weston Road, Weston Road \& Rutherford Road, Highway 7 \& McCowan Road, Highway 7 \& Leslie Street, and Jane Street \& Rutherford Road. From the case study on Highway 7 and Leslie street it can be inferred that the addition of the centre bus lanes have helped to see a decrease in accidents at this intersection. As well the retail plaza's exit and entrances are at another intersection controlled by traffic control. These factors could be helping to reduce the number of collisions at the intersection.

Even though these five intersections have seen a decrease, they still have more accidents in total and a higher number of accidents in 2015 (Table 6). While some of the intersections have seen a decrease, there are two that have seen an increase in the number of accidents, Major Mackenzie Drive West \& Exit 35/GO Carpool Lot - Hwy 400 \& Major Mackenzie Drive West and Yonge Street \& Green Lane East/Green Lane West (Table 6). When looking at the case study of Major Mackenzie Drive West \& Exit 35/ GO Carpool its shows that the GO bus stop and the Highway 400 exit is creating high volumes of traffic through the intersection. Because of this the intersection has seen a significant increase in the number of accidents. Changing the signal timing for the intersection as well as the intersections around it could help to relieve traffic congestion, which could in turn reduce collision. In the case of Highway 7 and Leslie Street the addition of bus only lanes were seen to reduce collisions. A similar GO transit lane could help reduce collisions as well. 
This study is subject to many limitations. One of the limitations is the time period. Many of the intersections that had many accidents were in construction areas. Once the construction has been completed, the number of accidents could change. Further analysis would need to be done in the next few years to see if construction is a contributing factor. A longer time period would be able to show if there are patterns that spread over a longer time period. This can cause patterns to emerge in areas that are growing and construction in the areas that could stop once construction is completed.

There are many built features that could contribute to traffic accidents and the variables used in this research are not an exhaustive list. There may be more factors that could be used like street width, distance of straight away before the intersection and volume, that can be included to help get a better picture of features that could be causing accidents. They were not used in this study due to a lack of the data.

For this paper only, intersections that had accidents were included; looking at all intersections in the region could help to give a view of what intersections with no accidents look like. It could also help to improve the significant levels with the logistic regression, while also being able to give a rate of how many intersections have had accidents. 


\section{Conclusions}

Accidents can be hard to predict and prevent. Many of the factors are out of municipalities' control. The time of day, weather and the experience of drivers cannot be changed. However, there are features that can help to decrease the likelihood of an accident occurring. From this paper, it can be seen that there is no one fix that could help across the York Region. Urban and rural areas have a range of factors that contribute to accidents. This means that there may need to be two plans put into place for the different land types. Rural and urban traffic zones were seen to correlate differently with unique features, like the red-light cameras. The red-light cameras are reducing accidents in urban traffic zones. It would still be beneficial to add more red-light cameras in these areas. In Rural traffic zones, red light cameras do not help in reducing accidents. In this case, adding more traffic signals rather than red light cameras could help to reduce accidents.

Red Light cameras work better for reducing angle collisions as well as in Urban traffic zones. From this information five intersections are recommended to have red light cameras installed. Weston Road \& Rutherford Road and Highway 7 \& McCowan road, this intersection had the highest number of angle collisions with 104 and 101. Yonge Street and Green Lane E/W, Highway 7 and Pine Valley Drive, and Major Mackenzie Drive East and Bayview Ave, all have between 96 and 99 angle collisions and are in urban areas. From the analysis completed it was found that those are two features where red-light camera work best at reducing accidents (Appendix A table 4).

From the case studies, it was seen that adding centre bus only lanes could be beneficial in reducing accidents. The recommendation for York region is to do an indepth study of the locations where bus lanes are located and determine if they are helping to reduce collisions in other areas of the region. If they are seen to reduce accidents similarly to what has occurred at Highway 7 and Leslie Street, locating 
similar intersections to add bus only lanes could help to reduce accidents at those intersections as well.

It was also found that cross intersections are where most accidents occur. From the literature review, cross intersection has the most conflict points as seen Figure 2 and have the highest chance of an accident occurring. Areas that are growing or under construction and are near shopping centres are locations that may need a program to help decrease the number of accidents at these locations. Using different intersection types could help to reduce conflict points and reduce the chance for an accident to occur.

Overall, there are many potential ways that York Region can consider changing the built environment to help reduce accidents. The Region has seen a decrease in accidents in the past five years. However, there are areas for improvement, like Highway 7 and Weston road, and Major Mckenzie Drive West and Exit 35 Carpool Lot, where the number of collisions are still high or increasing. As well as adding red light cameras to reduce the number of angle collisions. Consider creating $\mathrm{T}$, or roundabouts which have fewer collisions point could help to decrease the number of accidents. Using the statistical and qualitative analysis it has ways in which The Region can improve and areas that should be looked into. 


\section{APPENDEX}

APPENDEX A: Descriptive Statistic Tables 


\begin{tabular}{l|l} 
TRAFFIC CONTROL TYPE & \multicolumn{1}{l}{ COUNT } \\
\hline TRAFFIC SIGNAL & 28,605 \\
STOP SIGN & 2,480 \\
YIELD SIGN & 56 \\
PED. CROSSOVER & 25 \\
POLICE CONTROL & 49 \\
SCHOOL GUARD & 3 \\
SCHOOL BUS & 31 \\
TRAFFIC GATE & 19 \\
TRAFFIC CONTROLLER & 1,419 \\
NO CONTROL & 6,125 \\
OTHER & 54
\end{tabular}

Table 1: The number of accidents at each different traffic controls. 


\begin{tabular}{|c|c|c|c|c|c|c|c|c|}
\hline Time & Monday & Tuesday & Wednesday & Thursday & Friday & Saturday & Sunday & Total \\
\hline 00:00-00:59 & 42 & 34 & 45 & 66 & 51 & 53 & 88 & 379 \\
\hline 01:00-01:59 & 23 & 31 & 25 & 34 & 29 & 63 & 69 & 274 \\
\hline 02:00-02:59 & 20 & 16 & 15 & 23 & 31 & 61 & 58 & 224 \\
\hline 03:00-03:59 & 20 & 19 & 17 & 13 & 19 & 41 & 50 & 179 \\
\hline 04:00-04:59 & 8 & 9 & 17 & 10 & 20 & 30 & 45 & 139 \\
\hline 05:00-05:59 & 58 & 48 & 42 & 38 & 50 & 38 & 28 & 302 \\
\hline 06:00-06:59 & 167 & 160 & 184 & 161 & 169 & 43 & 40 & 924 \\
\hline 07:00-07:59 & 320 & 361 & 397 & 390 & 317 & 82 & 51 & 1918 \\
\hline 08:00-08:59 & 505 & 596 & 603 & 582 & 485 & 147 & 65 & 2983 \\
\hline 09:00-09:59 & 340 & 440 & 375 & 432 & 350 & 227 & 106 & 2270 \\
\hline $10: 00-10: 59$ & 298 & 298 & 265 & 315 & 307 & 277 & 163 & 1923 \\
\hline 11:00-11:59 & 264 & 312 & 303 & 317 & 326 & 360 & 243 & 2125 \\
\hline $12: 00-12: 59$ & 308 & 353 & 369 & 358 & 427 & 405 & 284 & 2504 \\
\hline $13: 00-13: 59$ & 333 & 378 & 365 & 345 & 377 & 429 & 324 & 2551 \\
\hline 14:00-14:59 & 332 & 417 & 375 & 393 & 418 & 444 & 269 & 2648 \\
\hline $15: 00-15: 59$ & 452 & 516 & 554 & 511 & 589 & 398 & 279 & 3299 \\
\hline $16: 00-16: 59$ & 551 & 633 & 610 & 569 & 690 & 355 & 277 & 3685 \\
\hline $17: 00-17: 59$ & 661 & 764 & 783 & 751 & 712 & 337 & 300 & 4308 \\
\hline 18:00-18:59 & 488 & 545 & 575 & 570 & 528 & 305 & 216 & 3227 \\
\hline 19:00-19:59 & 282 & 350 & 350 & 339 & 360 & 238 & 195 & 2114 \\
\hline $20: 00-20: 59$ & 209 & 247 & 237 & 258 & 253 & 204 & 190 & 1598 \\
\hline $21: 00-21: 59$ & 162 & 192 & 210 & 238 & 203 & 153 & 138 & 1296 \\
\hline 22:00-22:59 & 123 & 135 & 135 & 154 & 157 & 147 & 115 & 966 \\
\hline $23: 00-23: 59$ & 70 & 92 & 91 & 98 & 137 & 120 & 78 & 686 \\
\hline Total & 6036 & 6946 & 6942 & 6965 & 7005 & 4957 & 3671 & 42522 \\
\hline
\end{tabular}

Table 2: Number of accidents by time and day 


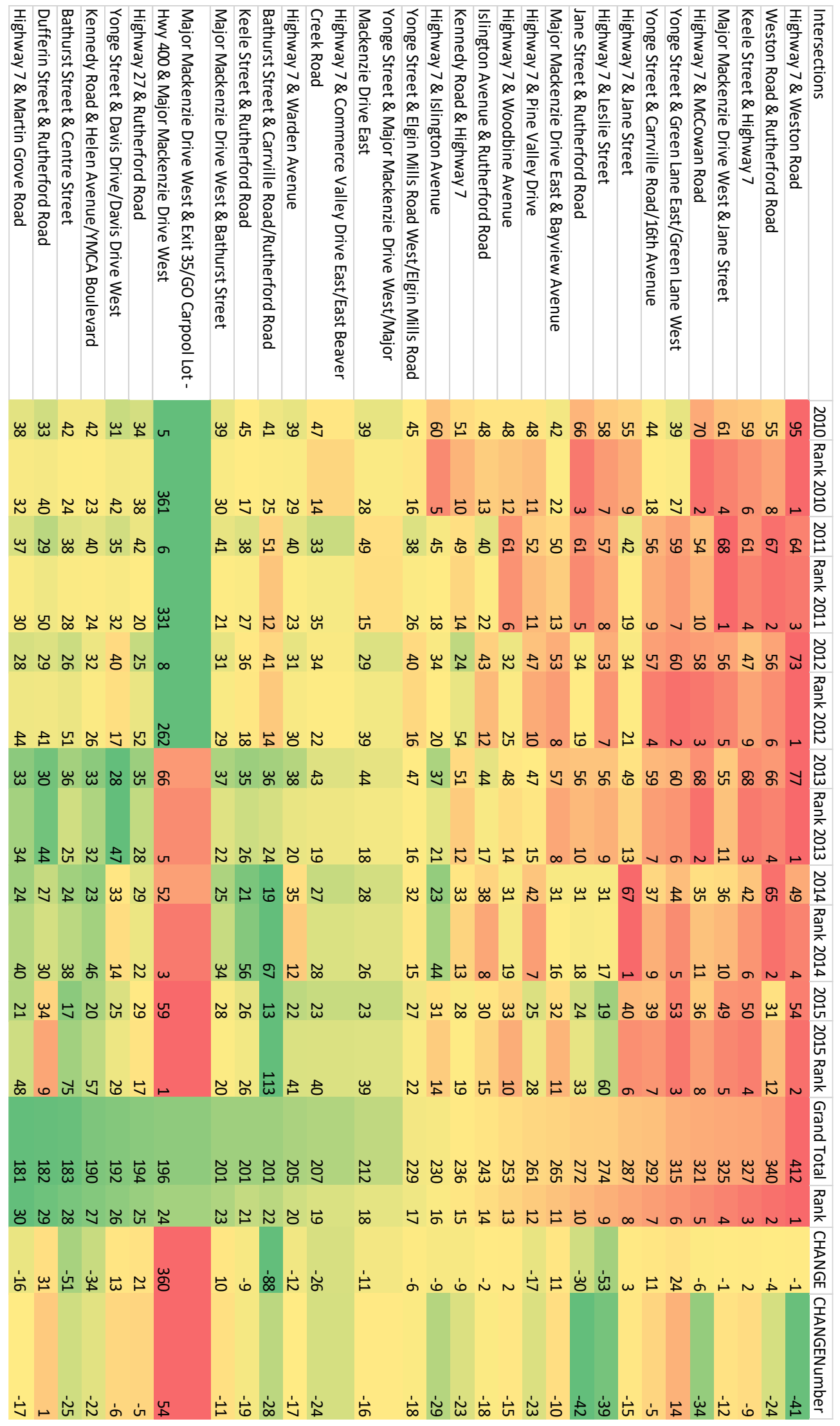


Table 3: Number of accidents at an intersection over six years

\begin{tabular}{|ll}
\hline Intersection & Number of Angle collisions \\
\hline Weston Road \& Rutherford Road & 104 \\
\hline Highway 7 \& McCowan Road & 101 \\
\hline Yonge Street \& Green Lane East/Green Lane West & 99 \\
\hline Highway 7 \& Pine Valley Drive & 97 \\
\hline Major Mackenzie Drive East \& Bayview Avenue & 96 \\
\hline Highway 7 \& Weston Road & 91 \\
\hline Kennedy Road \& Highway 7 & 91 \\
\hline Major Mackenzie Drive West \& Jane Street & 91 \\
\hline Highway 7 \& Jane Street & 84 \\
\hline Highway 7 - Yonge Street Ramp \& Highway 7 & 82 \\
\hline Highway 7 \& Woodbine Avenue & 78 \\
\hline Jane Street \& Rutherford Road & 78 \\
\hline Rutherford Road \& Sweetriver Boulevard & 74 \\
\hline Yonge Street \& Carrville Road/16th Avenue & 73 \\
\hline Wellington Street East \& Yonge Street/Wellington & 72 \\
Street West & 68 \\
\hline Highway 7 - Bayview Avenue Ramp \& Highway 7 & 67 \\
\hline Keele Street \& Highway 7 & 67 \\
\hline Rutherford Road \& Julliard Drive & 67 \\
\hline Woodbine Avenue \& 16th Avenue & 66 \\
\hline Highway 7 \& Leslie Street &
\end{tabular}

Table 4 Intersections with the highest angle collisions 
APPENDEX B: Crosstabs tables 
TRAFFIC CONTROL * COLLISION TYPE Crosstabulation

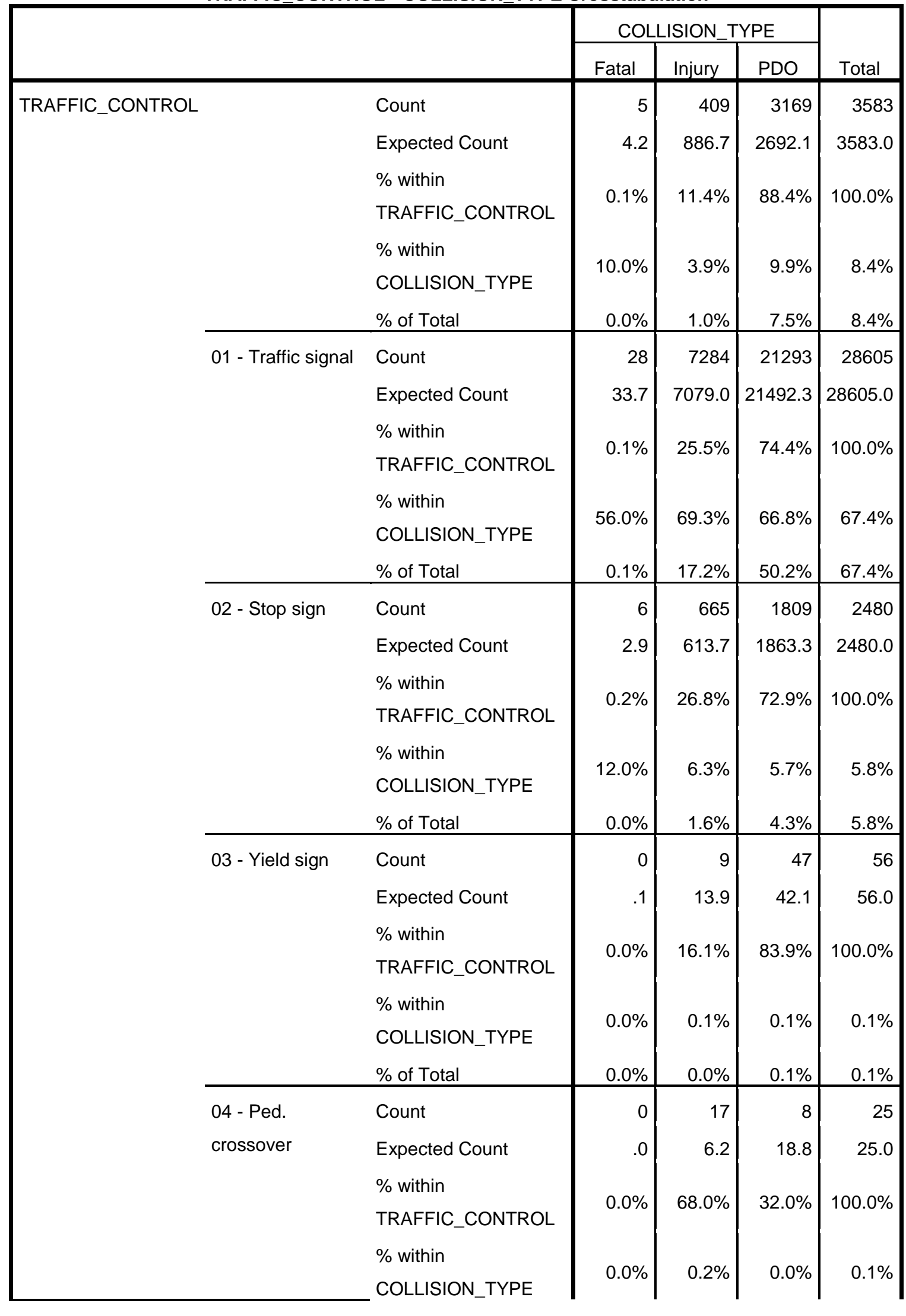




\begin{tabular}{|c|c|c|c|c|c|}
\hline & $\%$ of Total & $0.0 \%$ & $0.0 \%$ & $0.0 \%$ & $0.1 \%$ \\
\hline \multirow[t]{7}{*}{05 - Police control } & Count & 0 & 9 & 40 & 49 \\
\hline & Expected Count & .1 & 12.1 & 36.8 & 49.0 \\
\hline & $\%$ within & $00 \%$ & 1010 & 01601 & 10000 \\
\hline & TRAFFIC_CONTROL & 0.010 & 年 & 01.0 & 100.070 \\
\hline & $\%$ within & $00 \%$ & $01 \%$ & $01 \%$ & $01 \%$ \\
\hline & COLLISION_TYPE & & $0.1 \%$ & & \\
\hline & $\%$ of Total & $0.0 \%$ & $0.0 \%$ & $0.1 \%$ & $0.1 \%$ \\
\hline \multirow[t]{7}{*}{06 - School guard } & Count & 0 & 0 & 3 & 3 \\
\hline & Expected Count & .0 & .7 & 2.3 & 3.0 \\
\hline & $\%$ within & $00 \%$ & $00 \%$ & $1000 \%$ & $1000 \%$ \\
\hline & TRAFFIC_CONTROL & 0.010 & $0.0 \%$ & 100.010 & 100.070 \\
\hline & $\%$ within & $00 \%$ & $00 \%$ & $00 \%$ & $00 \%$ \\
\hline & COLLISION_TYPE & 0.010 & & & \\
\hline & $\%$ of Total & $0.0 \%$ & $0.0 \%$ & $0.0 \%$ & $0.0 \%$ \\
\hline \multirow[t]{7}{*}{07 - School bus } & Count & 0 & 12 & 19 & 31 \\
\hline & Expected Count & .0 & 7.7 & 23.3 & 31.0 \\
\hline & $\%$ within & $00 \%$ & 3870 & 6130 & 10000 \\
\hline & TRAFFIC_CONTROL & & & 年. & \\
\hline & $\%$ within & $00 \%$ & $01 \%$ & $0 . \%$ & $01 \%$ \\
\hline & COLLISION_TYPE & 0.070 & & & \\
\hline & $\%$ of Total & $0.0 \%$ & $0.0 \%$ & $0.0 \%$ & $0.1 \%$ \\
\hline \multirow[t]{7}{*}{08 - Traffic gate } & Count & 0 & 5 & 14 & 19 \\
\hline & Expected Count & .0 & 4.7 & 14.3 & 19.0 \\
\hline & $\%$ within & $00 \%$ & $26.3 \%$ & $737 \%$ & $1000 \%$ \\
\hline & TRAFFIC_CONTROL & $0.0 \%$ & $20.0 \%$ & 10.170 & \\
\hline & $\%$ within & $00 \%$ & $00 \%$ & $00 \%$ & $00 \%$ \\
\hline & COLLISION_TYPE & 0.070 & 0.070 & $0.0 \%$ & $0.0 \%$ \\
\hline & $\%$ of Total & $0.0 \%$ & $0.0 \%$ & $0.0 \%$ & $0.0 \%$ \\
\hline \multirow{7}{*}{$\begin{array}{l}09 \text { - Traffic } \\
\text { controller }\end{array}$} & Count & 2 & 538 & 879 & 1419 \\
\hline & Expected Count & 1.7 & 351.2 & 1066.2 & 1419.0 \\
\hline & $\%$ within & $01 \%$ & $379 \%$ & $619 \%$ & $1000 \%$ \\
\hline & TRAFFIC_CONTROL & & $31.5 \%$ & 01.510 & $100.0 \%$ \\
\hline & $\%$ within & $40 \%$ & $5 . \%$ & $28 \%$ & $3.3 \%$ \\
\hline & COLLISION_TYPE & & $0.1 \%$ & & \\
\hline & $\%$ of Total & $0.0 \%$ & $1.3 \%$ & $2.1 \%$ & $3.3 \%$ \\
\hline 10 - No control & Count & 8 & 1543 & 4574 & 6125 \\
\hline
\end{tabular}




\begin{tabular}{|c|c|c|c|c|c|c|}
\hline & & $\begin{array}{l}\text { Expected Count } \\
\text { \% within } \\
\text { TRAFFIC_CONTROL } \\
\text { \% within } \\
\text { COLLISION_TYPE } \\
\% \text { of Total }\end{array}$ & $\begin{array}{r}7.2 \\
0.1 \% \\
16.0 \% \\
0.0 \% \\
\end{array}$ & $\begin{array}{r}1515.8 \\
25.2 \% \\
14.7 \% \\
3.6 \% \\
\end{array}$ & $\begin{array}{l}4602.0 \\
74.7 \% \\
14.3 \% \\
10.8 \% \\
\end{array}$ & $\begin{array}{r}6125.0 \\
100.0 \% \\
14.4 \% \\
14.4 \% \\
\end{array}$ \\
\hline & 99 - Other & $\begin{array}{l}\text { Count } \\
\text { Expected Count } \\
\text { \% within } \\
\text { TRAFFIC_CONTROL } \\
\text { \% within } \\
\text { COLLISION_TYPE } \\
\text { \% of Total }\end{array}$ & $\begin{array}{r}1 \\
.1 \\
1.9 \% \\
2.0 \% \\
0.0 \%\end{array}$ & $\begin{array}{r}14 \\
13.4 \\
25.9 \% \\
0.1 \% \\
0.0 \%\end{array}$ & $\begin{array}{r}39 \\
40.6 \\
72.2 \% \\
0.1 \% \\
0.1 \%\end{array}$ & $\begin{array}{r}54 \\
54.0 \\
100.0 \% \\
0.1 \% \\
0.1 \%\end{array}$ \\
\hline Total & & $\begin{array}{l}\text { Count } \\
\text { Expected Count } \\
\text { \% within } \\
\text { TRAFFIC_CONTROL } \\
\text { \% within } \\
\text { COLLISION_TYPE } \\
\text { \% of Total }\end{array}$ & $\begin{array}{r}50 \\
50.0 \\
0.1 \% \\
100.0 \% \\
0.1 \%\end{array}$ & $\begin{array}{r}10505 \\
10505.0 \\
24.7 \% \\
100.0 \% \\
24.7 \%\end{array}$ & $\begin{array}{r}31894 \\
31894.0 \\
75.1 \% \\
100.0 \% \\
75.1 \%\end{array}$ & $\begin{array}{r}42449 \\
42449.0 \\
100.0 \% \\
100.0 \% \\
100.0 \%\end{array}$ \\
\hline
\end{tabular}

Table 1: Traffic signal and Accident type by year 
TRAFFIC CONTROL * Intersection TYPE Crosstabulation

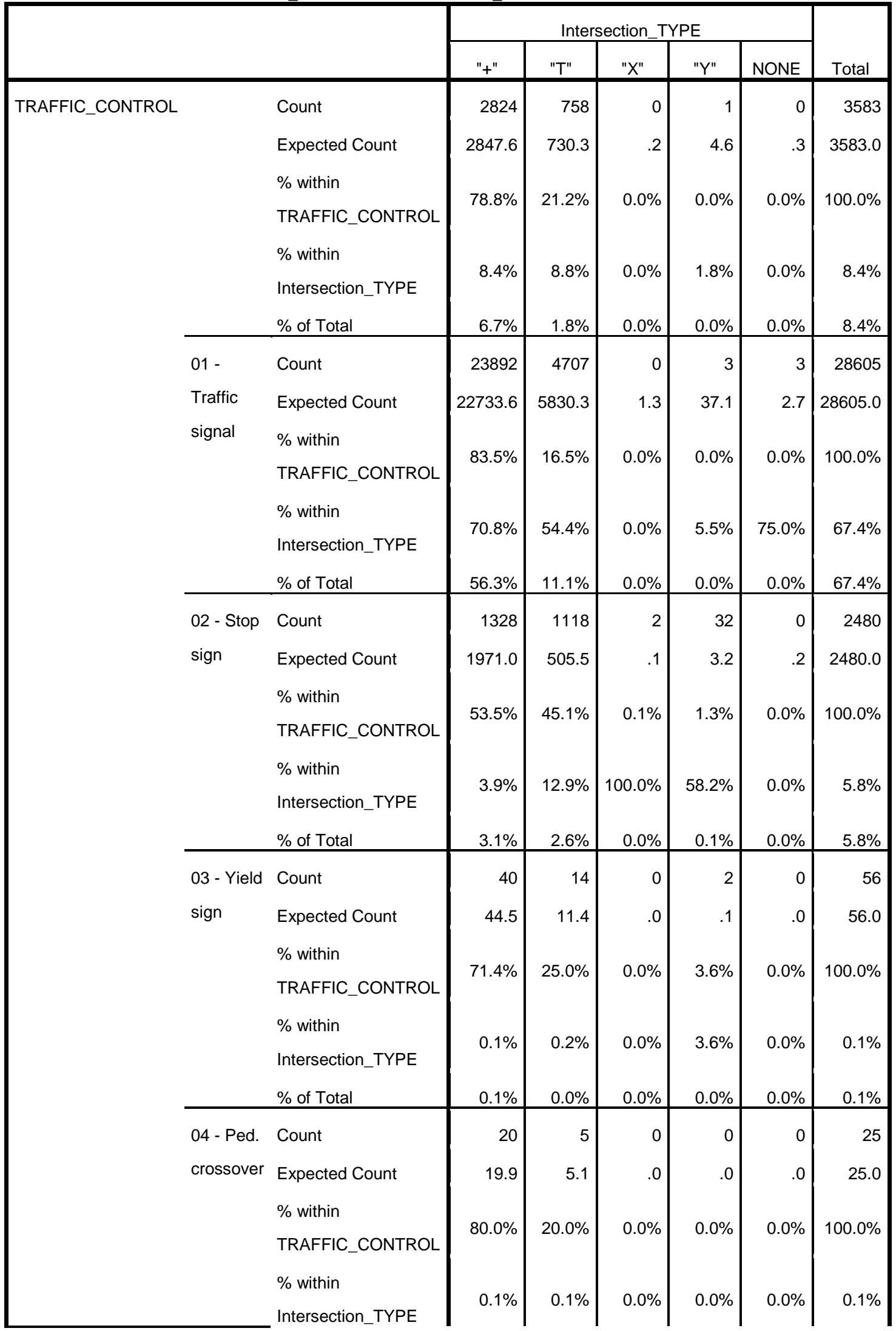




\begin{tabular}{|c|c|c|c|c|c|c|c|}
\hline & $\%$ of Total & $0.0 \%$ & $0.0 \%$ & $0.0 \%$ & $0.0 \%$ & $0.0 \%$ & $0.1 \%$ \\
\hline \multirow{7}{*}{$\begin{array}{l}05 \text { - } \\
\text { Police } \\
\text { control }\end{array}$} & Count & 42 & 7 & 0 & 0 & 0 & 49 \\
\hline & Expected Count & 38.9 & 10.0 & .0 & .1 & .0 & 49.0 \\
\hline & $\%$ within & & & & & & \\
\hline & TRAFFIC_CONTROL & & & & & & \\
\hline & $\%$ within & & & & & & \\
\hline & Intersection_TYPE & & & & & 0.070 & \\
\hline & $\%$ of Total & $0.1 \%$ & $0.0 \%$ & $0.0 \%$ & $0.0 \%$ & $0.0 \%$ & $0.1 \%$ \\
\hline \multirow{5}{*}{$\begin{array}{l}06 \text { - } \\
\text { School } \\
\text { guard }\end{array}$} & Count & 3 & 0 & 0 & 0 & 0 & 3 \\
\hline & Expected Count & 2.4 & .6 & .0 & .0 & .0 & 3.0 \\
\hline & $\begin{array}{l}\text { \% within } \\
\text { TRAFFIC_CONTROL }\end{array}$ & $100.0 \%$ & $0.0 \%$ & $0.0 \%$ & $0.0 \%$ & $0.0 \%$ & $100.0 \%$ \\
\hline & $\begin{array}{l}\text { \% within } \\
\text { Intersection_TYPE }\end{array}$ & $0.0 \%$ & $0.0 \%$ & $0.0 \%$ & $0.0 \%$ & $0.0 \%$ & $0.0 \%$ \\
\hline & $\%$ of Total & $0.0 \%$ & $0.0 \%$ & $0.0 \%$ & $0.0 \%$ & $0.0 \%$ & $0.0 \%$ \\
\hline \multirow{5}{*}{$\begin{array}{l}07 \text { - } \\
\text { School } \\
\text { bus }\end{array}$} & Count & 19 & 12 & 0 & 0 & 0 & 31 \\
\hline & Expected Count & 24.6 & 6.3 & .0 & .0 & .0 & 31.0 \\
\hline & $\begin{array}{l}\text { \% within } \\
\text { TRAFFIC_CONTROL }\end{array}$ & $61.3 \%$ & $38.7 \%$ & $0.0 \%$ & $0.0 \%$ & $0.0 \%$ & $100.0 \%$ \\
\hline & $\begin{array}{l}\text { \% within } \\
\text { Intersection_TYPE }\end{array}$ & $0.1 \%$ & $0.1 \%$ & $0.0 \%$ & $0.0 \%$ & $0.0 \%$ & $0.1 \%$ \\
\hline & $\%$ of Total & $0.0 \%$ & $0.0 \%$ & $0.0 \%$ & $0.0 \%$ & $0.0 \%$ & $0.1 \%$ \\
\hline \multirow{5}{*}{$\begin{array}{l}08 \text { - } \\
\text { Traffic } \\
\text { gate }\end{array}$} & Count & 15 & 4 & 0 & 0 & 0 & 19 \\
\hline & Expected Count & 15.1 & 3.9 & .0 & .0 & .0 & 19.0 \\
\hline & $\begin{array}{l}\text { \% within } \\
\text { TRAFFIC_CONTROL }\end{array}$ & $78.9 \%$ & $21.1 \%$ & $0.0 \%$ & $0.0 \%$ & $0.0 \%$ & $100.0 \%$ \\
\hline & $\begin{array}{l}\text { \% within } \\
\text { Intersection_TYPE }\end{array}$ & $0.0 \%$ & $0.0 \%$ & $0.0 \%$ & $0.0 \%$ & $0.0 \%$ & $0.0 \%$ \\
\hline & $\%$ of Total & $0.0 \%$ & $0.0 \%$ & $0.0 \%$ & $0.0 \%$ & $0.0 \%$ & $0.0 \%$ \\
\hline \multirow{5}{*}{$\begin{array}{l}09 \text { - } \\
\text { Traffic } \\
\text { controller }\end{array}$} & Count & 1215 & 204 & 0 & 0 & 0 & 1419 \\
\hline & Expected Count & 1127.7 & 289.2 & .1 & 1.8 & .1 & 1419.0 \\
\hline & $\begin{array}{l}\text { \% within } \\
\text { TRAFFIC_CONTROL }\end{array}$ & $85.6 \%$ & $14.4 \%$ & $0.0 \%$ & $0.0 \%$ & $0.0 \%$ & $100.0 \%$ \\
\hline & $\begin{array}{l}\text { \% within } \\
\text { Intersection_TYPE }\end{array}$ & $3.6 \%$ & $2.4 \%$ & $0.0 \%$ & $0.0 \%$ & $0.0 \%$ & $3.3 \%$ \\
\hline & $\%$ of Total & $2.9 \%$ & $0.5 \%$ & $0.0 \%$ & $0.0 \%$ & $0.0 \%$ & $3.3 \%$ \\
\hline 10 - No & Count & 4295 & 1812 & 0 & 17 & 1 & 6125 \\
\hline
\end{tabular}




\begin{tabular}{|c|c|c|c|c|c|c|c|c|}
\hline & control & $\begin{array}{l}\text { Expected Count } \\
\% \text { within } \\
\text { TRAFFIC_CONTROL } \\
\% \text { within } \\
\text { Intersection_TYPE } \\
\% \text { of Total }\end{array}$ & $\begin{array}{r}4867.8 \\
70.1 \% \\
12.7 \% \\
10.1 \% \\
\end{array}$ & $\begin{array}{r}1248.4 \\
29.6 \% \\
20.9 \% \\
4.3 \% \\
\end{array}$ & $\begin{array}{r}.3 \\
0.0 \% \\
0.0 \% \\
0.0 \% \\
\end{array}$ & $\begin{array}{r}7.9 \\
0.3 \% \\
30.9 \% \\
0.0 \% \\
\end{array}$ & $\begin{array}{r}.6 \\
0.0 \% \\
25.0 \% \\
0.0 \% \\
\end{array}$ & $\begin{array}{r}6125.0 \\
100.0 \% \\
14.4 \% \\
14.4 \% \\
\end{array}$ \\
\hline & $\begin{array}{l}99 \text { - } \\
\text { Other }\end{array}$ & $\begin{array}{l}\text { Count } \\
\text { Expected Count } \\
\text { \% within } \\
\text { TRAFFIC_CONTROL } \\
\text { \% within } \\
\text { Intersection_TYPE } \\
\text { \% of Total }\end{array}$ & \begin{tabular}{r|}
43 \\
42.9 \\
$79.6 \%$ \\
$0.1 \%$ \\
$0.1 \%$ \\
\end{tabular} & $\begin{array}{r}11 \\
11.0 \\
20.4 \% \\
0.1 \% \\
0.0 \%\end{array}$ & $\begin{array}{r}0 \\
.0 \\
0.0 \% \\
0.0 \% \\
0.0 \%\end{array}$ & $\begin{array}{r}0 \\
.1 \\
0.0 \% \\
0.0 \% \\
0.0 \%\end{array}$ & $\begin{array}{r}0 \\
.0 \\
0.0 \% \\
0.0 \% \\
0.0 \%\end{array}$ & $\begin{array}{r}54 \\
54.0 \\
100.0 \% \\
0.1 \% \\
0.1 \%\end{array}$ \\
\hline Total & & $\begin{array}{l}\text { Count } \\
\text { Expected Count } \\
\text { \% within } \\
\text { TRAFFIC_CONTROL } \\
\% \text { within } \\
\text { Intersection_TYPE } \\
\% \text { of Total }\end{array}$ & $\begin{array}{r}33736 \\
33736.0 \\
79.5 \% \\
100.0 \% \\
79.5 \%\end{array}$ & $\begin{array}{r}8652 \\
8652.0 \\
20.4 \% \\
100.0 \% \\
20.4 \%\end{array}$ & $\begin{array}{r}2 \\
2.0 \\
0.0 \% \\
100.0 \% \\
0.0 \%\end{array}$ & $\begin{array}{r}55 \\
55.0 \\
0.1 \% \\
100.0 \% \\
0.1 \%\end{array}$ & $\begin{array}{r}4 \\
4.0 \\
0.0 \% \\
\\
100.0 \% \\
0.0 \%\end{array}$ & $\begin{array}{r}42449 \\
42449.0 \\
100.0 \% \\
100.0 \% \\
100.0 \%\end{array}$ \\
\hline
\end{tabular}

Table 2 Traffic Control and Intersection Type 
Intersection_TYPE * COLLISION_TYPE Crosstabulation

\begin{tabular}{|c|c|c|c|c|c|c|}
\hline & \multicolumn{3}{|c|}{ COLLISION_TYPE } & \multirow[b]{2}{*}{ Total } \\
\hline & & & Fatal & Injury & PDO & \\
\hline \multirow[t]{25}{*}{ Intersection_TYPE } & \multirow[t]{5}{*}{ "+" } & Count & 33 & 8272 & 25431 & 33736 \\
\hline & & Expected Count & 39.7 & 8348.8 & 25347.5 & 33736.0 \\
\hline & & \% within Intersection_TYPE & $0.1 \%$ & $24.5 \%$ & $75.4 \%$ & $100.0 \%$ \\
\hline & & \% within COLLISION_TYPE & $66.0 \%$ & $78.7 \%$ & $79.7 \%$ & $79.5 \%$ \\
\hline & & $\%$ of Total & $0.1 \%$ & $19.5 \%$ & $59.9 \%$ & $79.5 \%$ \\
\hline & \multirow[t]{5}{*}{ "T" } & Count & 17 & 2221 & 6414 & 8652 \\
\hline & & Expected Count & 10.2 & 2141.1 & 6500.7 & 8652.0 \\
\hline & & \% within Intersection_TYPE & $0.2 \%$ & $25.7 \%$ & $74.1 \%$ & $100.0 \%$ \\
\hline & & \% within COLLISION_TYPE & $34.0 \%$ & $21.1 \%$ & $20.1 \%$ & $20.4 \%$ \\
\hline & & $\%$ of Total & $0.0 \%$ & $5.2 \%$ & $15.1 \%$ & $20.4 \%$ \\
\hline & \multirow[t]{5}{*}{ "X" } & Count & 0 & 2 & 0 & 2 \\
\hline & & Expected Count & .0 & .5 & 1.5 & 2.0 \\
\hline & & $\%$ within Intersection_TYPE & $0.0 \%$ & $100.0 \%$ & $0.0 \%$ & $100.0 \%$ \\
\hline & & \% within COLLISION_TYPE & $0.0 \%$ & $0.0 \%$ & $0.0 \%$ & $0.0 \%$ \\
\hline & & $\%$ of Total & $0.0 \%$ & $0.0 \%$ & $0.0 \%$ & $0.0 \%$ \\
\hline & \multirow[t]{5}{*}{ "Y" } & Count & 0 & 10 & 45 & 55 \\
\hline & & Expected Count & .1 & 13.6 & 41.3 & 55.0 \\
\hline & & \% within Intersection_TYPE & $0.0 \%$ & $18.2 \%$ & $81.8 \%$ & $100.0 \%$ \\
\hline & & \% within COLLISION_TYPE & $0.0 \%$ & $0.1 \%$ & $0.1 \%$ & $0.1 \%$ \\
\hline & & $\%$ of Total & $0.0 \%$ & $0.0 \%$ & $0.1 \%$ & $0.1 \%$ \\
\hline & \multirow[t]{5}{*}{ NONE } & Count & 0 & 0 & 4 & 4 \\
\hline & & Expected Count & .0 & 1.0 & 3.0 & 4.0 \\
\hline & & $\%$ within Intersection_TYPE & $0.0 \%$ & $0.0 \%$ & $100.0 \%$ & $100.0 \%$ \\
\hline & & \% within COLLISION_TYPE & $0.0 \%$ & $0.0 \%$ & $0.0 \%$ & $0.0 \%$ \\
\hline & & $\%$ of Total & $0.0 \%$ & $0.0 \%$ & $0.0 \%$ & $0.0 \%$ \\
\hline \multirow[t]{5}{*}{ Total } & & Count & 50 & 10505 & 31894 & 42449 \\
\hline & & Expected Count & 50.0 & 10505.0 & 31894.0 & 42449.0 \\
\hline & & $\%$ within Intersection_TYPE & $0.1 \%$ & $24.7 \%$ & $75.1 \%$ & $100.0 \%$ \\
\hline & & $\%$ within COLLISION_TYPE & $100.0 \%$ & $100.0 \%$ & $100.0 \%$ & $100.0 \%$ \\
\hline & & $\%$ of Total & $0.1 \%$ & $24.7 \%$ & $75.1 \%$ & $100.0 \%$ \\
\hline
\end{tabular}

Table 3: Intersection type and collision 
APPENDEX C: Logistic Regression 


\begin{tabular}{|cl|r|r|}
\hline & & & \\
\hline Step $1^{\mathrm{a}}$ & B & Sig. \\
& StopSign & .478 & .455 \\
& TrafficSignal & -.277 & .569 \\
& NoControl & .169 & .785 \\
RLC & -1.329 & .084 \\
BusSt & -.053 & .851 \\
ShopCent & -.415 & .483 \\
School & -.361 & .553 \\
Trees & -.486 & .086 \\
Constant & 1.930 & .000 \\
\hline
\end{tabular}

Table 1: Cyclist and Injury

\begin{tabular}{|cl|r|r|}
\hline & & & \\
& & B & Sig. \\
\hline Step $1^{\mathrm{a}}$ & StopSign & -.165 & .901 \\
& TrafficSignal & -.513 & .521 \\
& NoControl & -.529 & .673 \\
RLC & -16.655 & .998 \\
BusSt & -1.410 & .017 \\
ShopCent & -16.806 & .998 \\
School & 1.345 & .127 \\
Trees & .651 & .348 \\
Constant & -3.161 & .000 \\
\hline
\end{tabular}

Table 2: Pedestrian and Fatal 


\begin{tabular}{|cl|r|r|}
\hline & & & \\
\hline Step $1^{\text {a }}$ & B & Sig. \\
& StopSign & -1.179 & .109 \\
& TrafficSignal & -.062 & .900 \\
NoControl & -.695 & .259 \\
RLC & -1.758 & .003 \\
BusSt & .441 & .137 \\
ShopCent & .691 & .399 \\
School & -.468 & .465 \\
Trees & .178 & .676 \\
Constant & 2.648 & .000 \\
\hline
\end{tabular}

Table 3: Pedestrian and injury

\begin{tabular}{|c|c|c|c|}
\hline & & $\mathrm{B}$ & Sig. \\
\hline \multirow[t]{10}{*}{ Step $1^{a}$} & StopSign & -.408 & .000 \\
\hline & TrafficSignal & -.361 & .000 \\
\hline & NoControl & -.389 & .000 \\
\hline & RLC & -.084 & .120 \\
\hline & BusSt & .070 & .004 \\
\hline & ShopCent & .135 & .028 \\
\hline & School & -.081 & .298 \\
\hline & SchoFlash & .141 & .716 \\
\hline & Trees & -.149 & .000 \\
\hline & Constant & 1.537 & .000 \\
\hline
\end{tabular}

Table 4 Motor vehicle and property 
APPENDEX D: Case Studies 


\begin{tabular}{|l|c|c|c|c|c|c|c} 
& $\mathbf{2 0 1 0}$ & $\mathbf{2 0 1 1}$ & $\mathbf{2 0 1 2}$ & $\mathbf{2 0 1 3}$ & $\mathbf{2 0 1 4}$ & $\mathbf{2 0 1 5}$ & Total \\
\hline Fatal Accidents & 0 & 1 & 0 & 0 & 0 & 0 & 1 \\
\hline Injury & 7 & 12 & 15 & 17 & 12 & 14 & 77 \\
\hline $\begin{array}{l}\text { Property } \\
\text { Damage }\end{array}$ & 88 & 51 & 58 & 60 & 37 & 40 & 334 \\
\hline Total & $\mathbf{9 5}$ & $\mathbf{6 4}$ & $\mathbf{7 3}$ & $\mathbf{7 7}$ & $\mathbf{4 9}$ & $\mathbf{5 4}$ & $\mathbf{4 1 2}$ \\
\hline
\end{tabular}

Table 1 Highway 7 and Weston Accident Classification 


\begin{tabular}{|c|c|c|c|c|c|c|c|}
\hline Row Labels & 2010 & 2011 & 2012 & 2013 & 2014 & 2015 & Grand Total \\
\hline 01 - Approaching & & 2 & 1 & 2 & 2 & & 7 \\
\hline 01 - North & & 1 & & & 1 & & 2 \\
\hline 02 - South & & 1 & & & & & 1 \\
\hline 03 - East & & & 1 & 1 & 1 & & 3 \\
\hline 04 - West & & & & 1 & & & 1 \\
\hline 02 - Angle & 15 & 14 & 6 & 15 & 9 & 2 & 61 \\
\hline 01 - North & 2 & 2 & 3 & 4 & & & 11 \\
\hline 02 - South & 6 & 4 & 1 & 7 & 2 & 1 & 21 \\
\hline 03 - East & 3 & 3 & 2 & 4 & 4 & 1 & 17 \\
\hline 04 - West & 4 & 5 & & & 3 & & 12 \\
\hline 03 - Rear end & 52 & 33 & 45 & 29 & 27 & 21 & 207 \\
\hline 01 - North & 6 & 2 & 13 & 6 & 4 & 7 & 38 \\
\hline 02 - South & 7 & 11 & 5 & 4 & 3 & 6 & 36 \\
\hline 03 - East & 25 & 8 & 16 & 8 & 12 & 7 & 76 \\
\hline 04 - West & 14 & 12 & 11 & 11 & 8 & 1 & 57 \\
\hline 04 - Sideswipe & 21 & 12 & 14 & 15 & 6 & 15 & 83 \\
\hline 01 - North & 3 & 4 & 5 & 3 & 1 & 2 & 18 \\
\hline 02 - South & 7 & 1 & 2 & 6 & & 7 & 23 \\
\hline 03 - East & 5 & 3 & 3 & 3 & 2 & 5 & 21 \\
\hline 04 - West & 6 & 4 & 4 & 3 & 3 & 1 & 21 \\
\hline 05 - Turning movement & 5 & 2 & 2 & 7 & 4 & 10 & 30 \\
\hline 01 - North & 1 & 1 & 1 & 4 & 1 & 3 & 11 \\
\hline 02 - South & 1 & & & 1 & 2 & 2 & 6 \\
\hline 03 - East & 1 & & 1 & 2 & 1 & 5 & 10 \\
\hline 04 - West & 2 & 1 & & & & & 3 \\
\hline 06 - SMV unattended vehicle & & & 2 & 1 & & & 3 \\
\hline 01 - North & & & 1 & & & & 1 \\
\hline 02 - South & & & 1 & & & & 1 \\
\hline (blank) & & & & 1 & & & 1 \\
\hline 07 - SMV other & 1 & 1 & 2 & 2 & 1 & 4 & 11 \\
\hline 01 - North & 1 & 1 & 1 & & 1 & 3 & 7 \\
\hline 02 - South & & & & 1 & & & 1 \\
\hline 03 - East & & & 1 & 1 & & & 2 \\
\hline 04 - West & & & & & & 1 & 1 \\
\hline 99 - Other & 1 & & & & & 2 & 3 \\
\hline 01 - North & & & & & & 1 & 1 \\
\hline 02 - South & 1 & & & & & & 1 \\
\hline 04 - West & & & & & & 1 & 1 \\
\hline
\end{tabular}




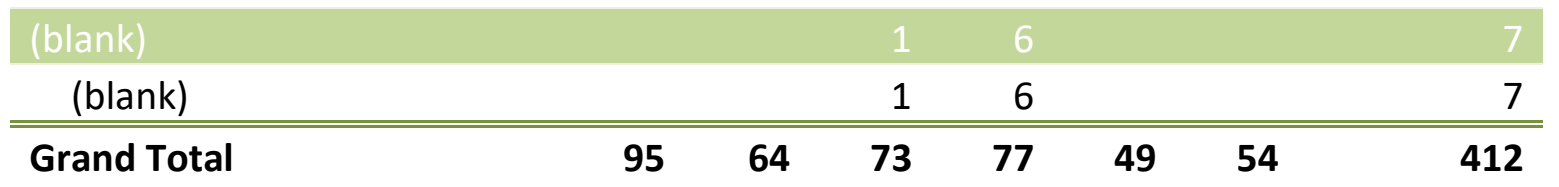

Table 2 Highway 7 and Weston Road Initial impact type and direction

\begin{tabular}{|l|c|c|c|c|c|c|c|} 
& $\mathbf{2 0 1 0}$ & $\mathbf{2 0 1 1}$ & $\mathbf{2 0 1 2}$ & $\mathbf{2 0 1 3}$ & $\mathbf{2 0 1 4}$ & $\mathbf{2 0 1 5}$ & Total \\
\hline Fatal Accidents & 0 & 0 & 0 & 0 & 0 & 0 & 1 \\
\hline Injury & 1 & 1 & 2 & 18 & 15 & 19 & 56 \\
\hline $\begin{array}{l}\text { Property } \\
\text { Damage }\end{array}$ & 4 & 5 & 6 & 48 & 37 & 40 & 140 \\
\hline Total & $\mathbf{5}$ & $\mathbf{6}$ & $\mathbf{8}$ & $\mathbf{6 6}$ & $\mathbf{5 2}$ & $\mathbf{5 9}$ & $\mathbf{1 9 6}$ \\
\hline
\end{tabular}

Table 3 Major Mackenzie Drive West and Exit 35 GO Carpool Lot Accident Classification 


\begin{tabular}{|c|c|c|c|c|c|c|c|}
\hline Row Labels & 2010 & 2011 & 2012 & 2013 & 2014 & 2015 & Grand Total \\
\hline 01 - Approaching & & & & & 4 & & 4 \\
\hline 01 - North & & & & & 1 & & 1 \\
\hline 02 - South & & & & & 1 & & 1 \\
\hline 03 - East & & & & & 2 & & 2 \\
\hline 02 - Angle & & 1 & 1 & 2 & & & 4 \\
\hline 01 - North & & & 1 & & & & 1 \\
\hline 03 - East & & & & 2 & & & 2 \\
\hline 04 - West & & 1 & & & & & 1 \\
\hline 03 - Rear end & 3 & 5 & 6 & 49 & 37 & 32 & 132 \\
\hline 01 - North & & & & 14 & 4 & 5 & 23 \\
\hline 02 - South & & 1 & & 1 & 5 & 6 & 13 \\
\hline 03 - East & 1 & 1 & 2 & 9 & 9 & 6 & 28 \\
\hline 04 - West & 2 & 3 & 4 & 25 & 19 & 15 & 68 \\
\hline 04 - Sideswipe & 1 & & 1 & 3 & 2 & 4 & 11 \\
\hline 01 - North & & & & 1 & 1 & & 2 \\
\hline 02 - South & & & & 1 & & & 1 \\
\hline 03 - East & 1 & & & & 1 & 4 & 6 \\
\hline 04 - West & & & 1 & 1 & & & 2 \\
\hline 05 - Turning movement & & & & 8 & 7 & 18 & 33 \\
\hline 01 - North & & & & 1 & 2 & 7 & 10 \\
\hline 02 - South & & & & 3 & 1 & 3 & 7 \\
\hline 03 - East & & & & 3 & 1 & 5 & 9 \\
\hline 04 - West & & & & 1 & 3 & 3 & 7 \\
\hline 06 - SMV unattended vehicle & & & & & & 1 & 1 \\
\hline 01 - North & & & & & & 1 & 1 \\
\hline 07 - SMV other & 1 & & & 1 & 2 & 3 & 7 \\
\hline 01 - North & & & & & & 1 & 1 \\
\hline 02 - South & & & & 1 & & & 1 \\
\hline 03 - East & & & & & 2 & 1 & 3 \\
\hline 04 - West & 1 & & & & & 1 & 2 \\
\hline 99 - Other & & & & & & 1 & 1 \\
\hline 04 - West & & & & & & 1 & 1 \\
\hline (blank) & & & & 3 & & & 3 \\
\hline (blank) & & & & 3 & & & 3 \\
\hline Grand Total & 5 & 6 & 8 & 66 & 52 & 59 & 196 \\
\hline
\end{tabular}

Table 4 Major Mackenzie Drive West and Exit 35 GO Carpool Lot Initial impact and direction 


\begin{tabular}{l|c|c|c|c|c|c|c} 
& $\mathbf{2 0 1 0}$ & $\mathbf{2 0 1 1}$ & $\mathbf{2 0 1 2}$ & $\mathbf{2 0 1 3}$ & $\mathbf{2 0 1 4}$ & $\mathbf{2 0 1 5}$ & Total \\
\hline Fatal Accidents & 0 & 0 & 1 & 0 & 0 & 0 & $\mathbf{1}$ \\
\hline Injury & 4 & 11 & 12 & 11 & 9 & 3 & $\mathbf{5 0}$ \\
\hline $\begin{array}{l}\text { Property } \\
\text { Damage }\end{array}$ & 54 & 46 & 40 & 45 & 22 & 16 & $\mathbf{2 2 3}$ \\
\hline Total & $\mathbf{5 8}$ & $\mathbf{5 7}$ & $\mathbf{5 3}$ & $\mathbf{5 6}$ & $\mathbf{3 1}$ & $\mathbf{1 9}$ & $\mathbf{2 7 4}$ \\
\hline
\end{tabular}

Table 5 Highway 7 and Leslie Street accident classification 


\begin{tabular}{|c|c|c|c|c|c|c|c|}
\hline Row Labels & 2010 & 2011 & 2012 & 2013 & 2014 & 2015 & $\begin{array}{l}\text { Grand } \\
\text { Total }\end{array}$ \\
\hline 01 - Approaching & & & 1 & 1 & 1 & 1 & 4 \\
\hline 03 - East & & & 1 & 1 & & & 2 \\
\hline 04 - West & & & & & 1 & 1 & 2 \\
\hline 02 - Angle & 5 & 9 & 19 & 9 & 2 & 2 & 46 \\
\hline 01 - North & 1 & 3 & 1 & & & & 5 \\
\hline 02 - South & 3 & 2 & 4 & 5 & & & 14 \\
\hline 03 - East & & 4 & 7 & 3 & 1 & & 15 \\
\hline 04 - West & 1 & & 7 & 1 & 1 & 2 & 12 \\
\hline 03 - Rear end & 37 & 31 & 19 & 28 & 17 & 8 & 140 \\
\hline 01 - North & 5 & 6 & 4 & 4 & 1 & & 20 \\
\hline 02 - South & 7 & 2 & 6 & 4 & 3 & 1 & 23 \\
\hline 03 - East & 18 & 18 & 2 & 11 & 10 & 6 & 65 \\
\hline 04 - West & 7 & 5 & 7 & 9 & 3 & 1 & 32 \\
\hline 04 - Sideswipe & 13 & 9 & 9 & 13 & 6 & 3 & 53 \\
\hline 01 - North & 3 & & 1 & & 2 & & 6 \\
\hline 02 - South & 2 & 1 & 4 & 2 & & 3 & 12 \\
\hline 03 - East & 6 & 7 & 2 & 2 & 2 & & 19 \\
\hline 04 - West & 2 & 1 & 2 & 9 & 2 & & 16 \\
\hline 05 - Turning movement & 2 & 5 & 4 & 2 & 3 & 4 & 20 \\
\hline 01 - North & 1 & & 1 & & 2 & 3 & 7 \\
\hline 02 - South & & & & 2 & & & 2 \\
\hline 03 - East & 1 & 3 & 2 & & & & 6 \\
\hline 04 - West & & 2 & 1 & & 1 & 1 & 5 \\
\hline \multicolumn{8}{|l|}{06 - SMV unattended } \\
\hline vehicle & 1 & 2 & 1 & & & 1 & 5 \\
\hline 01 - North & 1 & 1 & & & & & 2 \\
\hline 03 - East & & 1 & & & & & 1 \\
\hline 04 - West & & & 1 & & & & 1 \\
\hline (blank) & & & & & & 1 & 1 \\
\hline 07 - SMV other & & & & & 2 & & 2 \\
\hline 02 - South & & & & & 1 & & 1 \\
\hline 03 - East & & & & & 1 & & 1 \\
\hline 99 - Other & & 1 & & & & & 1 \\
\hline 03 - East & & 1 & & & & & 1 \\
\hline (blank) & & & & 3 & & & 3 \\
\hline (blank) & & & & 3 & & & 3 \\
\hline Grand Total & 58 & 57 & 53 & 56 & 31 & 19 & 274 \\
\hline
\end{tabular}




\begin{tabular}{|c|c|c|c|c|c|c|c|}
\hline Row Labels & 2010 & 2011 & 2012 & 2013 & 2014 & 2015 & Grand Total \\
\hline 01 - Approaching & & & 1 & 1 & 1 & 1 & 4 \\
\hline 02 - Angle & 5 & 9 & 19 & 9 & 2 & 2 & 46 \\
\hline 03 - Rear end & 37 & 31 & 19 & 28 & 17 & 8 & 140 \\
\hline 04 - Sideswipe & 13 & 9 & 9 & 13 & 6 & 3 & 53 \\
\hline $\begin{array}{l}05 \text { - Turning } \\
\text { movement }\end{array}$ & 2 & 5 & 4 & 2 & 3 & 4 & 20 \\
\hline $\begin{array}{l}06 \text { - SMV } \\
\text { unattended vehicle }\end{array}$ & 1 & 2 & 1 & & & 1 & 5 \\
\hline 07 - SMV other & & & & & 2 & & 2 \\
\hline 99 - Other & & 1 & & & & & 1 \\
\hline (blank) & & & & 3 & & & 3 \\
\hline Grand Total & 58 & 57 & 53 & 56 & 31 & 19 & 274 \\
\hline
\end{tabular}

Table 7 Highway7 \& Leslie Street Initial impact by year 


\section{Works Cited}

Arason, N. (2014). No Accident: Eliminating Injury and Death on Canadian Roads. Waterloo, Ont, Canada: Wilfrid Laurier University Press.

Arthur, R. M., \& Waters, N. M. (1998). Formal scientific research of traffic collision data for utilizing GIS. Transportation Planning and Technology , 21, 121-137.

Azadeh, A., Zarrin, M., \& Hamid , M. (2015). A novel framework for improvemnts of road accidents considering decision-making styles of drivers in a large metropolitan area. Accident Analysis and Prevention, 87, 17-33.

Choueiri, E. M., Choueiri, G. M., \& Choueiri, B. M. (2010, June 2-5). Analysis of Accident Patterns in Lebanon. 4th International Symposium on Highway Geometric Design, pp. 1-22.

Ewing, R., \& Dumbaugh, E. (2009). The Built Environment and Traffic Safety. Journal of Planning, 23(4), 347-367.

Fernandes, A., \& Neves, J. (2013). An approach to accidents modeling based on compounds road environments. Accident Analysis and Prevention, 53, 39-45.

Garder, P. (2008). Traffic Safety Before and After Introduction of Red-Light Running Photo Enforcement in Maine. In G. P. Bartley, Traffic Accidents; Causes and Outcomes (pp. 29-73). New York: Nova Science Publishers, Inc.

GO Transit. (2017). Newmarket/North York Express Bus Train \& Bus. Retrieved from Go Transit:

http://www.gotransit.com/timetables/en/schedules/schedules_window.asp x?tableid=66\&dir $=$ N\&date $=2017-08-27 \&$ parentid $=1$

Golob, T. F., \& Recker, W. W. (2003). Relationships Among Urban Freeway Accidents, Traffic Flow, Weather, and Lighting Conditions . Journal of Transportation Engineering, 342 - 353.

Lu, J., Chen, S., Ge, X., \& Pan , F. (2013). A programmable calculation procedure for number of traffic conflict points at highway intersections. Journal of Advanced Transportation, 47(692-703).

Miranda-Moreno, L. F., Morency, P., \& El-Geneidy, A. M. (2011). The link between built environment, pedestrian activity and pedestrian-vehicle collision occurrence at signalized intersection. Accident Analysis and Prevention, 43, 1624-1634.

Pan, F., Zhang, L., Lu, J., Zhao, J., \& Wang, F. (2013). A Method for Determining the Number of Traffic Conflict Point Between Vehicles at Major-Minor Highway Intersection. Traffic Injury Prevention, 14, 424-433.

Prato, C. G. (2009). Reducing teen fatalities: do graduated Licensing prgrams help solve the problem. In H. Bedard, \& G. Delashmit, Accidents: Causes, Analysis and Prevention (pp. 1-23). New York: Nova Science Publishers, Inc.

Quddus, M. A. (2008). Times Series count data models: An emporocal application to traffic accidents. Accident Analysis and Prevention, 1732-1741.

Statistics Canada . (2016, May 2). Census Profile Georgina and King. Retrieved June 22, 2016, from Census Program : http://www12.statcan.gc.ca/censusrecensement/2011/dp- 
pd/prof/details/page.cfm?Lang=E\&Geo1=CSD \&Code1=3519070\&Geo2=CSD $\&$ Code2 $=3519049 \&$ Data $=$ Count $\&$ SearchText=Georgina\&SearchType $=$ Begins $\&$ SearchPR $=01 \&$ B1 $=$ All \&Custom $=\&$ TABID $=1$

Statistics Canada. (2016, May 2). Census Profile. Retrieved June 22, 2016, from Statistics Canada: http://www12.statcan.gc.ca/censusrecensement/2011/dppd/prof/details/page.cfm?Lang=E\&Geo1=CD\&Code1=3519\&Geo2=PR\&Code $2=35 \&$ Data $=$ Count $\&$ SearchText $=$ York $\&$ SearchType $=$ Begins $\&$ SearchPR $=01 \& B$ $1=$ All \&Custom $=\&$ TABID $=1$

Transportation Services. (2015). Annual Traffic Safety Report. York Region , Newmarket.

Wang, S. (1993). In quest of 'forgiving' environment: residential planning and pedestrian safety in Edmonton, Canada.

Wang, S., \& Smith, P. (1997). In quest of 'forgiving' environment: residential planning and pedestrian safety in Edmonton, Canada. Planning Perspectives, 12(2), 225-250.

York Regio. (2015, November). 2041 Preferred Growth Scenario. Retrieved June 22, 2016, from York Region:

https://www.york.ca/wps/wcm/connect/yorkpublic/77c5e970-8020-4b89a3d0-ff62c60403f1/nov+5+preferred+att+2.pdf?MOD=AJPERES

York Region. (2015). Traffic Safety Status Report 2012 to 2014. Newmarket.

York Region. (2016). Local Municipalities . Retrieved June 22, 2016, from York Region: http://www.york.ca/wps/portal/yorkhome/yorkregion/yr/localmunicipalit ies/lut/p/a1/jZDNTsMwEISfpYccG2_dn1jcrCDqJFRB4kDqC3Iix7Hk2pHjEsH TYyouSNCyt119szuziKMGcSvetBJBOyvMV893rwXdF4xVUNYbkgOFmpY4I0C qLALHCMAfReGWvvzHAewP-

UEhPoowLLXtHWqM64Q5na3u9CiMDlp06AXxyzKMNzu2yqEEVhMoHrKn7T 1hK8i3N4AKfwNX4kS_yrj28pojte2aRGNe9tJLn559HA8hjNNdAgnM85wq55S RaScS-

E0xuCmg5geIxlPz8dg_F0vevs90sfgE0W4xSQ!!/dl5/d5/L2dBISEvZ0FBIS9nQ SEh/\#.V2rrQ-YrJE4

Zhou, Q., \& Li, Z. (2015). Experimental Analysis of Various Types of Road Intersections for Interchange Detection. Transactions in GIS, 19(1), 19-42. 